\title{
Effects of essential oils on rumen fermentation, eating behavior and milk production in lactating dairy cattle
}

\author{
Lisa Rachel Tager \\ West Virginia University
}

Follow this and additional works at: https://researchrepository.wvu.edu/etd

\section{Recommended Citation}

Tager, Lisa Rachel, "Effects of essential oils on rumen fermentation, eating behavior and milk production in lactating dairy cattle" (2010). Graduate Theses, Dissertations, and Problem Reports. 4663.

https://researchrepository.wvu.edu/etd/4663

This Dissertation is protected by copyright and/or related rights. It has been brought to you by the The Research Repository @ WVU with permission from the rights-holder(s). You are free to use this Dissertation in any way that is permitted by the copyright and related rights legislation that applies to your use. For other uses you must obtain permission from the rights-holder(s) directly, unless additional rights are indicated by a Creative Commons license in the record and/ or on the work itself. This Dissertation has been accepted for inclusion in WVU Graduate Theses, Dissertations, and Problem Reports collection by an authorized administrator of The Research Repository @ WVU.

For more information, please contact researchrepository@mail.wvu.edu. 


\title{
EFFECTS OF ESSENTIAL OILS ON RUMEN FERMENTATION, EATING
} BEHAVIOR AND MILK PRODUCTION IN LACTATING DAIRY CATTLE

\author{
Lisa Rachel Tager \\ Dissertation submitted to the Davis College of Agriculture, Natural Resources and Design at \\ West Virginia University in partial fulfillment of the \\ requirements for the degree of \\ Doctor of Philosophy \\ in \\ Animal and Nutritional Sciences \\ K. Marie Krause, Ph.D., Chair \\ Chaouki Benchaar, Ph.D. \\ Gene Felton, Ph.D. \\ Kimberly M. Barnes, Ph.D. \\ Joe Moritz, Ph.D.
}

Division of Animal and Nutritional Sciences

Morgantown, West Virginia

2010

Keywords: Essential oil, dairy cow, feeding behavior, rumen fermentation, rumen $\mathrm{pH}$ 


\title{
ABSTRACT \\ Effects of essential oils on rumen fermentation, eating behavior and milk production in lactating dairy cattle
}

\section{Lisa Rachel Tager}

\begin{abstract}
Manipulation of rumen fermentation to improve feed efficiency is often achieved by feeding sub-therapeutic levels of antibiotics to ruminant animals. However, there has been increased concern over the use of antibiotics in the livestock industry due to the possible rise of antibiotic resistant bacteria. In the last decade, plant essential oils (EO) have emerged as a suggestion for replacement of antibiotic feed additives due to their known antimicrobial properties. Examples include: cinnamaldehyde (CIN), eugenol (EUG), and capsicum oil (CAP), which may act as rumen modifiers. The objectives of the current studies were to: (1) investigate the effects of CIN, EUG, and CAP on rumen fermentation and $\mathrm{pH}$ characteristics in continuous culture using a corn-based dairy ration; (2) to assess the in vivo effects of CAP at the recommended dosage, a blend of CIN and EUG at the recommended dosage, and a blend of CIN and EUG at a high dosage closer to levels used in vitro, on rumen fermentation, rumen $\mathrm{pH}$, milk production, and feeding behavior; and (3) to assess the effects of CAP in a larger scale study on eating behavior and milk production in lactating dairy cattle. To study in vitro effects of EO on rumen fermentation and $\mathrm{pH}$, a 12-unit continuous culture system was used in a complete randomized design with treatments including: no oil $(\mathrm{CON}), \mathrm{CIN}, \mathrm{EUG}$, and CAP [500 $\mathrm{mg} \mathrm{L}^{-1} \mathrm{~d}$ ${ }^{-1}$ ]. Dry matter $(\mathrm{DM})$ digestibility did not differ among treatments $(P=0.97)$. Organic matter $(\mathrm{OM})$ digestibility tended to decrease with CIN $(P=0.06)$. Digestibility of neutral detergent and acid detergent fiber (NDF and ADF respectively) tended to be highest with $\mathrm{CAP}(P=0.04$ and $0.08)$. Crude protein digestibility and bacterial nitrogen flow was depressed with CIN and EUG $(P=0.01$ and $<0.01$ respectively). Cinnamaldehyde tended to decrease microbial protein synthesis $(P=0.06)$ and increase effluent ammonia nitrogen $(P=0.06)$. Total volatile fatty acid (VFA) production did not differ among treatments $(P=0.16)$. Cinnamaldehyde and EUG had higher mean $\mathrm{pH}$, spent fewer $\mathrm{hr} / \mathrm{d}$ and had smaller area under the curve at $\mathrm{pH}<5.6$ and $5.8(P<$ $0.01)$. Capsicum had the smallest area under the curve at $\mathrm{pH}<5.6(P<0.01)$. A second experiment was designed to examine the effects of these oils in vivo. Seven ruminally cannulated lactating Holstein dairy cows were used in an incomplete Latin rectangle design to assess the effects of 2 commercial EO products on rumen fermentation, milk production, and feeding behavior. Treatments included addition of: $0.5 \mathrm{~g} / \mathrm{d}$ XT 6965 (CE Lo; $85 \mathrm{mg}$ CIN and 140 mg EUG; Pancosma S.A., Bellegarde-sur-Valserine, France), 10 g/d XT 6965 (CE Hi; 1700 mg CIN and 2800 mg EUG), 0.25 g/d XT 6933 (50 mg CAP; Pancosma S.A., Bellegarde-surValserine, France), or CON. Dry matter intake, number of meals/d, h eating/d, mean meal length, rumination events/d, h ruminating/d and mean rumination length were not affected by EO $(P>0.20)$. However, length of the first meal after feeding decreased with addition of CE Hi (47.2 $\mathrm{min}$ ) and CAP (49.4 min) compared to CON (65.4 min; $P=0.01)$. Milk yield and composition did not change with EO $(P>0.20)$. Volatile fatty acid profile, acetate:propionate ratio, and ammonia concentration were not affected by EO $(P>0.15)$. Rumen $\mathrm{pH}$ was unaffected by EO $(P>0.30)$. Total tract digestibility of OM, DM, NDF, ADF, crude protein, and starch as well as in situ DM disappearance of ground soybean hulls was not affected by EO $(P>0.50)$. However, in situ OM disappearance tended to decrease compared to CON with $\mathrm{CE}$
\end{abstract}


Hi $(P=0.08)$. Compared to CON, NDF disappearance $(41.5 \%$ vs. $37.6 \%)$ and ADF disappearance ( $44.5 \%$ vs. $38.8 \%)$ decreased with addition of CE Hi $(P=0.05$ and 0.04 respectively). To further investigate the effects of $\mathrm{CAP}$ on eating behavior, 40 lactating dairy cows were used in a replicated crossover design to study the effect of CAP on feeding behavior and milk production using the GrowSafe system (GrowSafe Systems Ltd., Airdrie, AB, Canada). Experimental treatments included: $1 \mathrm{~g} / \mathrm{cow} / \mathrm{d}$ Xtract 6933 (200 mg CAP) or CON. There was no difference in DMI (23.4 kg/d vs. $23.1 \mathrm{~kg} / \mathrm{d}$ ), number of meals/d (12.5 vs. 12.2), total h spent eating/d ( $3.1 \mathrm{~h}$ vs. $3.1 \mathrm{~h}$ ), mean meal length (16.3 min vs. 16.4), length of first meal after feeding $(44.6 \mathrm{~min}$ vs. $45.7 \mathrm{~min})$, or eating rate $(7.8 \mathrm{~kg} / \mathrm{h}$ vs. $8.0 \mathrm{~kg} / \mathrm{h})$ between CAP and CON $(P>0.30)$. Milk yield did not differ between CAP and CON $(31.8 \mathrm{~kg} / \mathrm{d}$ vs. $32.3 \mathrm{~kg} / \mathrm{d} ; P=0.81)$. In summary, the results from these 3 experiments suggest that $\mathrm{EO}$ have limited effects, in vitro and in vivo, on rumen fermentation, rumen $\mathrm{pH}$, eating behavior, and milk production in lactating dairy cattle except at very high dosages, which would be both biologically and economically inappropriate in a commercial dairy operation. 


\section{TABLE OF CONTENTS}

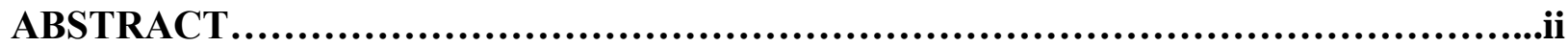

TABLE OF CONTENTS.....................................................................iv

LIST OF FIGURES..........................................................................vi

LIST OF TABLES......................................................................vii

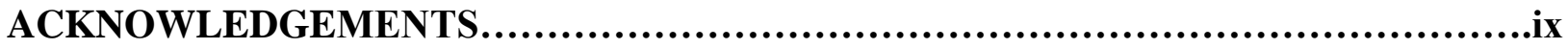

CHAPTER 1 - Introduction and Literature Review.......................................1

Introduction, Research Justification, and Objectives................................2

Literature Review.......................................................................4

Antibiotics as Rumen Manipulators.........................................4

Essential Oils as Rumen Modifiers........................................6

Secondary Plant Metabolites ...............................................6 6

Antimicrobial Activity of Essential Oils ..................................8

Discovery and Use in Ruminant Nutrition ..................................9

Benefits of Cinnamaldehyde, Eugenol, and Capsicum ......................10

In Vitro Rumen Manipulation by Essential Oils...............................11

Batch Culture vs. Continuous Culture .......................................11

Volatile Fatty Acid Profile and Culture pH..................................11

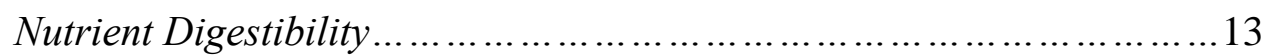

Nitrogen Metabolism ...................................................... 14

In Vivo Rumen Manipulation by Essential Oils................................15

Feeding Behavior and Production ....................................... 15

Rumen Fermentation Characteristics..................................... 17

Nitrogen Metabolism .................................................... 18

Future Considerations in Essential Oil Research.............................19

References......................................................................20

CHAPTER 2 - Effects of Cinnamaldehyde, Eugenol, and Capsicum on Fermentation of a

Corn-based Dairy Ration in Continuous Culture......................................32

Abstract.........................................................................32

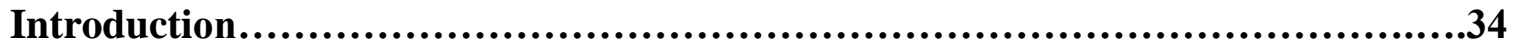

Materials and Methods................................................................36

Experimental Design............................................... 36

Source of Inocula, Fermenter Diet, and Feeding.......................... 36

Sample Collection.................................................. 37

Chemical Analyses...................................................... 38 


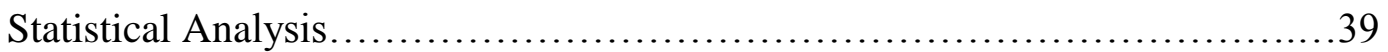

Results and Discussion.......................................................40

Nutrient Digestibilities............................................40

Nitrogen Metabolism and Microbial Protein Synthesis........................42

Volatile Fatty Acid Production...........................................44

$\mathrm{pH}$ Characteristics...................................................45

Conclusions.............................................................................46

References.......................................................................47

CHAPTER 3 - Effect of Commercial Essential Oil Products at Recommended and High Dosages on Rumen Fermentation, Milk Production, and Feeding Behavior in Lactating Dairy Cows...............................................................................58

Abstract...............................................................................60

Introduction........................................................................61

Materials and Methods............................................................62

Experimental Design, Animals, and Diet..............................62

Experimental Treatments............................................63

Sample Collection................................................64

Laboratory Analyses..................................................66

Statistical Analysis................................................67

Results and Discussion................................................................67

Feeding and Rumination Behavior....................................67

Milk Yield and Composition..........................................69

Nutrient Digestibilities and In Situ Disappearance............................70

Ammonia and Volatile Fatty Acid Concentration.............................. 72

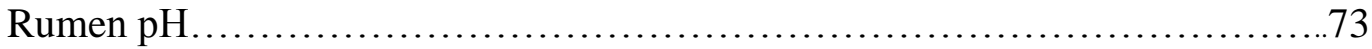

Conclusions................................................................................74

References.................................................................................75

CHAPTER 4 - Effect of Capsicum Oil on Feeding Behavior and Milk Production in Lactating Dairy Cattle......................................................................887

Abstract..............................................................................89

Introduction......................................................................89

Materials and Methods..............................................................90

Results and Discussion........................................................92

Conclusions..........................................................................94

References............................................................................94

GENERAL SUMMARY 


\section{LIST OF FIGURES}

\section{Chapter 1}

Figure 1. Chemical structures of isoprenes (terpenes), phenylpropenes, cinnamaldehyde, eugenol, and

capsaicin.

\section{Chapter 2}

Figure 1. Least square means of capsicum oil (long-dash), cinnamaldehyde oil (short-dash), eugenol oil (solid), and no essential oil (dotted) on rumen $\mathrm{pH}$ in a continuous culture system $(\mathrm{SEM}=0.02)$. There was no difference in $\mathrm{pH}$ behavior between morning and evening feedings; therefore, all $\mathrm{pH}$ values are reported bi-hourly over a $12 \mathrm{~h}$ period..........................52 


\section{LIST OF TABLES}

\section{Chapter 1}

Table 1. Effects of cinnamaldehyde (CIN) and eugenol (EUG) on rumen fermentation and nutrient digestibility in continuous culture.

Table 2. Effects of cinnamaldehyde (CIN), eugenol (EUG), and capsicum (CAP) on in vivo rumen fermentation, intake, and nutrient digestibility

\section{Chapter 2}

Table 1. Diet composition and chemical composition of diets fed to continuous culture fermenters

Table 2. Effects of capsicum oil (CAP), cinnamaldehyde oil (CIN), eugenol oil (EUG), and no essential oil $(\mathrm{CON})$ on rumen digestibilities in a continuous culture system.....

Table 3. Effects of capsicum oil (CAP), cinnamaldehyde oil (CIN), eugenol oil (EUG), and no essential oil $(\mathrm{CON})$ on rumen nitrogen efficiency and nitrogen flow in a continuous culture system.

Table 4. Effects of capsicum oil (CAP), cinnamaldehyde oil (CIN), eugenol oil (EUG), and no essential oil $(\mathrm{CON})$ on rumen VFA production in a continuous culture system

Table 5. Effects of capsicum oil (CAP), cinnamaldehyde oil (CIN), eugenol oil (EUG), and no essential oil on rumen $\mathrm{pH}$, time spent under $\mathrm{pH} 5.6$ and 5.8, and area under the curve (AUC) below $\mathrm{pH} 5.6$ and 5.8 during $24 \mathrm{~h}$ in a continuous culture system

\section{Chapter 3}

Table 1. Diet ingredient, chemical composition, and particle size distribution of the TMR.....80

Table 2. Feeding and rumination behavior of lactating Holstein dairy cows fed a 42:58 forage to concentrate ratio diet supplemented with essential oils

Table 3. Milk yield and composition of lactating Holstein dairy cows fed a 42:58 forage to concentrate ratio diet supplemented with essential oils

Table 4. Total tract digestibility of lactating Holstein dairy cows fed a 42:58 forage to concentrate ratio diet supplemented with essential oils

Table 5. 24-h in situ nutrient disappearance of soybean hulls in lactating Holstein dairy cows fed a 42:58 forage to concentrate ratio diet supplemented with essential oils 
Table 6. Ammonia and VFA (volatile fatty acid) concentration in lactating Holstein dairy cows fed a 42:58 forage to concentrate ratio diet supplemented with essential oils ..................85

Table 7. Rumen $\mathrm{pH}$ of lactating Holstein dairy cows fed a 42:58 forage to concentrate ratio diet supplemented with essential oils ................................................ 86

\section{Chapter 4}

Table 1. Diet ingredients and chemical composition of TMR .............................96

Table 2. Eating behavior and milk production of lactating dairy cattle supplemented with capsicum oil 


\section{ACKNOWLEDGMENTS}

First and foremost, I would like to sincerely thank my adviser, Dr. Marie Krause, for providing guidance, support, and knowledge to me throughout my studies. I would also like to thank Dr. Chaouki Benchaar, Dr. Gene Felton, Dr. Joe Moritz, and Dr. Kimberly Barnes for not only serving as my graduate committee, but also supplying advice and support in helping me formulate and carry out my research goals.

I am greatly indebted and cannot express enough gratitude to Will McClung and the staff of the West Virginia University Research Farm. Without the support of Will and his staff, these projects would have been impossible to achieve. I would also like to thank Ms. Tammy Webster and her girls in the West Virginia University Rumen Fermentation Profile Lab. Not only did Tammy coach and then allow me to utilize her continuous culture fermenters, but she also provided guidance and knowledge when greatly needed. I am also thankful for the help of Tammy's girls in helping to complete my lab work. For her help with difficult statistics, I would like to thank Dr. Claudia Leonardi for all of her counseling and suggestions when data got messy. Lastly, I would like to thank Gatha Clevenger, Bobbi Bailey, and Caleb Lemley, who helped with endless field work and provided the emotional support that only a fellow graduate student can when things get tough.

I would like to dedicate this dissertation to my family and friends who have shown me unending support throughout my ten years in higher education. My parents, Anne and Steven Tager, have listened, supported, and advised me when I did not think I could continue, and for that I will be forever grateful. My brother and his wife, Glenn and Darcie Tager, have given me a place of refuge to escape the pressures of graduate life. To my best friend, and soul sister, Jennifer Bonczek, I will be forever grateful for all of the emotional support she provided when the road was rocky and nobody else understood. And finally, to my soul mate, James Hart who has only been with me on this final leg of the journey, but has provided the most amazing and unsurpassable love and support that I could only dream of, thank you. I love you all, and without you, I would not have made it here. 


\section{CHAPTER 1}

\section{Introduction and Literature Review}




\section{INTRODUCTION, RESEARCH JUSTIFICATION, AND OBJECTIVES}

Manipulation of rumen fermentation to improve feed efficiency is often achieved by feeding sub-therapeutic levels of antibiotics to ruminant animals. However, there has been increased concern over the use of antibiotics in the livestock industry due to the possible rise of antibiotic resistant bacteria, which would be of great risk to human health (Benchaar et al., 2008). In the last decade, plant essential oils (EO) and their active components have emerged as a suggestion to replace antibiotic feed additives (Wallace, 2005) due to their known antimicrobial properties (Acamovic and Brooker, 2005).

Much of the research concerning EO effects on rumen fermentation have been done using in vitro methods such as batch culture and continuous culture (McIntosh et al., 2003; Cardozo et al., 2004; Busquet et al., 2005a; Castillejos et al., 2005; Fraser et al., 2007). However, data from these studies are often inconclusive and lead to conflicting results due to variation of dosages, structures, diets, blends, and EO providers. Further, in vitro studies that investigated the use of EO in dairy rations have commonly utilized rations containing mainly barley-straw, -silage, grain and ground corn-grain (Cardozo et al., 2004; Busquet et al., 2005a; Castillejos et al., 2006; Fraser et al., 2007). While barley and ground corn are considered highly fermentable, few studies have investigated EO effects on dairy feeds that have been processed for more rapid fermentability, such as steam-flaked corn. Feeds that are more highly fermentable cause sharp decreases in rumen $\mathrm{pH}$ at a fast rate (Zinn et al., 1995). Rumen $\mathrm{pH}$ is an important indicator of rumen acidosis and overall cow health, particularly in cows fed a more highly fermentable diet. However, little is known about how supplementing these oils may affect rumen $\mathrm{pH}$ fluctuations in vitro or in vivo. 
Cinnamaldehyde (CIN), eugenol (EUG), and capsicum oil (CAP) are known to have antimicrobial properties, and may act as rumen modifiers. While CIN, EUG, and CAP have been studied extensively in vitro, much less is known about their effects on rumen fermentation in vivo or how they affect feeding behavior, particularly in lactating dairy cattle. Some in vivo studies utilizing beef cattle consuming a high concentrate diet (10:90 forage:concentrate ratio, DM basis) reported CIN (Cardozo et al., 2006), EUG (Cardozo et al., 2006), and CAP (Cardozo et al., 2006; Fandiño et al., 2008) may provide some positive effects on rumen fermentation, often leading to increased feed digestibility. Again, however, there is little data to support these effects in lactating dairy cattle.

Furthermore, in vitro studies have reported that CIN (Busquet et al., 2004, 2005a, 2005b, 2006; Fraser et al., 2007), EUG (Busquet et al., 2005b, 2006), and CAP (Busquet et al., 2006) often have little effect on microbial fermentation except at very high dosages (> $100 \mathrm{mg} / \mathrm{L} / \mathrm{d})$. This high dosage of EO is often necessary to elicit an observable response. A dosage of 100 $\mathrm{mg} / \mathrm{L}$ is equivalent to feeding $>10 \mathrm{~g} / \mathrm{cow} / \mathrm{d} \mathrm{EO}$ (assuming a $100 \mathrm{~L}$ rumen volume) in vivo. For most EO, this is $>5$ times the recommended feeding dosage. However, there has been no research using such high dosages in vivo, making it difficult to extrapolate in vitro research to real-life applications.

More recently, it has been suggested that CAP may affect feeding behavior in ruminant animals (Rodriquez-Prado et al., 2008). Increased DMI and water consumption have been reported in beef cattle receiving CAP as a supplement (Cardozo et al., 2006; Fandiño et al., 2007), possibly increasing production. It has further been suggested that CAP may modify eating patterns beneficially by stabilizing intake patterns and controlling drastic drops in rumen 
pH caused by high concentrate beef diets (Rodriquez-Prado et al., 2008). However, there is no available data to support this observation in lactating dairy cattle.

Therefore, specific objectives of the research presented here included:

1. investigating the effects of $\mathrm{CIN}, \mathrm{EUG}$, and CAP on rumen fermentation characteristics in continuous culture and to assess their effects on $\mathrm{pH}$ fluctuations using a corn-based dairy diet including steam-flaked corn;

2. to assess the in vivo effects of CAP at the recommended dosage, a blend of CIN and EUG at the recommended dosage, and a blend of CIN and EUG at a high dosage closer to levels used in vitro, on rumen fermentation, rumen $\mathrm{pH}$, milk production, and feeding behavior; and

3. to assess the effects of CAP in a larger scale study on eating behavior and milk production in lactating dairy cattle.

\section{LITERATURE REVIEW}

\section{Antibiotics as Rumen Manipulators}

Modification of the rumen environment to improve animal production has been a major focus of ruminant nutrition for several decades. Since their advent in the 1970's, antibiotic ionophores have been used to manipulate rumen microbial populations and improve animal production and health (Martinez et al., 2006). The most common ionophore additives used in ruminant nutrition include monensin, lasalocid, and laidlomycin propionate (Benchaar et al., 2009). While ionophores are mainly used in beef production systems, they have been approved for lactating dairy cows in Australia, Argentina, Brazil, Canada, New Zealand, South Africa, and the United States (Odongo et al., 2007). However, the use of ionophores in dairy cattle 
production, even in these approved areas, is still limited due to the risk of transferring ionophore residues to milk (Benchaar et al., 2009).

Use of ionophores, such as monensin, in ruminant diets has been found to increase production, enhance feed efficiency, and decrease digestive disturbance (i.e. acidosis) due to its antimicrobial activities in the rumen (McGuffrey et al., 2001). Indeed, monensin supplementation inhibits many of the bacteria that produce lactate in the rumen, causing an increase in ruminal $\mathrm{pH}$ particularly in animals consuming higher grain diets (Thornton and Owens, 1981; McGuffrey et al., 2001). Increased production and feed efficiency with monensin supplementation is often linked to an increase in propionate production and a decrease in acetate production, thus lowering the acetate to propionate ratio (Thornton and Owens, 1981; Ramanzin et al., 1997). Further, numerous studies have reported decreased ammonia production with monensin supplementation due to its antimicrobial activity against some deaminative bacteria, allowing for improved nitrogen metabolism and gut absorption (Yang and Russell, 1993; McGuffrey et al., 2001).

The benefits of feeding monensin to ruminants have been well documented. In a metaanalysis, monensin supplementation to lactating dairy cows was shown to improve overall energy/nutrient metabolism (Duffield et al., 2008a). Further, the meta-analysis reported decreased dry matter intake, increased milk yields, improved milk production efficiency (Duffield et al., 2008b), and improved cow health, as was evidenced by a decreased incidence of ketosis, displaced abomasa, and mastitis in lactating dairy cows supplemented with monensin (Duffield et al.; 2008c).

As extensively indicated, antibiotic ionophores such as monensin have many benefits in ruminant nutrition. However, their usage is starting to lose social acceptance (Calsamiglia et al., 
2007) due to the perceived risk of transferring antibiotic residues into meat and milk (Fandiño et al., 2008). Yet, the concern of transferring these residues may be unfounded. Bagg et al. (2005) fed up to 10 times the recommended dose of monensin ( $24 \mathrm{ppm}$; maximum approved dose for dairy cattle in Canada) to lactating dairy cattle and found no detectable residues $(<0.005 \mu \mathrm{g} / \mathrm{L})$ of monensin in milk samples. Further, a summary report on monensin in the European Union by the European Medicines Agency (2007) revealed no detectable residues in meat or milk samples in 16 lactating dairy cows fed $0.9 \mathrm{mg} / \mathrm{kg} \mathrm{BW} / \mathrm{d}$ monensin (maximum approved dosage in European Union). Nevertheless, social concern over transferring antibiotic residues in milk and meat products has led the European Union to place a ban on the use of antibiotics in animal feed production systems as of January 2006 (OJEU, 2003).

Establishment of antibiotics in the 1950's and ionophores in the 1970's made the study and use of plant derivatives as antimicrobials nearly nonexistent for some time (Cowan, 1999). While some researchers were interested in plant oil effects on rumen fermentation and forage selection of wild deer and sheep (Oh et al., 1967; Oh et al., 1968; Nagy and Tengerdy, 1968), the use of plant secondary metabolites in ruminant production systems was mainly not studied. However, with recent decreased social acceptance of antibiotics in animal feeding, along with the ban in Europe, researchers are looking towards the natural products made by plants as an alternative (Wallace et al., 2005; Benchaar et al., 2009).

\section{Essential Oils as Rumen Modifiers}

\section{Secondary Plant Metabolites}

Essential oils have been documented to possess anti-bacterial, -fungal, -viral, and inflammatory effects for many centuries (Acamovic and Brooker, 2005). Trichomes, located on the surface of plant leaves, are the main site of EO synthesis and storage (Acamovic and 
Brooker, 2005), although EO may also be found present in any organ of plants including roots, stems, leaves, flowers, and fruits (Hili et al., 1997). Essential oils are extracted from plants as oily liquids and contain secondary metabolites that are hydrophobic and have low molecular weight (Benchaar et al., 2009). Many of these secondary metabolites are what give EO antimicrobial properties. The name 'essential' is misleading as they are not essential to nutrition; rather they are what give a plant its specific 'essence', or fragrance and flavor (Cowan et al., 1999; Calsamiglia et al., 2007; Benchaar et al., 2009). Essential oils serve an important role to plants as a defense from, or attractor to, microorganisms, insects, and herbivores (Cowan et al., 1999). Consequently, concentrations of EO within the plant are tightly regulated and linked to environmental, seasonal, and other external stimuli (Acamovic and Brooker, 2005). Extraction of EO is done in many ways including steam distillation, liquid solvation, supercritical $\mathrm{CO}_{2}$ extraction, and expression. Some of these methods should be used with caution, however, as the high temperatures used in steam distillation can destroy some important metabolites and solvent extraction can leave solvent residues in the final product (Benchaar et al., 2009).

Plant secondary metabolites fall into three groups: saponins, tannins, and essential oils (Calsamiglia et al., 2007). Secondary metabolites are built from smaller units synthesized by metabolic processes such as glycolysis, the citric acid cycle, and photosynthesis (Benchaar et al., 2009). The most common active components found in EO include terpenes and phenylpropenes (terpenoids and phenylpropenoids when they contain oxygen; Calsamiglia et al., 2007; Benchaar et al., 2009; Figure 1).

Phenylpropenes are found in high concentrations in plants, making them highly biologically active (Calsamiglia et al., 2007). Phenylpropenes $\left(\mathrm{C}_{6} \mathrm{C}_{3}\right)$ are synthesized from phenylalanine and tyrosine and contain a six carbon aromatic ring joined by a three carbon chain 
(Calsamiglia et al., 2007; Benchaar et al., 2009; Figure 1). Aromatic phenylalanine and tyrosine are derived by the shikimate pathway found in micro-organisms and plants, and are deaminated to cinnamic and 4-coumaric acid (converted to cinnamic acid in an extra step), respectively. Cinnamic acids are reduced to cinnamyl alcohols which are used to synthesize the phenylpropenes (Benchaar et al., 2009).

Terpenes $\left(\mathrm{C}_{10} \mathrm{H}_{16}\right)$ consist of five carbon isoprene units, which may be linear or cyclic, and are synthesized by the mevalonate and deoxyxylulose cycles (Cowan, 1999; Benchaar et al., 2009; Figure 1). The isoprene unit isopentenyl diphosphate can be derived from mevalonic acid in the mevalonate cycle which is phosphorylated and decarboxylated to make isopentenyl diphosphate. Isopentenyl diphosphate is also converted from the intermediate deoxyxylulose phosphate (glyceraldehyde 3-phosphate + pyruvate) in the deoxyxyulose pathway. Isopentenyl diphosphate can then be isomerized to dimethylallyl diphosphate, the other common isoprene unit in terpenes (Benchaar et al., 2009).

\section{Antimicrobial Activity of Essential Oils}

Common active components in EO that have been well characterized as antimicrobials include CIN (active phenylpropenoid in cinnamon oil), EUG (active phenylpropenoid in cinnamon and clove oil), and capsaicin (active terpenoid/carotenoid in hot pepper oil). The hydrophobic nature of EO active components allows them to dwell in the lipid bilayer of microbial membranes (Benchaar et al., 2009). In the lipid bilayer, these compounds can change membrane function and permeability by interacting with membrane proteins, or by diffusing into the cytoplasm to alter cell metabolic processes (Burt et al., 2004). The active compounds in EO that are known to be most antimicrobial are those that are phenolic (Dorman and Deans, 2000). 
Phenolic components interact with membrane ion transport as well as cytoplasmic enzyme function (Burt, 2004).

While most EO tend to exert their effects on gram-positive bacteria (Benchaar et al., 2009), gram-negative bacteria can also be susceptible (Dorman and Deans, 2000). Gramnegative bacteria possess a cell envelope which may inhibit access of some EO to the cellular membrane (Helander et al., 1998). However, hydrophobic compounds that have low molecular weights can indeed diffuse through the porins of the cellular envelope of gram-negative bacteria and gain access to the phospholipid bilayer (Helander et al., 1998; Dorman and Deans, 2000). Many EO exhibit antimicrobial effects against gram-positive and gram-negative bacteria, as well as yeasts. In fact, cinnamon and clove oils are highly anti-microbial towards all three types of micro-organisms (Hili et al., 1997; Helander et al., 1998). In particular, aldehydes, such as CIN, are highly antimicrobial due to the electronegativity created by the arrangement of an aldehyde conjugated with a carbon to carbon double bond. This electronegativity allows CIN to inhibit electron transfer, enzyme activity, and growth (Dorman and Deans, 2000), rather than disrupting and destroying the cell membrane (Helander et al., 1998; Burt, 2004). Eugenol, a main active component in both cinnamon and clove oils, is antimicrobial due to its ability to disrupt the cell membrane, causing cell lysis (Di Pasqua et al., 2007), as well as inhibiting several microbial enzymes by binding to them (Burt, 2004). These modes of microbial inhibition have lead to interest in using these plant compounds as natural rumen manipulators (Calsamiglia et al., 2007).

\section{Discovery and Use in Ruminant Nutrition}

Humans have used plants and their extracts for medicinal purposes for thousands of years. The first written accounts of EO use date back to 2600 BC (Newman et al., 2000). Borchers (1965) became the first to research and report the possible benefits of using EO to 
modify rumen fermentation when he observed that thymol resulted in decreased ammonia production and increased amino acid accumulation when added to rumen fluid in vitro. However, the enthusiasm for the use of EO in ruminant nutrition stemmed from wildlife biologists who observed that wild deer made specific forage selections depending on their health, the climate, and the season. Oh et al. (1967) observed that deer were most attracted to the needles of Pseudotsuga menziesii (Douglas fir), and thus commenced an experiment to test the oils extracted from the needles on rumen fermentation. This experiment led to another experiment by Oh et al. (1968) where the effects of oils extracted from unpalatable species to deer and sheep were tested on rumen microorganisms. Similarly, Nagy and Tengerdy (1968) examined the sensitivity of rumen microorganisms to Artemisia tridentate (sagebrush) because of its observed high intake by deer. However, the rise of antibiotics in the 1950's, and consequently ionophores in the 1970's caused the study of EO as rumen manipulators to cease (Cowan, 1999).

Benefits of cinnamaldehyde, eugenol, and capsicum

The reported antimicrobial activity of CIN, EUG, and CAP lend to some specific benefits as rumen modifiers. Cinnamaldehyde has been found to improve rumen fermentation characteristics in high grain diets (Cardozo et al., 2006), but it may not be useful in animals fed high forage diets. It has been observed that EUG may increase volatile fatty acid (VFA) production and improve the VFA profile by increasing propionate and butyrate concentrations, while decreasing acetate concentration (Calsamiglia et al., 2007). Eugenol may also help increase nitrogen use in lactating animals eating a low concentrate diet (Calsamiglia et al., 2007). Capsicum oil has been shown to have positive benefits in production systems where high concentrate levels are fed. Addition of CAP to a high concentrate diet (10:90 forage to 
concentrate ratio) has been reported to increase dry matter intake and feed efficiency

(Calsamiglia et al., 2007) as well as shifts in the animals' eating behavior (Rodriguez-Prado et al., 2008). While many of these antimicrobial activities are beneficial to ruminants consuming a high concentrate diet (mainly beef production), these compounds have received little attention as possible rumen modifiers in dairy production systems.

\section{In Vitro Rumen Manipulation by Essential Oils}

\section{Batch culture vs. continuous culture}

Due to the vast number of essential oils and the active compounds within them, in vitro models have been used as the main tool for evaluating their effects on rumen fermentation characteristics (Benchaar et al., 2009). However, using in vitro models to predict in vivo outcomes can be problematic. The commonly used batch culture method is designed to mimic in vivo conditions as close as possible for several hours. However, batch culture is unable to truly assess the effects of essential oils on the rumen microbial population long-term due to the difficulty in removal, and subsequent accumulation, of fermentation end-products (Benchaar et al., 2009). Conversely, the method of continuous culture allows for the removal of fermentation end-products, thus allowing rumen microbes to act more naturally. Still, studies using continuous culture to screen essential oil components have revealed that microbial populations can adapt to these compounds during continuous culture examination (Busquet et al., 2005a), making it important for the researcher to interpret in vitro results prudently (Cardozo et al., 2004). Nonetheless, in vitro techniques are a good screening tool and help the researcher to evaluate possible effects of many essential oils on rumen microbial fermentation in a short period of time.

Volatile fatty acid profile and culture $\mathrm{pH}$ 
At low dosages $(<100 \mathrm{mg} / \mathrm{L}$ culture fluid) essential oils and their active components generally have no effect on total volatile fatty acid (VFA) production in vitro (Cardozo et al., 2004; Busquet et al., 2005b; Castillejos et al., 2005; Busquet et al., 2006; Fraser et al., 2007; Chaves et al., 2009; Table 1). However, at high dosages (> $100 \mathrm{mg} / \mathrm{L}$ culture fluid), essential oils decrease total VFA production (Busquet et al., 2006; Laureñço et al., 2008; Table 1). Cinnamaldehyde in particular is known to inhibit gram positive (mainly acetate and butyrate producers) and gram negative bacteria (mainly propionate producers) making it more antimicrobial than other oils (Busquet et al., 2005b). Consequently, it is not surprising that a high dose of CIN (i.e. $500 \mathrm{mg} / \mathrm{L}$ in continuous culture) would decrease total VFA production due to its inhibition of microbial activity (Laurenço et al., 2008). This reduction in total VFA by high doses of essential oils is usually an indicator of a reduction in fermentation, which is considered undesirable since VFA's are the main source of energy to the ruminant animal (Benchaar et al., 2009).

Increasing total VFA production with essential oils in vitro is not common; however, the proportions of individual VFA's are often altered by essential oils. One goal in the manipulation of rumen fermentation is to decrease acetate production and increase propionate production, thus creating a more desirable VFA profile. Several in vitro studies have shown the ability of essential oils to achieve this goal (Benchaar et al., 2009). Busquet et al. (2005b) observed that the addition of CIN at $31.2 \mathrm{mg} / \mathrm{L}$ culture fluid decreased acetate and increased propionate proportions in continuous culture, and decreased acetate and increased butyrate when used at a higher dosage of $312 \mathrm{mg} / \mathrm{L}$ culture fluid without altering total VFA production. Further, when compared to monensin, the same study found CIN $(31.2 \mathrm{mg} / \mathrm{L})$ to have similar effects on fermentation profile, although the mechanism may not be the same (Castillejos et al., 2005). 
Though some studies report positive changes in VFA profile by essential oil addition, others have found oils and their components to negatively affect VFA parameters (Benchaar et al., 2009). Eugenol, for example, may have less desirable effects on fermentation profile as was demonstrated by Fraser et al. (2007) when 500 mg/L culture fluid of cinnamon leaf oil (76\% EUG) was added to continuous culture and propionate production decreased creating a higher acetate to propionate ratio, although total VFA production was not altered. Similarly, Castillejos et al. (2006) saw a decrease in total VFA production as well as a decrease in propionate proportion and an increase in acetate proportion and acetate to propionate ratio when EUG (500 and 5,000 mg/L culture fluid) was added in batch culture to a 10:90 forage to concentrate ratio finishing ration. Also in batch culture, Benchaar et al. (2007a) observed that $800 \mathrm{mg} / \mathrm{L} \mathrm{EUG}$ reduced propionate production without changing the total amount of VFA.

While not always recorded in vitro, $\mathrm{pH}$ of culture fluid usually reflects the pattern of VFA production (Busquet et al., 2006) as VFA's are the main source of acid in the rumen environment. Chaves et al. (2009), found no differences in total VFA production, and thus, no differences in $\mathrm{pH}$ when $\mathrm{CIN}$ was added to continuous culture at $0.2 \mathrm{~g} / \mathrm{kg}$ DM. Conversely, at high dosages of 3,000 mg/L, Busquet et al. (2006) observed a decrease in total VFA production and increased $\mathrm{pH}$ in batch culture with CIN and EUG supplementation. It is interesting to note that in this same batch culture study there was no effect of CAP oil at any dosage (3 to 3,000 $\mathrm{mg} / \mathrm{L}$ culture fluid) on total VFA production or culture $\mathrm{pH}$.

\section{Nutrient digestibility}

Similar to VFA production, organic matter (OM), dry matter (DM), acid detergent fiber (ADF), and neutral detergent fiber (NDF) digestibility is usually unchanged by low doses $(<100$ $\mathrm{mg} / \mathrm{L}$ culture fluid) of essential oils and their compounds in vitro (Table 1). With a blend of 
essential oil components (1.5 mg/L culture fluid; thymol, guajacol, and limonene), Castillejos et al. (2005) found only a numerical increase in OM digestibility and no change in DM, ADF, or NDF digestibility in continuous culture. Specifically, CIN does not affect OM, DM, ADF, or NDF digestibility at dosages $<312 \mathrm{mg} / \mathrm{L}$ culture fluid in continuous culture (Busquet et al., 2005b; Chaves et al., 2009). Only at higher dosages (i.e. $>500 \mathrm{mg} / \mathrm{L}$ ) do essential oils affect nutrient digestibility in vitro. Fraser et al. (2007) reported a trend towards decreased OM and DM digestibilities and a decrease in ADF and NDF digestibilities when $500 \mathrm{mg} / \mathrm{L}$ cinnamon leaf oil (76\% EUG) was added to continuous culture. The authors speculated that this decrease in fiber digestibility, and subsequently OM and DM digestibility, may be due to the known antiprotozoal effect of cinnamon leaf oil, as protozoa are thought to be responsible for nearly $30 \%$ of fiber digestion.

Nitrogen metabolism

Essential oils and their compounds have their greatest effect in vitro on nitrogen and protein metabolism, and if an optimal dosage could be identified, may help to improve efficiency of nitrogen metabolism. At low dosages (0.22 mg/L culture fluid), Cardozo et al. (2004) observed an accumulation in peptide nitrogen when cinnamon extract (59\% CIN) was added to continutuous culture, suggesting increased protein degradation or decreased peptide degradation. Conversely, at higher dosages (> $500 \mathrm{mg} / \mathrm{L}$ culture fluid) in continuous culture and batch culture, protein degradation seems to decrease with cinnamon leaf oil (76\% EUG; Fraser et al., 2007) and CIN (Macheboeuf et al., 2008).

Ammonia nitrogen, on the other hand, is not as easily affected by essential oils and their compounds (Table 1). A reduction in ammonia nitrogen is often considered a positive effect because it signifies a decrease in deamination and overall protein metabolism, therefore 
increasing ruminal escape of proteins and nitrogen which is necessary for efficient ruminant

production (Macheboeuf et al., 2008). However, at most dose levels, essential oils do not have an effect on ammonia nitrogen concentration in vitro (Cardozo et al., 2004; Busquet et al., 2005a; Castillejos et al., 2005; Fraser et al., 2007; Chaves et al., 2008b; Chaves et al., 2009; Table 1). Only at very high dosages $(3,000 \mathrm{mg} / \mathrm{L})$ of CIN, EUG, and CAP did Busquet et al. (2006) see a decrease in ammonia nitrogen production, which was accompanied by decreased overall fermentation.

One of the main goals of supplementing with essential oils and their components is to improve nitrogen metabolism by increasing efficiency of microbial protein synthesis (EMPS), thus increasing the amount of amino acids flowing out of the rumen for absorption postruminally (Benchaar et al., 2009). This goal is not often met, however, as EMPS is usually unchanged by low dosages ( $1.5 \mathrm{mg} / \mathrm{L}$ blend of essential oils) of essential oils (Castillejos et al., 2005) in vitro. Moreover, at very high dosages (500 mg/L cinnamon leaf oil; 76\% EUG; Fraser et al., 2007) EMPS has been reported to decrease (Table 1). This decrease in EMPS may negatively impact animal productivity due to decreased flow of protein and amino acids for postruminal absorption (Fraser et al., 2007).

\section{In Vivo Rumen Manipulation by Essential Oils}

Though in vitro models help to screen essential oils and their compounds quickly, the only successful way to assess their long-term effects on rumen fermentation is in vivo (Benchaar et al., 2009). Thus, research on the effects of essential oils and their components in vivo has become more popular in recent years.

Feeding behavior and production 
Enhancing animal performance is the main goal in ruminant production, and one way to do this is by modifying feed intake and eating behavior. There is some variation in the effects among oils and their compounds on dry matter intake (DMI; Table 2). In beef heifers fed a 10:90 forage to concentrate ratio ration, Fandiño et al. (2007) reported an increase of $12.1 \%$ in DMI with CAP supplementation (500 mg/d), and Cardozo et al. (2006) reported an increase in DMI and water intake with a dosage of $1 \mathrm{~g} / \mathrm{d}$, suggesting it may act as an appetite stimulant. There has been some speculation that EO may also alter overall eating behavior. RodriguezPrado et al. (2008) observed an increase in total h eating/d (2.64 vs. $1.92 \mathrm{~h}$ ) as well as a more stable eating pattern (shorter, more frequent meals) in beef heifers fed a 10:90 forage to concentrate ratio diet supplemented with $0.5 \mathrm{~g} \mathrm{CAP} / \mathrm{d}$, which the authors concluded may be beneficial in preventing acidosis by decreasing the sharp drop in rumen $\mathrm{pH}$ after feeding.

Other oils may elicit a decrease in DMI and water intake, or have no effect at all. A mixture of CIN $(0.18 \mathrm{~g} / \mathrm{d})$ and EUG $(0.09 \mathrm{~g} / \mathrm{d})$ fed to beef heifers receiving a 10:90 forage to concentrate ration decreased DMI and water intake (Cardozo et al., 2006). In lambs fed either a barley- or a corn-based diet, CIN (200 mg/kg dietary DM) had no effect on DMI (Chaves et al., 2008a). Benchaar et al. (2006; 2007b; 2008), reported no effects of two blends of essential oils on DMI when fed to lactating dairy cows.

Although using essential oils and their components to improve rumen fermentation is an important goal, it is important to remember the ultimate goal is to improve animal production. There is little evidence that essential oils and their components improve production. Carcass characteristics and meat quality were unaffected by $200 \mathrm{mg} / \mathrm{kg}$ dietary DM CIN fed to growing lambs (Chaves et al., 2008a). Moreover, milk yield was not affected by a blend of essential oils (thymol, eugenol, vanillin, and limonene) supplemented at $2 \mathrm{~g} / \mathrm{d}$ to dairy cattle (Benchaar et al., 
2006), or by a different blend of essential oils (thymol, eugenol, vanillin, guaiacol, and limonene) at $0.75 \mathrm{~g} / \mathrm{d}$ (Benchaar et al., 2007b). More specifically, Benchaar and Chouinard (2009) hypothesized that $1.0 \mathrm{~g} / \mathrm{d}$ CIN may affect biohydrogentation in the rumen of lactating dairy cows, thus affecting milk fatty acid profiles. However, no effect on fatty acid composition was reported, suggesting low ability of CIN to alter rumen biohydrogenation.

\section{Rumen Fermentation Characteristics}

Effects of essential oils and their components on nutrient digestibility in vivo have been studied very minimally. At a dosage of $0.75 \mathrm{~g} / \mathrm{d}$, a blend of essential oils (thymol, eugenol, vanillin, guaiacol, and limonene) had no effect on DM, OM, ADF, or NDF digestibility when fed to lactating dairy cows (Benchaar et al., 2007b). In an earlier study on dairy cattle by the same lab, a different blend of essential oils (thymol, eugenol, vanillin, and limonene) at a dosage of 2 g/d yielded no differences in DM, OM, or NDF digestibility, but did increase ADF digesitibility

(Benchaar et al., 2006). At such low doses, it is not surprising that essential oils have little effect on nutrient digestibility in vivo. In fact, to achieve a level of $500 \mathrm{mg} / \mathrm{L}$ and elicit an effect similar to in vitro conditions, researchers studying dairy cattle would have to supplement $\sim 70 \mathrm{~g} / \mathrm{d}$ of essential oil, which is currently biologically and economically not feasible (Benchaar et al., 2009).

Total VFA concentration in sheep (Newbold et al., 2004), beef cattle (Cardozo et al., 2006; Fandiño et al., 2007), or dairy cattle (Benchaar et al., 2006; Benchaar et al., 2007b) is not usually affected by essential oils and their compounds in vivo (Table 2). Some in vivo research suggests that essential oils may alter concentrations of individual VFA's in a positive manner. Cardozo et al. (2006) reported decreased acetate concentration in beef heifers fed a 10:90 forage to concentrate ratio ration and supplemented with CAP $(1 \mathrm{~g} / \mathrm{d})$ or a blend of CIN $(0.6 \mathrm{~g} / \mathrm{d})$ and 
EUG $(0.3 \mathrm{~g} / \mathrm{d})$. They also reported an increase in propionate concentration for the combination of CIN and EUG. These changes occurred without any total difference in VFA's, thus creating a lower acetate to propionate ratio and a more desirable VFA profile. Fandiño et al. (2007) reported similar effects of CAP at a lower dosage $(0.5 \mathrm{~g} / \mathrm{d})$ on acetate concentration also in beef cattle fed a high concentrate diet.

Without a drastic change in total VFA production, it is uncommon to see changes in rumen pH by essential oils (Cardozo et al., 2006; Fandiño et al., 2007). In dairy cattle, however, Benchaar (2006; 2007b) observed an increase in pH (i.e. 6.50 vs. 6.39; 2006) without a change in total VFA production. This may be due to suppression of lactic acid producing bacteria by some essential oils and their compounds; however the mechanism is not fully understood.

\section{Nitrogen metabolism}

Similar to in vitro research, most of the effects seen with essential oil supplementation in vivo are changes in nitrogen metabolism. While some studies report no effects of essential oils on protein degradation (Benchaar et al., 2006; Benchaar et al., 2008), others report decreased in situ degradation of protein, decreases in amino acid deamination, and increases in the amount of small and large peptides (McIntosh et al., 2003; Molero et al., 2004; Newbold et al., 2004), suggesting that more proteins are leaving the rumen undegraded for post-ruminal absorption.

Ammonia nitrogen concentrations in vivo also indicate that essential oils may decrease protein degradation and increase flow, thereby increasing nitrogen efficiency and flow of dietary proteins out of the rumen. Many studies report no change in ammonia nitrogen with essential oil supplementation (Newbold et al., 2004; Benchaar et al., 2006; Fandiño et al., 2007; Benchaar et al., 2008; Table 2). Conversely, Cardozo et al. (2006) observed that supplementation with two blends of CIN $(0.18 \mathrm{~g} / \mathrm{d}$ or $0.6 \mathrm{~g} / \mathrm{d})$ and EUG $(0.09 \mathrm{~g} / \mathrm{d}$ or $0.3 \mathrm{~g} / \mathrm{d})$ resulted in decreased ruminal 
ammonia nitrogen concentrations in beef heifers fed a 10:90 forage to concentrate diet. A decrease in ammonia nitrogen with essential oil supplementation and their compounds may be due to their antimicrobial effects towards hyper-ammonia producing bacteria which are also sensitive to monensin. These specific bacteria are highly deaminative and allow nitrogen to escape the rumen as gas (Castillejos et al., 2005; Benchaar et al., 2006), decreasing overall nitrogen metabolism and efficiency.

Essential oil effects on EMPS have not been studied extensively, although it is an important fermentation characteristic in production. Thus far, essential oils and their compounds have not been reported to have effects on EMPS in vivo at the dosages fed. This was demonstrated by Newbold et al. (2004), who observed no change in EMPS when $0.11 \mathrm{~g} / \mathrm{d}$ of a blend of essential oils (thymol, guajacol, and limonene) were fed to sheep.

\section{Future Considerations in Essential Oil Research}

The effects of EO are still far from being well understood. While many of the effects observed are similar to those of ionophores like monensin, their modes of action are most likely different. Recent research has revealed that many of essential oils and their compounds may have additive, antagonistic, or synergistic effects when combined. This interaction among essential oil components may cause positive changes in rumen fermentation, but the combinations that will do this successfully are still unknown (Burt, 2004; Benchaar et al., 2009). Further, essential oils, as well as combinations of essential oils, have different effects on rumen fermentation depending on $\mathrm{pH}$ and diet type (Cardozo et al., 2005), making this an important area of study to determine if these oils can be alternatives to antiobiotic ionophores.

While essential oils and their major components have been researched extensively in vitro as rumen modifiers, there is still a large lack of knowledge on their effects in vivo, 
particularly in dairy nutrition. Moreover, in vitro studies use very high dosages of essential oils and their components to elicit an effect on fermentation parameters and make screening easier. However, these high dosages are far from comparable to what can be fed in vivo, therefore making it necessary to determine the optimal dosage of essential oils and their components in ruminant animal models (Calsamiglia et al., 2007; Chaves et al., 2009). Further, long-term in vitro studies have proven that rumen microbes may adapt to essential oils. However, little work has been done on the ability of the rumen to adapt to essential oils long-term in vivo (Calsamiglia et al., 2007). The majority of feeding behavior research with essential oil supplementation has been done in beef cattle, and little is known about essential oil effects on feeding behavior of dairy cattle. Recently published data further suggests that essential oils, particularly CIN, may enhance immune function in beef cattle exposed to high stress (Yang et al., 2010a; 2010b).

Many other areas have been left virtually untouched in the examination of essential oils and their active components. As stated previously, concern over the transfer of antibiotic residues to meat and milk is the main reason for the study of these essential oils as alternatives. However, little work has been done to identify whether these oils and their components may also transfer into meat and milk products. It is also important to determine if the use of these oils in a feeding system is cost effective, however this area has not been addressed (Calsamiglia et al., 2007). While the possibilities of changes in rumen biohydrogenation, milk and meat composition, and immunology have been touched on, there is still a need for validation of the few hypotheses that have been made in these areas. Although our understanding of essential oils and their active components as rumen modifiers has improved over the last decade, there is still much to examine in order to use these compounds effectively and efficiently in ruminant animal production systems. 


\section{REFERENCES}

Acamovic, T., J. D. Brooker. 2005. Biochemistry of plant secondary metabolites and their effects on animals. Proceedings of the Nutrition Society 64:403-412.

Bagg, R., G. H. Vessie, C.P. Dick, T. Duffield, J. B. Wilson, J. J. Aramini. 2005. Milk residues and performance of lactating dairy cows administered high doses of monensin. The Canadian Journal of Veterinary Research 69:180-185.

Benchaar, C., A. N. Hristov, H. Greathead. 2009. Essential oils as feed additives in ruminant nutrition. Pages 111-146 in Steiner, T. ed. Phytogenics in Animal Nutrition. Nottingham University Press, Nottingham, United Kingdom.

Benchaar, C., A. V. Chaves, G. R. Fraser, Y. Wang, K.A. Beauchemin, T. A. McAllister. 2007a. Effects of essential oils and their components on in vitro rumen microbial fermentation. Canadian Journal of Animal Science 87:413-419.

Benchaar, C., H. V. Petit, R. Berthiaume, T. D. Whyte, P. Y. Chouinard. 2006. Effects of addition of essential oils and monensin premix on digestion, ruminal fermentation, milk production, and milk composition in dairy cows. Journal of Dairy Science 89:4352-4364.

Benchaar, C., H. V. Petit, R. Berthiaume, D. R. Ouellet, J. Chiquette, P. Y. Choinard. 2007b. Effects of essential oils on digestion, ruminal fermentation, rumen microbial populations, milk production, and milk composition in dairy cows fed alfalfa silage or corn silage. Journal of Dairy Science 90:886-897.

Benchaar, C., P. Y. Chouinard. 2009. Short communication: Assessment of the potential of cinnamaldehyde condensed tannins, and saponins to modify milk fatty acid composition of dairy cows. Journal of Dairy Science 92:3392-3396.

Benchaar, C., T. A. McAllister, P. Y. Chouinard. 2008. Digestion, ruminal fermentation, ciliate 
protozoal populations, and milk production from dairy cows fed CIN, quebracho condensed tannin, or Yucca schidigera saponin extracts. Journal of Dairy Science 24:1033-1038.

Borchers, R. 1965. Proteolytic activity of rumen fluid in vitro. Journal of Animal Science 24:1033-1038.

Burt, S. 2004. Essential oils: their antibacterial properties and potential applications in foods - a review. International Journal of Food Microbiology 94:223-253.

Busquet, M., S. Calsamiglia, A. Ferret, C. Kamel. 2004. Effects of different doses of plant extracts on rumen microbial fermentation. Journal of Dairy Science 87(Suppl. 1): 213. (Abstr.).

Busquet, M., S. Calsamiglia, A. Ferret, C. Kamel. 2005a. Screening for the effects of natural plant extracts and secondary plant metabolites on rumen microbial fermentation in continuous culture. Animal Feed Science and Technology 123:597-613.

Busquet, M., S. Calsamiglia, A. Ferret, P. W. Cardozo, C. Kamel. 2005b. Effects of cinnamaldehyde and garlic oil on rumen microbial fermentation in a dual flow continuous culture. Journal of Dairy Science 88:2508-2516.

Busquet, M., S. Calsamiglia, A. Ferret, C. Kamel. 2006. Plant extracts affect in vitro rumen microbial fermentation. Journal of Dairy Science 89:761-771.

Calsamiglia, S., M. Busquet, P. W. Cardozo, L. Castillejos, A. Ferret. 2007. Invited Review: Essential oils as modifiers of rumen microbial fermentation. Journal of Dairy Science $90: 2580-2595$.

Cardozo, P. W., S. Calsamiglia, A. Ferret, C. Kamel. 2004. Effects of natural plant extracts on ruminal protein degradation and fermentation profiles in continuous culture. Journal of 
Animal Science 82:3230-3236.

Cardozo, P. W., S. Calsamiglia, A. Ferret, C. Kamel. 2005. Screening for the effects of natural plant extracts at different $\mathrm{pH}$ on in vitro rumen microbial fermentation of highconcentrate diet for beef cattle. Journal of Animal Science 83:2572-2579.

Cardozo, P. W., S. Calsamiglia, A. Ferret, C. Kamel. 2006. Effects of alfalfa extract, anise, capsicum and a mixture of cinnamaldehyde and eugenol on ruminal fermentation and protein degradation in beef heifers fed a high-concentrate diet. Journal of Animal Science 84:2801-2808.

Castillejos, L., S. Calsamiglia, A. Ferret, R. Losa. 2005. Effects of a specific blend of essential oil compounds and the type of diet on rumen microbial fermentation and nutrient flow from a continuous culture system. Animal Feed Science and Technology 119:29-41.

Castillejos, L., S. Calsamiglia, A. Ferret. 2006. Effect of essential oil active compounds on rumen microbial fermentation and nutrient flow in in vitro systems. Journal of Dairy Science 89:2649-2658.

Chaves, A. V., I. Schei, Y. Wang, T. A. McAllister, C. Benchaar. 2009. Effects of carvacrol and cinnamaldehyde on microbial fermentation when added to a barley- or corn-based diet in a continuous-culture system. Canadian Journal of Animal Science 89:97-104.

Chaves, A. V., K. Stanford, L. Gibson, T. A. McAllister, C. Benchaar. 2008a. Effects of carvacrol and cinnamaldehyde on intake, rumen fermentation, growth performance, and carcass characteristics of growing lambs. Animal Feed Science and Technology 145:396-408.

Chaves, A. V., M.L. He, W. Z. Yang, A. N. Hristov, T. A. McAllister, C. Benchaar. 2008b. Effects of essential oils on proteolytic, deaminative and methanogenic activities of mixed 
ruminal bacteria. Canadian Journal of Animal Science 88:117-122.

Cowan, M. M. 1999. Plant products as antimicrobial agents. Clinical Microbiology Review $12: 564-582$.

Di Pasqua, R., G. Betts, N. Hoskins, M. Edwards, D. Ercolini, G. Mauriello. 2007. Membrane toxicity of antimicrobial compounds from essential oils. Journal of Agricultural and Food Chemistry 55:4863-4890.

Dorman, H. J. D., S. G. Deans. 2000. Antimicrobial agents from plants: antibacterial activity of plant volatile oils. Journal of Applied Microbiology 88:308-316.

Duffield, T. F., A. R. Rabiee, I. J. Lean. 2008a. A meta-analysis of the impact of monensin in lactating dairy cattle. Part 1. Metabolic effects. Journal of Dairy Science 91:1334-1336.

Duffield, T. F., A. R. Rabiee, I. J. Lean. 2008b. A meta-analysis of the impact of monensin in lactating dairy cattle. Part 2. Production effects. Journal of Dairy Science 91:1347-1360.

Duffield, T. F., A. R. Rabiee, I. J. Lean. 2008c. A meta-analysis of the impact of monensin in lactating dairy cattle. Part 3. Health and reproduction. Journal of Dairy Science 91:2328-2341.

European Medicines Agency (Veterinary Medicines and Inspections). 2007. Final summary report: Monensin (cattle, including dairy cows). Committee for Medicinal Products for Veterinary Use. EMEA/CVMP/185123/2007-Final. 9 pages.

Fandiño, G. R., A. V. Chaves, Y. Wang, T. A. McAllister, K.A. Beauchemin, C. Benchaar. 2008. Assessment of the effects of cinnamon leaf oil on rumen microbial fermentation using two continuous culture systems. Journal of Dairy Science 90:2315-2328.

Fraser, G. R., A. V. Chaves, Y. Wang, T.A. McAllister, K. A. Beauchemin, C. Benchaar. 2007. Assessment of the effects of cinnamon leaf oil on rumen microbial fermentation using 
two continuous culture systems. Journal of Dairy Science 90:2315-2328.

Helander, I. M., H. Alakomi, K. Latva-Kala, T. Mattila-Sandholm, I. Pol, E. J. Smid, L. G. M. Gorris, A. von Wright. 1998. Characterization of the action of selected essential oil components on gram-negative bacteria. Journal of Agricultural and Food Chemistry 46:3590-3595.

Hili, P, C. S. Evans, R. G. Veness. 1997. Antimicrobial action of essential oils: the effect of dimethylsulphoxide on the activity of cinnamon oil. Letters in Applied Microbiology $24: 269-275$.

Lourenço, M., P. W. Cardozo, S. Calsamiglia, V. Fievez. 2008. Effects of saponins, quercetin, eugenol, and cinnamaldehyde on fatty acid biohydrogentation of forage polyunsaturated fatty acids in dual-flow continuous culture fermenters. Journal of Animal Science $86: 3045-3053$.

Macheboeuf, D., D. P. Morgavi, Y. Papon, J. L. Mousset, M. Arturo-Schaan. 2008. Doseresponse effects of essential oils on in vitro fermentation activity of the rumen microbial population. Animal Feed Science and Technology 145:335-350.

Martinez, S., J. Madrid, F. Hernandez., M. D. Megia, J. A. Sotomayor, M. J. Jordan. 2006. Effect of Thyme essential oils (Thymus hyemalis and Thymus zygis) and Monensin on in vitro ruminal degradation and volatile fatty acid production. Journal of Agricultural and Food Chemistry 54:6598-6602.

McGuffrey, R.K., L. F. Richardson, J. D. Wildinson. 2001. Ionophores for dairy cattle: current status and future outlook. Journal of Dairy Science 84:E194-203.

McIntosh, F. M., P. Williams, R. Losa, R. J. Wallace, D. A. Beever, C. J. Newbold. 2003. 
Effects of essential oils on ruminal microorganisms and their protein metabolism. Applied and Environmental Microbiology 69:5011-5014.

Molero, R. M. Ibars, S. Calsamiglia, A. Ferret, R. Losa. 2004. Effects of a specific blend of essential oil compounds on dry matter and crude protein degradability in heifers fed diets with different forage to concentrate ratios. Animal Feed Science and Technology 114:91-104.

Nagy, J. G., R. P. Tengerdy. 1968. Antibacterial action of essential oils of artemisia as an ecological factor. II. Antibacterial action of the volatile oils of Artemisia tridentata (big sagebrush) on bacteria from the rumen of mule deer. Journal of Applied Microbiology $16: 441-444$.

Newan, D. J., G. M. Cragg, K. M. Snader. 2000. The influence of natural products upon drug discovery. Natural Product Reports 17:215-234.

Newbold, C. J., F. M. McIntosh, P. Williams, R. Losa, R. J. Wallace. 2004. Effects of a specific blend of essential oil compounds on rumen fermentation. Animal Feed Science and Technology 114:105-112.

Odongo, N. E., M. M. Or-Rashid, R. Bagg, G. Vessi, P. Dick, E. Kebreab, J. France. 2007. Long-term effects of feeding monensin on milk fatty acid composition in lactating dairy cows. Journal of Dairy Science 90:5126-5133.

OJEU. 2003. Regulation (EC) No 1831/2003 of the European Parliament and the Council of 22 September 2003 on Additives for use in animal nutrition. Official Journal of European Union. Page L268/36 in OJEU of 10/18/2003.

Oh, H. K., M. B. Jones, W. M. Longhurst. 1967. Effect of various essential oils isolated from Douglas Fir needles upon sheep and deer rumen microbial activity. Applied 
Microbiology 15:777-784.

Oh, H. K., M. B. Jones, W. M. Longhurst. 1968. Comparison of rumen microbial fermentation inhibition resulting from various essential oils isolated from relatively unpalatable plant species. Applied Microbiology 16:39-44.

Ramanzin, M., L. Bailoni, S. Schiavon, G. Bittante. 1997. Effect of monensin on milk production and efficiency of dairy cows fed two diets differing in forage to concentrate ratios. Journal of Dairy Science 80:1136-1142.

Rodriguez-Prado, M. S. Calsamiglia, A. Ferret, J. Zieten, L. Gonzalez, D. Bravo. 2008. Effects of cinnamaldehyde-eugenol and capsicum on rumen fermentation and feeding behavior in beef heifers fed a high-concentrate diet. Journal of Animal Science 86(Suppl. 2):588. (Abstr.)

Tager, L. R., K. M. Krause. 2010. Effects of cinnamaldehyde, eugenol, and capsicum on fermentation of a corn-based dairy ration in continuous culture. Canadian Journal of Animal Science In Press.

Thornton, J. H., F. N. Owens. 1981. Monensin supplementation and in vivo methane production by steers. Journal of Animal Science 52:628-634.

Wallace, R. J. 2005. Symposium on 'Plants as animal foods: a case of catch 22?': Antimicrobial properties of plant secondary metabolites. Proceedings of the Nutrition Society 63:621629.

Yang, C. M., J. B. Russell. 1993. Effect of monensin on the specific activity of ammonia production by ruminal bacteria and disappearance of amino nitrogen from the rumen. Applied Environmental Microbiology 59:3250-3254.

Yang, W. Z., B. N. Ametaj, C. Benchaar, K. A. Beauchemin. 2010a. Cinnamaldehyde in feedlot 
cattle diets: intake, growth performance, carcass characteristics, and blood metabolites. Journal of Animal Scinece 88:1082-1092.

Yang, W. Z., B. N. Ametaj, C. Benchaar, K. A. Beauchemin. 2010b. Dose response to cinnamaldehyde supplementation in growing beef heifers: ruminal and intestinal digestion. Journal of Animal Science 88:680-688.

Zinn, R. A., C. F. Adam, M. S. Tamayo. 1995. Interaction of feed intake level on comparative ruminal and total tract digestion of dry-rolled and steam-flaked corn. Journal of Animal Science 73: 1239-1245. 
Table 1. Effects of cinnamaldehyde (CIN) and eugenol (EUG) on rumen fermentation and nutrient digestibility continuous culture ( $\uparrow=$ increase; $\downarrow=$ decrease; $\mathrm{NE}=$ no effect; - = not reported $)$

\begin{tabular}{|c|c|c|c|c|c|c|c|c|c|c|c|}
\hline Author(s) & $\begin{array}{c}\text { Essential } \\
\text { Oil(s) }\end{array}$ & $\begin{array}{c}\text { Dosage, } \\
\mathrm{mg} / \mathrm{L}\end{array}$ & Diet $^{1}$ & $\begin{array}{l}\text { Total } \\
\text { VFA }^{2} \\
\end{array}$ & $\mathrm{~A}: \mathrm{P}^{3}$ & $\begin{array}{c}\text { Ammonia } \\
\text { Nitrogen, } \\
\mathrm{mg} / \mathrm{dL}\end{array}$ & EMPS $^{4}$ & $\begin{array}{c}\text { Fermenter } \\
\mathrm{pH}\end{array}$ & $\begin{array}{c}\% \mathrm{DM} \\
\text { digestibility }^{5} \\
\end{array}$ & $\begin{array}{c}\% \mathrm{ADF} \\
\text { digestibility }^{5} \\
\end{array}$ & $\begin{array}{c}\% \text { NDF } \\
\text { digestibility }^{5}\end{array}$ \\
\hline \multirow[b]{2}{*}{ Busquet et al., 2005a } & $\mathrm{CIN}$ & \multirow[b]{2}{*}{2.2} & \multirow[b]{2}{*}{$60: 40$} & $\mathrm{NE}$ & $\mathrm{NE}$ & $\mathrm{NE}$ & - & - & - & - & - \\
\hline & EUG & & & $\mathrm{NE}$ & $\mathrm{NE}$ & NE & - & - & - & - & - \\
\hline \multirow[b]{2}{*}{ Busquet et al., 2005b } & \multirow[b]{2}{*}{ CIN } & 31.2 & \multirow[b]{2}{*}{$50: 50$} & $\mathrm{NE}$ & $\downarrow$ & $\mathrm{NE}$ & $\mathrm{NE}$ & - & $\mathrm{NE}$ & $\mathrm{NE}$ & $\mathrm{NE}$ \\
\hline & & 312 & & $\mathrm{NE}$ & $\mathrm{NE}$ & $\mathrm{NE}$ & $\mathrm{NE}$ & - & $\mathrm{NE}$ & NE & NE \\
\hline \multirow[t]{2}{*}{ Cardozo et al. 2004} & $\begin{array}{c}\text { CIN } \\
\text { extract }^{6}\end{array}$ & 0.22 & \multirow[t]{2}{*}{$52: 48$} & $\mathrm{NE}$ & $\mathrm{NE}$ & $\mathrm{NE}$ & - & - & - & - & - \\
\hline & $\mathrm{CAP}$ & & & $\mathrm{NE}$ & $\mathrm{NE}$ & $\mathrm{NE}$ & - & - & - & - & - \\
\hline \multirow[b]{2}{*}{ Chaves et al., 2009} & \multirow[b]{2}{*}{$\mathrm{CIN}$} & \multirow[b]{2}{*}{3.6} & \multirow{2}{*}{$\begin{array}{l}\text { corn-based } \\
\text { barley-based }\end{array}$} & $\mathrm{NE}$ & $\mathrm{NE}$ & $\mathrm{NE}$ & $\mathrm{NE}$ & $\mathrm{NE}$ & $\mathrm{NE}$ & - & - \\
\hline & & & & $\mathrm{NE}$ & $\mathrm{NE}$ & $\mathrm{NE}$ & NE & NE & $\mathrm{NE}$ & - & - \\
\hline Fraser et al., 2007 & $\begin{array}{c}\text { Cin. leaf } \\
\text { oil }^{7}\end{array}$ & 500 & $50: 50$ & $\mathrm{NE}$ & $\uparrow$ & $\mathrm{NE}$ & $\downarrow$ & $\mathrm{NE}$ & $\downarrow$ & $\downarrow$ & $\downarrow$ \\
\hline \multirow[t]{2}{*}{ Lourenço et al., 2008} & CIN & 500 & \multirow{2}{*}{$\begin{array}{l}\text { Perennial } \\
\text { Ryegrass }\end{array}$} & $\downarrow$ & $\bar{\uparrow}$ & - & - & - & - & - & - \\
\hline & EUG & 250 & & $\mathrm{NE}$ & $\mathrm{NE}$ & - & - & - & - & - & - \\
\hline
\end{tabular}

${ }^{1}$ Forage to concentrate ratio (DM basis) or main ration component

${ }^{2} \mathrm{VFA}=$ volatile fatty acid concentration, $\mathrm{mmol} / \mathrm{L}$

${ }^{3} \mathrm{~A}: \mathrm{P}=$ acetate to propionate ratio

${ }^{4}$ EMPS $=$ efficiency of microbial protein synthesis; $\mathrm{g}$ microbial nitrogen $\mathrm{kg}^{-1}$ digested $\mathrm{OM}$

${ }^{5} \mathrm{DM}=$ dry matter; $\mathrm{ADF}=$ acid detergent fiber; $\mathrm{NDF}=$ neutral detergent fiber

${ }^{6}$ Cinnamon extract contained $59 \%$ cinnamaldehyde

${ }^{7}$ Cinnamon leaf oil contained $76 \%$ eugenol 
Table 2. Effects of cinnamaldehyde (CIN), eugenol (EUG), and capsicum (CAP) on in vivo rumen fermentation, intake, and nutrient digestibility $(\uparrow=$ increase; $\downarrow=$ decrease; $\mathrm{NE}=$ no effect; - = not reported $)$

\begin{tabular}{|c|c|c|c|c|c|c|c|c|c|c|c|}
\hline Author(s) & $\begin{array}{c}\text { Essential } \\
\text { Oil(s) } \\
\end{array}$ & $\begin{array}{l}\text { Dosage, } \\
\text { g/cow/d }\end{array}$ & $\operatorname{Diet}^{1}$ & $\begin{array}{l}\text { Total } \\
\text { VFA }^{2} \\
\end{array}$ & $\mathrm{~A}: \mathrm{P}^{3}$ & $\begin{array}{c}\text { Ammonia } \\
\text { Nitrogen, } \\
\text { mg/dL }\end{array}$ & $\begin{array}{c}\text { Rumen } \\
\mathrm{pH}\end{array}$ & $\mathrm{DMI}^{4}$ & $\begin{array}{c}\% \text { DM } \\
\text { digestibility } \\
\end{array}$ & $\begin{array}{c}\% \text { ADF } \\
\text { digestibility }^{5} \\
\end{array}$ & $\begin{array}{c}\% \text { NDF } \\
\text { digestibility } \\
\end{array}$ \\
\hline Benchaar et al., 2006 & Blend $^{6}$ & $2.0 \mathrm{~g} / \mathrm{d}$ & $57: 43$ & $\mathrm{NE}$ & $\mathrm{NE}$ & $\mathrm{NE}$ & $\uparrow$ & $\mathrm{NE}$ & $\mathrm{NE}$ & $\uparrow$ & $\mathrm{NE}$ \\
\hline Benchaar et al., 2007 & Blend $^{7}$ & $0.75 \mathrm{~g} / \mathrm{d}$ & $50: 50^{8}$ & $\mathrm{NE}$ & $\mathrm{NE}$ & $\mathrm{NE}$ & $\uparrow$ & $\mathrm{NE}$ & $\mathrm{NE}$ & $\mathrm{NE}$ & $\mathrm{NE}$ \\
\hline \multirow[t]{2}{*}{ Benchaar et al., 2008} & $\mathrm{CIN}$ & $1.0 \mathrm{~g} / \mathrm{d}$ & $60: 40$ & $\mathrm{NE}$ & $\mathrm{NE}$ & $\mathrm{NE}$ & $\mathrm{NE}$ & $\mathrm{NE}$ & $\mathrm{NE}$ & $\mathrm{NE}$ & $\mathrm{NE}$ \\
\hline & $\mathrm{CIN}+\mathrm{EUG}$ & $0.18+0.09 \mathrm{~g} / \mathrm{d}$ & & $\mathrm{NE}$ & $\mathrm{NE}$ & $\bar{\downarrow}$ & $\mathrm{NE}$ & $\downarrow$ & - & - & - \\
\hline \multirow[t]{2}{*}{ Cardozo et al., 2006} & $\mathrm{CIN}+\mathrm{EUG}$ & $0.6+0.3 \mathrm{~g} / \mathrm{d}$ & 10:90 & NE & $\mathrm{NE}$ & $\downarrow$ & $\mathrm{NE}$ & $\mathrm{NE}$ & - & - & - \\
\hline & CAP & $1.0 \mathrm{~g} / \mathrm{d}$ & & $\mathrm{NE}$ & $\mathrm{NE}$ & $\mathrm{NE}$ & $\mathrm{NE}$ & $\uparrow$ & - & - & - \\
\hline Fandiño et al., 2007 & CAP & $0.5 \mathrm{~g} / \mathrm{d}$ & $10: 90$ & $\mathrm{NE}$ & $\mathrm{NE}$ & $\mathrm{NE}$ & $\mathrm{NE}$ & $\uparrow$ & - & - & - \\
\hline \multirow{3}{*}{ Rodriguez-Prado et al., 2008a } & $\mathrm{CIN}+\mathrm{EUG}$ & $0.17+0.33 \mathrm{~g} / \mathrm{d}$ & & $\mathrm{NE}$ & - & - & $\overline{\mathrm{NE}}$ & $\overline{\mathrm{NE}}$ & - & - & - \\
\hline & CAP & $0.5 \mathrm{~g} / \mathrm{d}$ & 10.90 & $\uparrow$ & - & - & $\uparrow$ & $\mathrm{NE}$ & - & - & - \\
\hline & & $0.63 \mathrm{~g} / \mathrm{d}$ & & $\frac{1}{\uparrow}$ & - & $\overline{\mathrm{NE}}$ & $\mathrm{NE}$ & $\mathrm{NE}$ & - & - & - \\
\hline \multirow[t]{2}{*}{ Rodriguez-Prado et al., 2008b } & CAP & $1.25 \mathrm{~g} / \mathrm{d}$ & 10:90 & $\mathrm{NE}$ & - & $\mathrm{NE}$ & $\mathrm{NE}$ & $\mathrm{NE}$ & - & - & - \\
\hline & & $2.50 \mathrm{~g} / \mathrm{d}$ & & $\uparrow$ & - & $\mathrm{NE}$ & $\mathrm{NE}$ & $\uparrow$ & - & - & - \\
\hline
\end{tabular}

1 Forage to concentrate ratio, DM basis

${ }^{2} \mathrm{VFA}=$ volatile fatty acid concentration, $\mathrm{mmol} / \mathrm{L}$

${ }^{3} \mathrm{~A}: \mathrm{P}=$ acetate to propionate ratio

${ }^{4} \mathrm{DMI}=$ dry matter intake, $\mathrm{kg} / \mathrm{d}$

${ }^{5} \mathrm{DM}=$ dry matter; $\mathrm{ADF}=$ acid detergent fiber; $\mathrm{NDF}=$ neutral detergent fiber

${ }^{6}$ Blend contained EUG, thymol, vanillin, and limonene

${ }^{7}$ Blend contained EUG, thymol, vanillin, guaiacol, and limonene

${ }^{8}$ Alfalfa or corn-silage based 

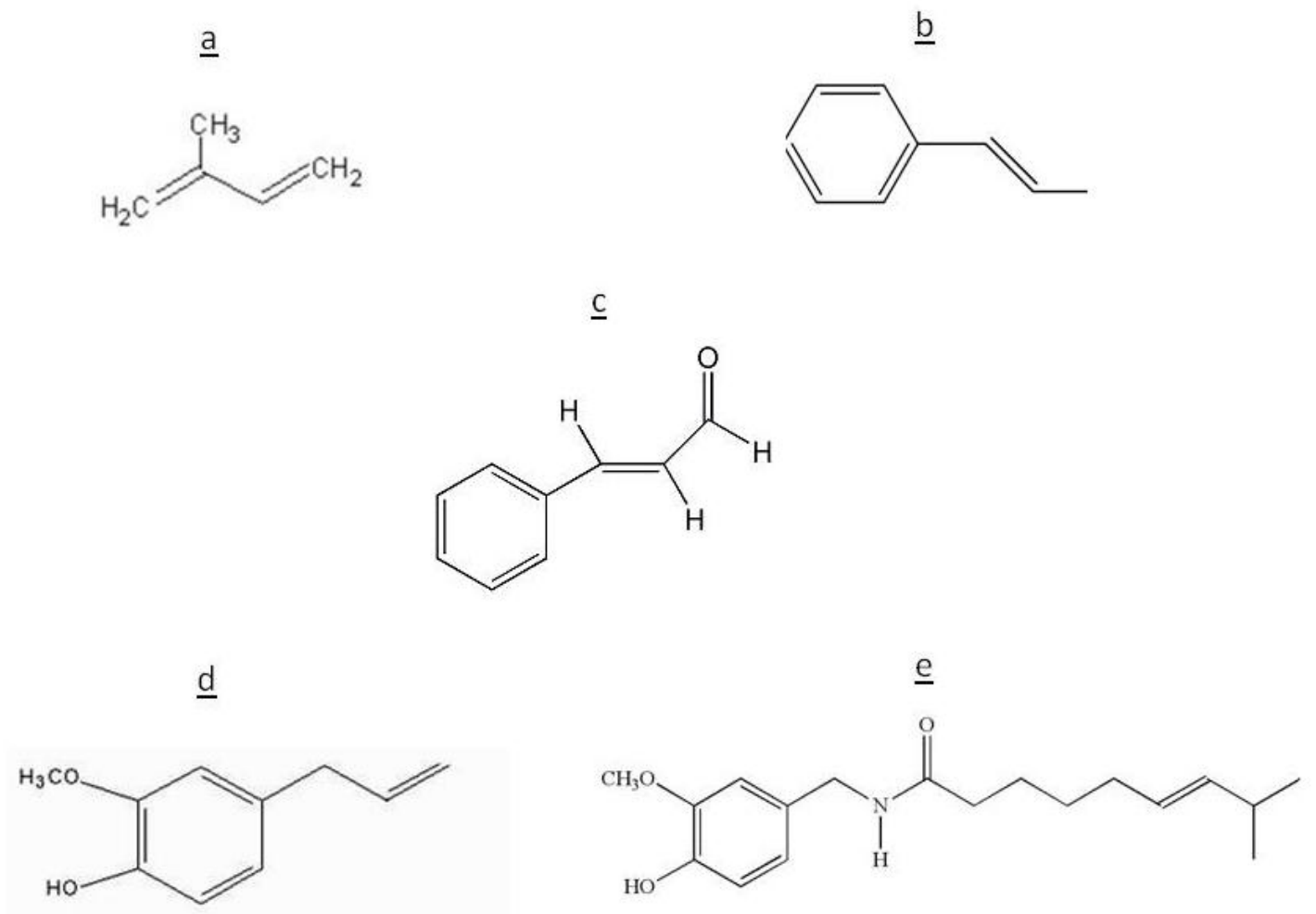

Figure 1. Chemical structures of (a) isoprenes (terpenes), (b) phenylpropenes, (c) cinnamaldehyde, (d) eugenol, and (e) capsaicin. 


\section{CHAPTER 2}

\section{Effects of cinnamaldehyde, eugenol, and capsicum on fermentation of a corn-based dairy ration in continuous culture ${ }^{1}$}

\footnotetext{
${ }^{1}$ Formatted for submission to the Canadian Journal of Animal Science
} 
TAGER AND KRAUSE - ESSENTIAL OIL EFFECT ON DAIRY RATION IN VITRO

Effects of cinnamaldehyde, eugenol, and capsicum on fermentation of a corn-based dairy ration in continuous culture.

\author{
L. R. Tager $^{1}$ and K. M. Krause ${ }^{1,2}$ \\ ${ }^{1}$ Department of Animal and Nutritional Science, West Virginia University, Morgantown 26506 \\ ${ }^{2}$ Corresponding Author: K. Marie Krause, Email: Marie.Krause@mail.wvu.edu
}

Tager, L. R. and Krause, K. M. 2010. Effects of cinnamaldehyde, eugenol, and capsicum on fermentation of a corn-based dairy ration in continuous culture. Can. J. Anim. Sci. Volume: pages. A 12-unit continuous culture system was used in a complete randomized design to study the effects of no oil (CON), cinnamaldehyde oil (CIN), eugenol oil (EUG), and capsicum oil (CAP) [500 $\mathrm{mg} \mathrm{L}^{-1} \mathrm{~d}^{-1}$ ] with a 45:55 forage:concentrate ratio (DM basis) ration on rumen fermentation. Dry matter digestibility did not differ among treatments. Organic matter digestibility tended to decrease with CIN. Digestibility of neutral detergent and acid detergent fiber tended to be highest with CAP. Crude protein digestibility and bacterial nitrogen flow was depressed with CIN and EUG. CIN tended to decrease microbial protein synthesis and increase effluent ammonia nitrogen. Total volatile fatty acid production did not differ among treatments; however, isovalerate production tended to be highest with CAP. CIN and EUG had higher mean $\mathrm{pH}$, spent fewer hr/d and had smaller area under the curve at $\mathrm{pH}<5.6$ and 5.8. CAP had smaller area under the curve at $\mathrm{pH}<5.6$. Supplementation with these oils at the current dose had limited effects on rumen fermentation, with the majority of effects observed being mainly attributable to the very high dosage of oil used.

Key words: dairy cow, essential oil, continuous culture, rumen fermentation, rumen $\mathrm{pH}$ 
Abbreviations: ADF, acid detergent fiber; BCVFA, branched-chain volatile fatty acids; CAP, capsicum oil; CIN, cinnamaldehyde oil; CON, control; DIM, days in milk; DM, dry matter; DMI, dry matter intake; EMPS, efficiency of microbial protein synthesis; EO, essential oil; EUG, eugenol oil; HAP, hyper-ammonia producing; NDF, neutral detergent fiber; OM, organic matter; TMR, total mixed ration; VFA, volatile fatty acids

Manipulation of rumen fermentation to improve feed efficiency in the livestock industry is often achieved through the use of antibiotics, such as the ionophore monensin. However, concern has increased recently over the use of antibiotics in the livestock industry due to the possible rise of antibiotic resistant bacteria, which would be of great risk to human health (Benchaar et al. 2008). The use of many plant EO and their active components has become a popular suggestion as a natural alternative to antibiotic feed additives (Wallace 2004). The antimicrobial and healing properties of EO have been well-known since ancient civilizations (Acamovic and Brooker 2005). In recent years, EO have been researched as a possible alternative to antibiotics due to their ability to alter microbial fermentation in the ruminant animal (Wallace 2004), possibly improving feed efficiency and rumen fermentation characteristics (Benchaar et al. 2008).

Many of the studies on EO have been done using in vitro methods (McIntosh et al. 2003; Cardozo et al. 2004; Busquet et al. 2005a; Castillejos et al. 2005; Fraser et al. 2007) such as batch culture and continuous culture. Data from these studies are often inconclusive and lead to conflicting results due to variation of dosages, structures, diets, blends, and EO providers. The majority of in vitro studies that investigate the use of EO in dairy rations have utilized rations containing mainly barley-straw, -silage, -ground grain and ground corn-grain (Cardozo et al. 2004; Busquet et al. 2005; Castillejos et al. 2007; Fraser et al. 2007). While barley and ground corn are considered highly fermentable, few studies have investigated EO effects on dairy feeds 
that have been processed for more rapid fermentability, such as steam-flaked corn. Feeds that are more highly fermentable cause sharp decreases in rumen $\mathrm{pH}$ at a fast rate (Zinn et al. 1995). Rumen $\mathrm{pH}$ is an important indicator of rumen acidosis and overall cow health, particularly in cows fed a more highly fermentable diet. The effects of supplementing EO with a highly fermentable corn-based dairy ration on $\mathrm{pH}$ patterns throughout the day has yet to be quantified in vitro.

Cinnamaldehyde (CIN), eugenol (EUG), and capsicum oil (CAP) are known to have antimicrobial properties, and may act as rumen modifiers. Little is known about the effects of CIN and EUG on high producing dairy cattle fed a highly fermentable, corn-based diet. Capsicum has recently been identified as an emerging possibility for manipulating rumen fermentation and feeding behavior (Cardozo et al. 2006; Fandiño et al. 2007). In vitro, CIN (Busquet et al. 2004, 2005a, 2005b, 2006; Fraser et al. 2007), EUG (Busquet et al. 2005b, 2006), and CAP (Busquet et al. 2006) often have little effect on microbial fermentation except at very high dosages (> $300 \mathrm{mg} \mathrm{L}^{-1}$ rumen fluid) when supplemented with ground barley- and corn-grain diets. While such high dosages of EO are considered toxic, they are often used to elicit an observable effect for screening purposes in vitro.

In vivo, when supplemented with higher concentrate beef diets (10:90 forage:concentrate ratio, DM basis) also containing ground barley- and corn-grain, CIN (Cardozo et al. 2006), EUG (Cardozo et al. 2006), and CAP (Cardozo et al. 2006; Fandiño et al. 2008) provide some positive effects on rumen fermentation, often leading to increased feed digestibility. However, little is known about how these oils affect rumen $\mathrm{pH}$ fluctuations, particularly when used as a supplement with corn-based diets processed for higher fermentability often fed to high producing dairy cattle. Therefore, the objective of the current study was to investigate the effects of CIN, 
EUG, and CAP on rumen fermentation characteristics in continuous culture and to assess their effects on $\mathrm{pH}$ fluctuations using a corn-based dairy diet including steam-flaked corn.

\section{MATERIALS AND METHODS}

\section{Experimental Design}

A 12-unit continuous culture system similar to that described by Hoover et al. (1976) was used. A complete randomized design with four dietary treatments and three replicates within each treatment was utilized. The fermentation period consisted of $10 \mathrm{~d}$ with $7 \mathrm{~d}$ of equilibration and 3 $\mathrm{d}$ of sampling.

\section{Source of Inocula, Fermenter Diet, and Feeding}

Inocula for the fermenters were obtained at $1000 \mathrm{~h}$ on the first day of the fermentation period from two ruminally cannulated, lactating Holstein cows that were $133 \pm 6$ DIM and weighed $620 \pm 19 \mathrm{~kg}$. The donor cows were fed a TMR (44:56 forage:concentrate ratio, DM basis) twice daily $(0800 \mathrm{~h}$ and $2000 \mathrm{~h})$ consisting of corn silage (20.7\%), mixed-grass haylage (15.8\%), pelleted supplement (36.4\%), premixed dairy concentrate (18.7\%), salt and mineral mix (0.3\%), and alfalfa hay (8.1\%), on a DM basis. The pelleted supplement contained soybean hulls (33.6\%), ground corn (37.5\%), $48 \%$ soybean meal (25.3\%), urea (1.2\%), ground limestone $(1.0 \%)$, dicalcium phosphate $(0.4 \%)$, magnesium oxide $(0.2 \%)$, salt and mineral mix $(0.5 \%)$, and vitamin mix $(0.4 \%)$, on a DM basis. The premixed dairy concentrate contained dry beet pulp pellets $(7.9 \%), 60 \%$ CP corn gluten meal (10.3\%), cracked corn grain (39.7\%), 48\% soybean meal (19.9\%), dicalcium phosphate (1.6\%), Megalac (5.9\%), soybean oil (1.5\%), E-soy (12.7\%), and Mag-O-Min $(0.5 \%)$, on a DM basis. The diet was formulated to meet the requirements of a 600-kg lactating dairy cow producing $38 \mathrm{~kg}$ milk d$^{-1}$ according to the NRC (2001). 
Fermenters were fed a lactating dairy ration with a forage to concentrate ratio of 45:55 (DM basis) formulated to support $45 \mathrm{~kg} \mathrm{~d}^{-1}$ of milk production in a 623-kg cow with a predicted DMI of $25.1 \mathrm{~kg} \mathrm{~d}^{-1}$. Dietary ingredients and nutrient composition are shown in Table 1. Silage, alfalfa, and grass hay were dried at $60^{\circ} \mathrm{C}$ and ground through a 4-mm screen (Wiley Mill grinder, Arthur H. Thomas, Philadelphia, PA) before mixing the ration. A subsample was taken from the TMR, and ground through a 1-mm screen for chemical analysis.

Rumen contents were collected from cannulated cows and strained through one layer of cheesecloth and rumen fluid was pooled before inoculating fermenters. Each fermenter was inoculated with $900 \mathrm{ml}$ of inoculum and $200 \mathrm{ml}$ artificial saliva (Weller and Pilgrim 1974). All procedures with animals were performed in accordance with the guidelines set by the West Virginia University Animal Care and Use Committee.

The four treatments in this experiment included: a) control (no addition of EO), b) addition of CIN, c) addition of EUG, and d) addition of CAP (all oils obtained from Pancosma S.A., Bellegarde-sur-Valserine, France). Diets were fed in two equal feedings at $12 \mathrm{~h}$ intervals $(0830 \mathrm{~h}$ and $2030 \mathrm{~h})$. Fermenters were treated with EO at each feeding to achieve a concentration of $500 \mathrm{mg} \mathrm{L}^{-1}$. Due to their liquid form, $\mathrm{EO}$ were added to the fermenters immediately prior to each feeding. Each fermenter had a working volume of $1164 \mathrm{~mL}$, and all diets were fermented under the following conditions: liquid dilution rate: $10 \% \mathrm{~h}^{-1}$, solids dilution rate: $5 \% \mathrm{~h}^{-1}$, temperature: $39^{\circ} \mathrm{C}$, feed intake $\mathrm{d}^{-1}: 95 \mathrm{~g}$ of $\mathrm{DM} \mathrm{d}^{-1}$. Fermenter $\mathrm{pH}$ was monitored bi-hourly for fluctuations with an inoLab pH Level $2 \mathrm{pH}$ meter (WTW, Weilheim, Germany). The artificial saliva of Weller and Pilgrim (1974) was continuously infused at a rate to provide $10 \% \mathrm{~h}^{-1}$ liquid flow.

\section{Sample Collection}


During the last $3 \mathrm{~d}$ the effluents were collected in an ice bath at $0800 \mathrm{~h}$ daily and a 1-L sample was composited and saved for analysis of VFA, ammonia, DM, ADF, NDF, ash, sugar, and starch. For analysis of DM, ADF, NDF, ash, sugar, and starch, $325 \mathrm{~g}$ of the composited effluents were weighed out, freeze-dried and ground through a 1-mm screen. Remaining effluents were refrigerated for analysis of VFA and ammonia.

After the effluent was collected on day 10, the contents of the fermenters were stirred vigorously prior to being allowed to settle in order to dislodge solids associated microbes. Then, after settling, the upper fluid layer was used for collection of microbes. Two $250 \mathrm{ml}$ samples were taken from each fermenter and centrifuged at $4^{\circ} \mathrm{C}$ for $20 \mathrm{~min}$ at $200 \times \mathrm{g}$. The supernatants were centrifuged for $15 \mathrm{~min}$ at $30,000 \times g$, the pellets were combined, re-suspended in saline, and again centrifuged at $4^{\circ} \mathrm{C}$ for $15 \mathrm{~min}$ at $30,000 \times g$. The supernatants were discarded and the pellets were re-suspended in $20 \mathrm{ml}$ of a 50:50 mixture of distilled water and methanol and centrifuged for $15 \mathrm{~min}$ at $30,000 \times g$. The supernatants were poured off, and the pellets were resuspended in distilled water and freeze-dried.

\section{Chemical Analyses}

Analytical DM of the feed was determined by oven drying at $100^{\circ} \mathrm{C}$ for $24 \mathrm{~h}(\mathrm{AOAC} 1995$; 967.03). Effluent DM was determined by centrifuging a 34 to $40 \mathrm{~g}$ sample of effluent at 30,000 $\times g$ for $45 \mathrm{~min}$. The supernatant was discarded and the particulate matter was dried at $100^{\circ} \mathrm{C}$ for $24 \mathrm{~h}$ and reweighed. Dry matter digestibility and OM digestibility were corrected for microbial DM and OM, respectively. Ether extraction of the feed was performed according to AOAC (1995; 920.39). Ash content of feed, effluents, and bacteria were determined by combustion at $550^{\circ} \mathrm{C}$ overnight, and $\mathrm{OM}$ was calculated as 100 minus the percentage ash (AOAC 1995; 942.05). Determination of the NDF and ADF content in the feed was done using the Ankom 200 
Fiber Analyzer (Ankom Technology Corp, Macedon, NY). The adaptations for NDF and ADF analysis of continuous culture effluents were as described by Crawford et al. (1983). Total nitrogen in feed and effluents, as well as bacterial nitrogen and ammonia concentration were analyzed according to AOAC $(1995 ; 976.05)$ using an automated Tecator digestion system (Tecator, Inc., Herndon, VA). Analysis of VFA concentrations in effluents were performed according to the gas chromatographic separation procedure (Anonymous 1975). The gas chromatograph was a Varian model 3300 with an FID detector (Varian, Inc., Palo Alto, CA). The column was a 2-m $\times 2$-mm glass column packed with $10 \%$ SP-1200/1\% H3HPO4 on 80/100 chromosorb WAW (Supelco,. Inc. Bellefonte, PA). Effluent and microbial concentrations of purines were determined by the procedures of Zinn and Owens (1986) to calculate g microbial nitrogen production. The ratio of $\mathrm{N}$ : purine in effluent and microbial samples was used to calculate microbial nitrogen flow from the fermenter. The sugars and starches of the feeds and effluents were determined by the procedure of Smith (1969), except that ferricyanide was used to detect reducing sugars. Digestibility of DM, OM, ADF, NDF, and CP, and total flows of nonammonia nitrogen, microbial nitrogen, and dietary nitrogen were calculated as outlined by Stern and Hoover (1990).

\section{Statistical Analysis}

Data were analyzed using the MIXED procedure of SAS (SAS Institute, 2003). All data, except culture $\mathrm{pH}$, were analyzed using a model including treatment as a fixed effect and fermenter within treatment as a random effect. Culture $\mathrm{pH}$ data were analyzed as repeated measurements. Based on model fitting statistics an Autoregressive Moving Average (ARMA 1,1) covariance structure was used for the $\mathrm{pH}$ analysis. The model included treatment, feeding (morning or evening), and hours post feeding as fixed variables, along with their two- and three-way 
interactions. Fermenter within treatment, sampling day, and fermenter $\times$ treatment $\times$ day $\times$ feeding were included as random effects in the model. The fermenter $\times$ treatment $\times$ day $\times$ feeding interaction was used as the subject of the repeated measure in the model. Statistical analysis was conducted using a Kenward-Roger adjustment and reported as least squared means. Time and area below pH 5.6 and 5.8 were calculated using Sigma Plot (SPSS Science Marketing, 2002) and analyzed using the same model as non-pH data. Separation of means was performed on data with significant treatment differences and tendency for treatment differences, and a Tukey's adjustment was used to make treatment comparisons. All results are reported with significance declared at $P \leq 0.05$ and tendency at $0.05<P \leq 0.10$.

\section{RESULTS AND DISCUSSION}

\section{Nutrient Digestibilities}

Dry matter digestibility was not affected by the treatments $(P=0.97$; Table 2$)$. This is consistent with published literature (Castillejos et al., 2005; Benchaar et al., 2006, 2007; Chaves et al., 2009). Conversely, OM digestibility tended to decrease with CIN (-5.9\%). This contradicts previous research where CIN did not affect OM digestibility either at low doses $\left(<4 \mathrm{mg} \mathrm{L}^{-1}\right.$; Chaves et al., 2009) or high doses (312 $\mathrm{mg} \mathrm{L}^{-1}$; Busquet et al., 2005b). Although inconsistent with other literature, results from the current study suggest that the use of CIN may cause a decrease in overall nutrient digestibility, particularly in diets with ingredients processed for higher rumen fermentability; therefore, caution should be used when considering CIN as a treatment in vivo.

Digestibility of NDF was depressed by CIN (-9.3\%) and EUG (8.8\%) and numerically increased by CAP (+7.9\%; Table 2). A similar trend was observed for ADF digestibility. These results do not agree with the majority of literature where no differences were reported in NDF 
digestibility of several EO blends and individual EO in vivo and in vitro at a range of dosages (Castillejos et al. 2005, 2006; Busquet et al. 2005a; Benchaar et al. 2007). The depressed fiber digestibility observed in the current study with the CIN treatment correlates with the depression observed in OM digestibility, and may be a consequence of CIN toxicity toward microbes at such a high dosage. While DM and OM digestibility did not change with EUG or CAP, the changes observed in fiber digestibility with these treatments suggests that they are affecting microbial populations. Again, the high dosage of EO used may have been toxic to specific microbial populations. Although microbial populations were not assessed, the results of this study suggest that EUG may be suppressing fiber digesting microbes, whereas CAP may be suppressing non-fiber digesting microbes.

Starch digestibility did not change with addition of EO $(P=0.27$; Table 2$)$. Few studies assess the effects of EO on starch digestibility. At a lower dose, supplementing CIN (3.6 $\mathrm{mg} \mathrm{L}^{-}$ ${ }^{1}$ ) in continuous culture (Chaves et al. 2009; corn- and barley-based diets) elicited no change in starch digestibility. Similarly, the high dosage of $500 \mathrm{mg} \mathrm{L}^{-1}$ in the current study did not change starch digestibility suggesting that these EO have no effects on starch digestion.

Crude protein digestibility was decreased by CIN and EUG $(P=0.01$; Table 2$)$, which does not agree with published literature. At a dosage of $500 \mathrm{mg} \mathrm{L}^{-1}$ (50:50 barley silage: concentrate ratio diet), Fraser et al. (2007) reported no effect of cinnamon leaf oil (76\% eugenol) on CP digestibility in continuous culture. The reduced CP digestibility by CIN and EUG may be attributed to the sensitivity of protein degrading bacteria to EO, particularly at such a high dosage. McIntosh et al. (2003) observed that a mixture of EO (thymol, eugenol, vanillin, and limonene) can potentially inhibit deamination of amino acids by up to $9 \%$ when added to batch culture at concentrations as low as $16 \mathrm{ppm}$. This may be considered beneficial as decreased 
metabolism of proteins in the rumen allows greater flow of protein out of the rumen where utilization and absorption are more efficient. However, many proteolytic bacteria and fungi are also cellulolytic, and the possible benefits of EO on protein metabolism must be weighed with the detrimental effects they may have on fiber digestion (McIntosh et al. 2003). Indeed, the current study not only had decreased CP digestion by CIN and EUG, but also decreases in fiber digestibility. Again, this may be explained by the possible toxicity toward microbial populations at the high dosage used in this study.

\section{Nitrogen metabolism and microbial protein synthesis}

The approach used to determine microbial nitrogen flow assumes complete degradation of feed purines, thus leaving only microbial purines in effluents. Although there is no way of measuring escape of feed-related purines from fermenters, there is high likelihood that some feed purines escaped digestion and were passed to effluents. Therefore, the microbial nitrogen flow data may be overestimated. Nonetheless, microbial nitrogen flow $\left(\mathrm{g} \mathrm{d}^{-1}\right)$ was depressed by CIN and EUG, while CAP did not affect microbial $\mathrm{N}$ flow $(P<0.01$; Table 3$)$. In previous studies, microbial nitrogen flow was not generally affected by the addition of EO blends or individual EO to continuous culture at a wide range of dosages (1.5 to $312 \mathrm{mg} \mathrm{L}^{-1}$; Busquet et al. 2005a; Castillejos et al. 2005). In agreement with the present study, Fraser et al. (2007) reported reduced bacterial nitrogen flow with a high dosage of $500 \mathrm{mg} \mathrm{L}^{-1}$ cinnamon leaf oil $(76 \%$ eugenol; 50:50 barley silage:concentrate ratio diet), and linked the reduced flow of microbial $\mathrm{N}$ to the tendency towards decreased OM digestibility and the numerical decrease in ADF and NDF digestibility, which agrees with the results observed for CIN and EUG in the present study. In both studies, a very high dosage of EO was used, which may have caused toxicity to microbial populations, thus leading to a decrease in microbial nitrogen flow after adaptation. 
Cinnamaldehyde tended to decrease ( $P=0.06$; Table 3 ) EMPS (g microbial nitrogen $\mathrm{kg}^{-1}$ digested OM). Decreases in EMPS could have negative effects on productivity due to a decrease in absorbable protein passing out of the rumen (Fraser et al. 2007). Data on EMPS reported in the literature varies widely among EO, dosage, and experimental technique (Benchaar et al. 2008). Busquet et al. (2005b) reported no effect of CIN at dosages of 31.2 and $312 \mathrm{mg} \mathrm{L}^{-1}$ when fed with a 50:50 forage:concentrate ratio diet, and Chaves et al. (2009) reported no effects with a dosage of $3.6 \mathrm{mg} \mathrm{L}^{-1} \mathrm{CIN}$ to both a corn- and barley-based diet. At dosages ranging from $1.5 \mathrm{mg}$ $\mathrm{L}^{-1}$ to $500 \mathrm{mg} \mathrm{L}^{-1}$ of a mixture of EO (thymol, limonene, and guaiacol), Castillejos et al. (2005, 2007) reported no effect on EMPS when supplemented with both a 10:90 or a 60:40 forage:concentrate ratio diet. The present study used a higher dosage of $500 \mathrm{mg} \mathrm{L}^{-1}$, which may account for the tendency of CIN to decrease EMPS due to its antimicrobial effects at high dosages compared to other EO. Likewise, using a higher dosage of $500 \mathrm{mg} \mathrm{L}^{-1}$ cinnamon leaf oil (76 \% EUG) also caused a decrease in EMPS when supplemented in continuous culture with a 50:50 forage:concentrate ratio diet (Fraser et al. , 2007), again suggesting that such high dosages of some EO are toxic to microbial populations.

Cinnamaldehyde tended to increase effluent ammonia nitrogen $\left(\mathrm{mg} \mathrm{dL}^{-1} ; P=0.06\right.$; Table 3). While decreased ammonia nitrogen concentration was reported with increasing dosages of CIN in vitro (0-660 $\mathrm{mg} \mathrm{L}^{-1}$; Macheboeuf et al. 2008), Busquet et al. (2004) reported increased ammonia nitrogen concentration with the addition of 300 and $3,000 \mathrm{mg} \mathrm{L}^{-1} \mathrm{CIN}$ to continuous culture, similar to the trend towards higher ammonia found in the current study with CIN addition. Although individual bacterial populations were not observed in this study, it is well understood that higher concentrations of ammonia nitrogen indicate an increase in deamination of amino acids by hyper-ammonia producing bacteria, which decrease rumen efficiency by 
allowing nitrogen to escape the system as ammonia instead of passing out of the rumen as protein for absorption (Castillejos et al. 2005; Benchaar et al. 2006). In the presence of EO, HAP bacteria such as Peptostreptococcus anaerobius and Clostridium sticklandii are highly sensitive (McIntosh et al. 2003) and their abundance and diversity tend to decrease (McEwan et al. 2002; McIntosh et al. 2003), causing a decrease in ammonia nitrogen production. The current study did observe a decrease in $\mathrm{CP}$ digestibility, suggesting antimicrobial activity against protein digesters by the high dosage of CIN used.

\section{Volatile Fatty Acid Production}

The present study found no effect of EO on total VFA production ( $\mathrm{mmol} \mathrm{d}^{-1} ; P=0.16$; Table 4). Among treatments, the EUG treatment had the greatest impact on individual VFA production. Compared to CON, EUG decreased propionate production (-27.2\%) and increased butyrate $(+79.1 \%)$, isobutyrate $(+35.7 \%)$, valerate $(+77.9 \%)$ and acetate to propionate ratio $(+33.3 \%)$. This is very different from published results at lower doses. Busquet et al. (2005a) observed no differences in individual VFA proportions, BCVFA proportions or acetate to propionate ratio when EUG was supplemented $\left(2.2 \mathrm{mg} \mathrm{L}^{-1}\right)$ in continuous culture with a $60: 40$ forage:concentrate ratio diet. The difference in VFA proportions in the current study may be due to the higher, more toxic level of EO or the steam-flaked corn used compared to previous research.

Isovalerate production tended to increase with $\mathrm{CAP}(P=0.10$; Table 4$)$. However, with the exception of isovalerate production, CAP was not different from CON in individual VFA production or acetate to propionate ratio. Similarly, fermenters receiving CIN had higher valerate production $(P=0.04)$, but no difference in production of individual VFA's or acetate to propionate ratio (Table 4). These results differ from those found in several other studies. Supplementation with CAP (Cardozo et al. 2004; Fandiño et al. 2008) in vitro generally 
decreased acetate proportion. The increase in isovalerate and valerate observed for CAP and CIN, respectively, also differs from the literature. There is often no effect of EO on BCVFA production (Busquet et al. 2005b; Castillejos et al. 2005; Fraser et al. 2007; Fandiño et al. 2008; Chaves et al. 2009). However, a decrease in BCVFA has been shown when CAP (Cardozo et al. 2004) and CIN (Busquet et al. 2005a, 2006) were supplemented in vitro, most likely due to the higher dosages used. The increase of valerate with CIN supplementation agrees with the increased ammonia $\mathrm{N}$ production occurring with that treatment. Deamination of branched-chain amino acids produces BCVFA, which also causes ammonia $\mathrm{N}$ production. Increased ammonia $\mathrm{N}$ often parallels increased BCVFA production (Fandiño et al. 2008). Effects of EO on individual VFA proportions, BCVFA proportions, and acetate to propionate ratio is highly variable and inconclusive in the literature, most likely due to differences in dosage, experimental design, diet, and EO source, among several other possible confounding factors. This has led to difficulty in finding an optimum EO or blend of EO for use in ruminant feeding.

\section{pH Characteristics}

There was no significant interaction between treatment, day and feeding; therefore bi-hourly $\mathrm{pH}$ patterns are shown over a $12 \mathrm{~h}$ period. A sharp drop in $\mathrm{pH}$ occurred for all treatments after each feeding, but $\mathrm{pH}$ recovered to $>6.0$ within $12 \mathrm{~h}$ post feeding (Figure 1). Compared to CON, fermenters containing CIN or EUG remained at a higher $\mathrm{pH}$ throughout the sampling period $(P<$ 0.01), while CAP supplemented fermenters stayed at a lower $\mathrm{pH}$, and was not significantly different from CON $(P=0.38)$.

Mean pH, AUC, and time spent below pH 5.6 and 5.8 are reported for a complete $24 \mathrm{~h}$ feeding cycle. Fermenters with CIN or EUG spent fewer hr/d $(P<0.01$; Table 5) and had smaller area under the curve $\left(\mathrm{pH}^{*} \mathrm{hr} \mathrm{d}^{-1} ; P<0.01\right.$; Table 5) at $\mathrm{pH}<5.6$ and 5.8. However, CAP 
had a smaller AUC at $\mathrm{pH}<5.6(P<0.01)$. Previous studies have reported increased mean $\mathrm{pH}$ with EO supplementation in vivo and in vitro (Benchaar et al. 2003, 2006, 2007). Unlike the current study, Busquet et al. (2006) had to use a dosage of 3,000 $\mathrm{mg} \mathrm{L}^{-1}$ in batch culture (50:50 forage:concentrate ratio) to increase the mean $\mathrm{pH}$ with EUG and CIN supplementation. Further, Fraser et al. (2007) reported no effect of cinnamon leaf oil (76\% eugenol; 50:50 barley silage:concentrate ratio diet) at $500 \mathrm{mg} \mathrm{L}^{-1}$. The tendency toward increased ammonia $\mathrm{N}$ in CIN and the numerical increase in ammonia $\mathrm{N}$ with EUG observed in the current study may explain their higher $\mathrm{pH}$, as ammonia acts as a buffer. Although neither lactic acid nor the bacterial populations that produce lactic acid were measured in the current study, another possible explanation for the increase in $\mathrm{pH}$ by $\mathrm{CIN}$ and EUG may be a specific antimicrobial effect of these $\mathrm{EO}$ on lactic acid producing bacteria.

\section{CONCLUSIONS}

The addition of EO to continuous culture using a dairy ration with steam-flaked corn did not positively modify fermentation. Although the $\mathrm{CIN}$ and EUG treatments raised $\mathrm{pH}$, the digestibilities of $\mathrm{OM}$, fiber, and $\mathrm{CP}$ as well as bacterial nitrogen production, were negatively impacted, most likely due to the extremely high, and possibly toxic, dosage of oil used. Further, CIN increased ammonia production and decreased EMPS. Although total VFA production was not changed by EO, EUG increased the acetate to propionate ratio, as well as increasing the total production of butyrate and BCVFA. While the CAP treatment did not increase $\mathrm{pH}$, it also had no negative effects on ammonia production, EMPS, bacterial nitrogen production, or VFA production, even at this extremely high dosage. The EO used in this study had few positive effects on rumen fermentation compared to CON. Moreover, a dosage of $500 \mathrm{mg} \mathrm{L}^{-1}$ is equivalent to feeding $\sim 50 \mathrm{~g}$ of EO in vivo, which may be biologically toxic and economically 
infeasible. Therefore, future study of these EO's with traditional dairy cattle diets at more biologically appropriate dosages both in vivo and in vitro are necessary to validate their possible effectiveness as alternatives to antibiotic rumen modifiers.

\section{ACKNOWLEDGMENTS}

The authors would like to thank Tammy Webster, M. S. of the West Virginia University Rumen Fermentation Profiling Lab for her guidance, support, and time in the continuous culture laboratory. We would also like to thank Dr. David Bravo of Pancosma S.A. (Bellegarde-surValserine, France) for providing the EO used in this study.

Acamovic, T. and Brooker, J. D. 2005. Biochemistry of plant secondary metablites and their effects on animals. Proc. Nutr. Soc. 64:403-412.Anonymous. 1975. Supelco Bulletin 749E. Supelco, Inc., Bellefonte,PA.

Association of Official Analytical Chemists. 1995. Official Methods of Analysis. Vol I. $16^{\text {th }}$ ed. AOAC, Arlington, VA.

Benchaar, C., Petit, H. V., Berthiaume, R., Ouellet, D. R., Chiquette, J. and Chouinard, P. Y. 2007. Effects of essential oils on digestion, ruminal fermentation, rumen microbial populations, milk production, and milk composition in dairy cows fed alfalfa silage or corn silage. J. Dairy Sci. 90: 886-897.

Benchaar, C., Petit, H. V., Berthiaume, R., Whyte, T. D. and Chouinard, P. Y. 2006.

Effects of addition of essential oils and Monensin Premix on digestion, ruminal fermentation, milk production, and milk composition in dairy cows. J. Dairy Sci. 89: 4352-4364.

Benchaar, C., Calsamiglia, S., Chaves, A. V., Fraser, G. R., Colombatto, D., McAllister, T. A. and Beauchemin, K. A. 2008. A review of plant-derived essential oils in ruminant nutrition and production. Anim. Feed Sci. Technol. 145: 209-228. 
Busquet, M., Calsamiglia, S., Ferret, A. and Kamel, C. 2004. Effects of different doses of plant extracts on rumen microbial fermentation J. Dairy. Sci. 7 (Suppl. 1): 213 (Abstr.).

Busquet, M., Calsamiglia, S., Ferret, A. and Kamel, C. 2005a. Screening for effects of plant extracts and active compounds of plants on dairy cattle rumen microbial fermentation in a continuous culture system. Anim. Feed Sci. Technol. 123-124: 597-613.

Busquet, M., Calsamiglia, S., Ferret, A. and Kamel, C. 2006. Plant extracts affect in vitro rumen microbial fermentation. J. Dairy Sci. 89: 761-771.

Busquet, M., Calsamiglia, S., Ferret, A., Cardozo, P. W. and Kamel, C. 2005b. Effects of cinnamaldehyde and garlic oil on rumen microbial fermentation in a dual flow continuous culture. J. Dairy Sci. 88: 2508-2516.

Calsamiglia, S., Busquet, M., Cardozo, P. W., Castillejos, L. and Ferret, A. 2007. Invited Review: Essential oils as modifiers of rumen microbial fermentation. J. Dairy Sci. 90: 25802595.

Cardozo, P. W., Calsamiglia, S., Ferret, A. and Kamel, C. 2004. Effects of natural plant extracts on ruminal protein degradation and fermentation profiles in continuous culture. J. Anim. Sci. 82: 3230-3236.

Cardozo, P. W., Calsamiglia, S., Ferret, A. and Kamel, C. 2006. Effects of alfalfa extract, anise, capsicum, and a mixture of cinnamaldehyde and eugenol on ruminal fermentation and protein degradation in beef heifers fed a high-concentrate diet. J. Anim. Sci. 84: 2801-2808. Castillejos, L., Calsamiglia, S. and Ferret, A. 2006. Effect of essential oil active compounds on rumen microbial fermentation and nutrient flow in in vitro systems. J. Dairy Sci. 89: 26492658. 
Castillejos, L., Calsamiglia, S., Ferret, A. and Losa, R. 2005. Effects of a specific blend of essential oil compounds and the type of diet on rumen microbial fermentation and nutrient flow from a continuous culture system. Anim. Feed Sci. Technol. 119: 29-41.

Castillejos, L., Calsamiglia, S., Ferret, A. and Losa, R. 2007. Effects of dose and adaptation time of a specific blend of essential oil compounds on rumen fermentation. Anim. Feed Sci. Technol. 132: 186-201.

Chaves, A. V., Schei, I., Wang, Y., McAllister, T. A. and Benchaar, C. 2009. Effects of carvacrol and cinnamaldehyde on microbial fermentation when added to a barley- or corn-based diet in a continuous-culture system. Can. J. Anim. Sci. 89: 97-104.

Crawford, R. J., Jr., Shiver, B. J., Varga, G. A. and Hoover, W. H. 1983. Buffer requirements for maintenance of $\mathrm{pH}$ during fermentation of individual feeds in continuous culture. J. Dairy Sci. 66: 1881-1890.

Dorman, H. J. D. and Deans, S. G. 2000. Antimicrobial agents from plants: antibacterial activity of plant volatile oils. J. Appl. Microbiol. 88: 308-316.

Fandiño, I., Calsamiglia, S., Ferret, A. and Blanch, M. 2008. Anise and capsicum as alternatives to monensin to modify rumen fermentation in beef heifers fed a high concentrate diet. Anim. Feed Technol. 145: 409-417.

Fraser, G. R., Chaves, A. V., Wang, Y., McAllister, T. A., Beauchemin, K. A. and Benchaar, C. 2007. Assessment of the effects of cinnamon leaf oil on rumen microbial fermentation using two continuous culture systems. J. Dairy Sci. 90: 2315-2328.

Goering, H. K. and Van Soest, P. J. 1970. Forage fiber analyses (apparatus, reagents, procedures, and some applications). Agric. Handbook No. 379. ARS, USDA, Washington, DC. 
Helander, I. M., Alakomi, H., Latva-Kala, K., Mattila-Sanholm, T., Pol, I., Smid, E. J., Gorris, L. G. M. and von Wright, A. 1998. Characterization of the action of selected essential oil components on gram-negative bacteria. J. Agric. Food Chem. 46: 3590-3595.

Hoover, W. H., Crooker, B. A. and Sniffern, C. J. 1976. Effects of differential solid-liquid removal rates on protozoa numbers in continuous culture of rumen contents. J. Anim. Sci. 43: $528-534$.

Macheboeuf, D., Morgavi, D. P., Papon, Y., Mousset, J. L. and Arturo-Schaan, M. 2008. Dose-response effects of essential oils on in vitro fermentation activity of the rumen microbial population. Anim. Feed Technol. 145: 335-350.

McEwan, N. R., Graham, R. C., Wallace, R. J., Losa, R., Williams, P. and Newbold, C. J. 2002. Effect of essential oils on protein digestion in the rumen. Reprod. Nutr. Dev. 42: S65S66.

McIntosh, F. M., Williams, P., Losa, R., Wallace, R. J., Beever, D. A. and Newbold, C. J. 2003. Effects of essential oils on ruminal microorganisms and their protein metabolism. Appl. Environ. Microbiol. 69: 5011-5014.

NRC. 2001. Nutrient Requirements of Dairy Cattle. $7^{\text {th }}$ rev. ed. Natl. Acad. Sci., Washington, DC.

Smith, D. 1969. Removing and analyzing total nonstructural carbohydrates from plant tissue. Wisconsin Agric. Exp. Sta. Res. Rep. 41. p 1. Madison, WI.

Stern, M. D. and Hoover, W. H. 1990. The dual flow continuous culture system. Proc. Continuous Culture Fermenters: Frustration or Fermentation, Northwest ADSA-ASAS Regional Meeting, Chazy, NY. 
Van Soest, P. J., Robertson, J. B. and Lewis, B. A. 1991. Methods for dietary fibre, neutral detergent fibre and nonstarch polysaccharides in relation to animal nutrition. J. Dairy Sci. 74: $3583-3597$.

Wallace, R. J. 2004. Symposium on 'Plants as animal foods: a case of catch 22?': antimicrobial properties of plant secondary metabolites. Proc. Nutr. Soc. 63: 621-629.

Weller, R. A. and Pilgrim, A. F. 1974. Passage of protozoa and volatile fatty acids from the rumen of a sheep and from a continuous in vitro fermentation system. Br. J. Nutr. 32: 341-351. Zinn, R. A., Adam, C.F. and Tamayo, M. S. 1995. Interaction of feed intake level on comparative ruminal and total tract digestion of dry-rolled and steam-flaked corn. J. Anim. Sci. 73: $1239-1245$.

Zinn, R. A. and Owens, F. N. 1986. A rapid procedure for purine measurement and its use for estimating net ruminal protein synthesis. Can. J. Anim. Sci. 66: 157-166. 


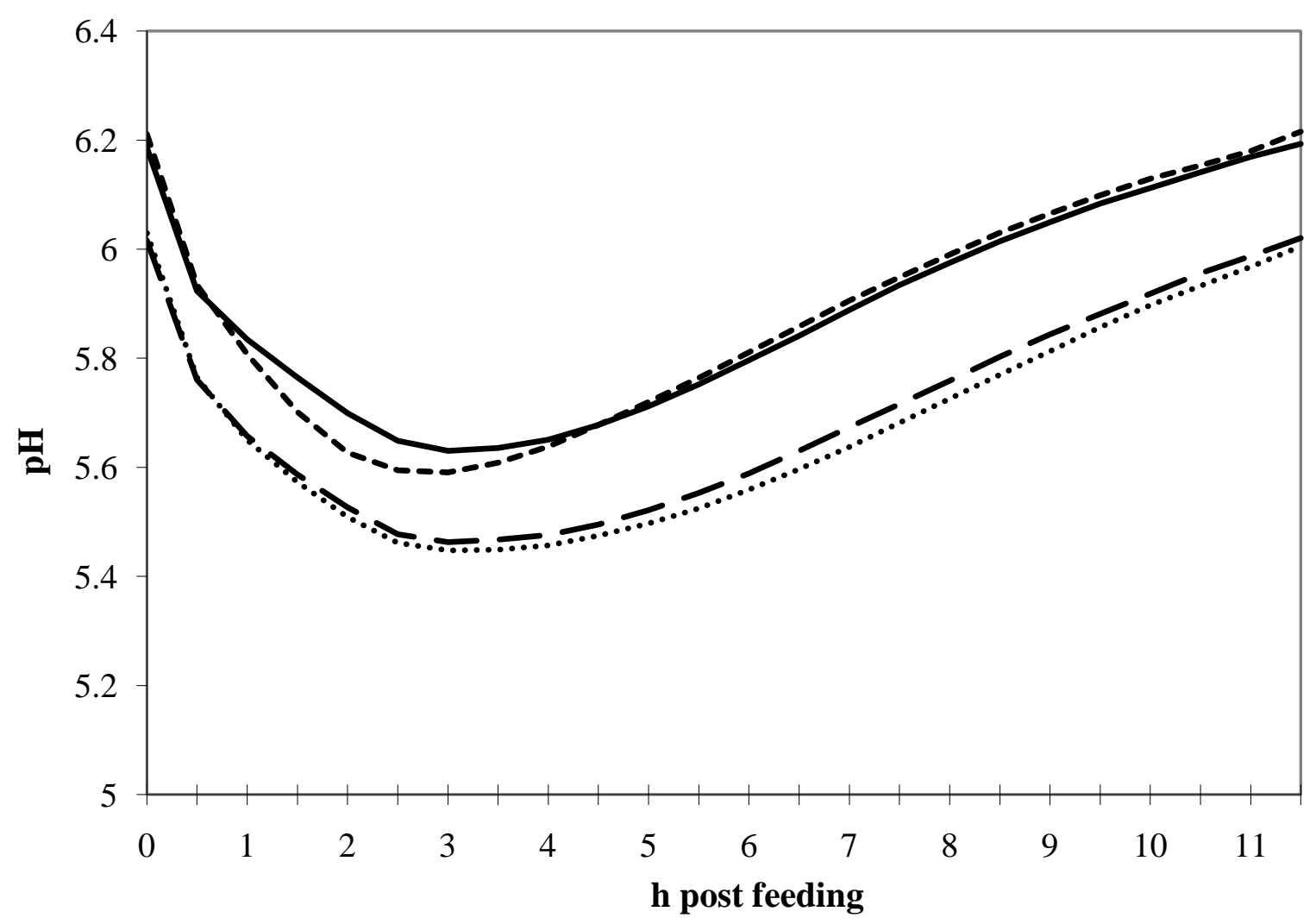

Figure 1. Least square means of capsicum oil (long-dash), cinnamaldehyde oil (shortdash), eugenol oil (solid), and no essential oil (dotted) on rumen pH in a continuous culture system $(\mathrm{SEM}=0.02)$. There was no difference in $\mathrm{pH}$ behavior between morning and evening feedings; therefore, all $\mathrm{pH}$ values are reported bi-hourly over a $12 \mathrm{~h}$ period. 


\begin{tabular}{|c|c|}
\hline Ingredient & $\%$ of Total DM \\
\hline Corn silage $^{z}$ & 30.9 \\
\hline Steam-flaked corn & 22.5 \\
\hline Alfalfa baylage $\mathrm{y}^{\mathrm{y}}$ & 11.0 \\
\hline Grass hay ${ }^{\mathrm{x}}$ & 3.4 \\
\hline Soybean meal, $47.5 \% \mathrm{CP}$ & 16.0 \\
\hline Soybean hull pellets & 5.5 \\
\hline Beet pulp pellets & 4.5 \\
\hline Corn gluten feed & 5.0 \\
\hline Limestone grind & 0.3 \\
\hline Calcium di-phosphate & 0.2 \\
\hline Salt $(\mathrm{NaCl})$ & 0.1 \\
\hline SaltTMineral Mix & 0.4 \\
\hline Vitamin Premix ${ }^{\mathrm{w}}$ & 0.2 \\
\hline \multicolumn{2}{|l|}{ Nutrients (DM basis) } \\
\hline Dry Matter (as fed basis) & 91.8 \\
\hline Organic Matter & 94.3 \\
\hline Crude Protein & 16.0 \\
\hline $\mathrm{NDF}$ & 24.6 \\
\hline $\mathrm{ADF}$ & 15.4 \\
\hline Starch & 28.8 \\
\hline NSC & 32.1 \\
\hline Ether Extract & 2.2 \\
\hline
\end{tabular}

\footnotetext{
${ }^{\mathrm{z}}$ Nutrient analysis (DM basis): 38.8\% DM (as fed); 42.2\% NDF; 21.5\% ADF; 46.4\% Starch; $2.9 \%$ Ash; $2.7 \%$ Ether Extract

${ }^{\mathrm{y}}$ Nutrient analysis (DM basis): $88.6 \%$ DM (as fed); 40.5\% NDF; 31.0\% ADF; 30.9\% Starch; $10.6 \%$ Ash; $1.4 \%$ Ether Extract

${ }^{\mathrm{x}}$ Nutrient analysis (DM basis): 37.6\% DM (as fed); 69.3\% NDF; 41.4\% ADF; 12.4\% Starch; 8.1\% Ash; 2.5\% Ether Extract

${ }^{\mathrm{w}}$ Vitamin ADE premix (North American Nutrition Companies Inc., Brookville, OH); 9920.9 IU $\mathrm{g}^{-1}$ vitamin A; 2 204.6 IU g ${ }^{-1}$ vitamin D; $4.4 \mathrm{IU} \mathrm{g}^{-1}$ vitamin $\mathrm{E}$
} 


\begin{tabular}{|c|c|c|c|c|c|c|}
\hline \multirow[b]{2}{*}{ Digestibility (\%) } & \multicolumn{4}{|c|}{ Treatment } & \multirow[b]{2}{*}{ SEM } & \multirow[b]{2}{*}{$P$} \\
\hline & CON & CAP & CIN & EUG & & \\
\hline $\mathrm{DM}$ & 58.9 & 59.4 & 60.8 & 58.3 & 4.8 & 0.97 \\
\hline $\mathrm{OM}$ & $42.3 a$ & $41.9 a$ & $36.4 b$ & $38.1 a b$ & 1.5 & 0.06 \\
\hline $\mathrm{ADF}$ & $31.7 a b$ & $46.1 a$ & $31.7 b$ & $23.5 b$ & 5.8 & 0.08 \\
\hline NDF & $29.9 a b$ & $37.8 a$ & $20.3 b$ & $21.1 b$ & 3.9 & 0.04 \\
\hline Starch & 99.7 & 99.7 & 99.8 & 99.7 & 0.04 & 0.27 \\
\hline $\mathrm{CP}^{\mathrm{z}}$ & $60.8 a$ & $64.5 a$ & $44.7 b$ & $49.4 b$ & 2.9 & 0.01 \\
\hline
\end{tabular}

${ }^{\mathrm{z}}$ corrected for microbial nitrogen 


\begin{tabular}{|c|c|c|c|c|c|c|}
\hline \multirow[b]{2}{*}{ Item } & \multicolumn{4}{|c|}{ Treatment } & \multirow[b]{2}{*}{ SEM } & \multirow[b]{2}{*}{$P$} \\
\hline & $\mathrm{CON}$ & CAP & CIN & EUG & & \\
\hline Bacterial nitrogen $\left(\mathrm{g} \mathrm{d}^{-1}\right)$ & $1.6 a$ & $1.6 a$ & $1.1 b$ & $1.2 b$ & 0.1 & $<0.01$ \\
\hline EMPS $^{z}$ & $40.2 a$ & $39.8 a$ & $34.6 b$ & $36.2 a b$ & 1.4 & 0.06 \\
\hline Ammonia $\left(\mathrm{mg} \mathrm{dL}^{-1}\right)$ & $2.5 b$ & $3.2 a b$ & $3.7 a$ & $3.1 a b$ & 0.3 & 0.06 \\
\hline
\end{tabular}

${ }^{\mathrm{z}}$ EMPS $=$ microbial protein synthesis $\left(\mathrm{g}\right.$ microbial nitrogen $\mathrm{kg}^{-1}$ digested OM$)$ 
Table 4. Effects of capsicum oil (CAP), cinnamaldehyde oil (CIN), eugenol oil (EUG), and no essential oil (CON) on rumen VFA production in a continuous culture system

\begin{tabular}{|c|c|c|c|c|c|c|}
\hline \multirow[b]{2}{*}{$\operatorname{VFA}\left(\mathrm{mmol} \mathrm{L}^{-1}\right)$} & \multicolumn{4}{|c|}{ Treatment } & \multirow[b]{2}{*}{ SEM } & \multirow[b]{2}{*}{$P$} \\
\hline & $\mathrm{CON}$ & CAP & $\mathrm{CIN}$ & EUG & & \\
\hline Total & 363.5 & 387.4 & 360.5 & 356.9 & 9.2 & 0.16 \\
\hline Acetate & 165.9 & 173.5 & 154.6 & 162.0 & 4.7 & 0.11 \\
\hline Propionate & $142.8 a$ & $148.4 a$ & $142.8 a$ & $103.9 b$ & 5.6 & $<0.01$ \\
\hline Butyrate & $36.1 b$ & $41.1 b$ & $42.4 b$ & $59.3 a$ & 1.9 & $<0.01$ \\
\hline Isobutyrate & $1.4 b$ & $1.8 a b$ & $1.4 b$ & $1.9 a$ & 0.1 & 0.03 \\
\hline Isovalerate & $1.2 b$ & $1.5 a$ & $1.2 b$ & $1.4 a b$ & 0.1 & 0.10 \\
\hline Valerate & $15.9 b$ & $22.3 a b$ & $25.0 a$ & $28.3 a$ & 2.4 & 0.04 \\
\hline $\mathrm{A}: \mathrm{P}^{\mathrm{z}}$ & $1.2 b$ & $1.2 b$ & $1.1 b$ & $1.6 a$ & 0.1 & 0.02 \\
\hline
\end{tabular}

${ }^{\mathrm{z}} \mathrm{A}: \mathrm{P}=$ Acetate: Propionate ratio 
Table 5. Effects of capsicum oil (CAP), cinnamaldehyde oil (CIN), eugenol oil (EUG), and no essential oil on rumen $\mathrm{pH}$, time spent under $\mathrm{pH} 5.6$ and 5.8, and area under the curve (AUC) below pH 5.6 and 5.8 during $24 \mathrm{~h}$ in a continuous culture system

\begin{tabular}{|c|c|c|c|c|c|c|}
\hline \multirow[b]{2}{*}{ Item } & \multicolumn{4}{|c|}{ Treatment } & \multirow[b]{2}{*}{ SEM } & \multirow[b]{2}{*}{$P$} \\
\hline & $\mathrm{CON}$ & CAP & CIN & EUG & & \\
\hline $\mathrm{pH}$ & $5.7 b$ & $5.7 b$ & $5.9 a$ & $5.9 a$ & 0.02 & $<0.01$ \\
\hline \multicolumn{7}{|c|}{ Time $\left(\mathrm{h} \mathrm{d}^{-1}\right)$} \\
\hline$<5.8$ & $17.2 a$ & $16.3 a$ & $9.8 b$ & $9.6 b$ & 0.6 & $<0.01$ \\
\hline$<5.6$ & $10.5 a$ & $9.6 a$ & $2.0 b$ & $0.9 b$ & 0.4 & $<0.01$ \\
\hline \multicolumn{7}{|l|}{$\mathrm{AUC}^{\mathrm{z}}$} \\
\hline$<5.8$ & $4.1 a$ & $3.4 a$ & $1.3 b$ & $1.1 b$ & 0.3 & $<0.01$ \\
\hline$<5.6$ & $1.0 a$ & $0.9 b$ & $0.1 c$ & $0.1 c$ & 0.1 & $<0.01$ \\
\hline
\end{tabular}

${ }^{\mathrm{z}}$ Area under the curve $=\mathrm{pH}^{*} \mathrm{~h} \mathrm{~d}^{-1}$ 


\section{CHAPTER 3}

Effect of commercial essential oil products at recommended and high dosages on rumen fermentation, milk production, and feeding behavior in lactating dairy cows ${ }^{1}$

\footnotetext{
${ }^{1}$ Formatted for submission to the Journal of Dairy Science
} 
Effect of commercial essential oil products at recommended and high dosages on rumen fermentation, milk production, and feeding behavior in lactating dairy cows. Tager. A mixture of cinnamaldehyde and eugenol at the recommended dosage and a high dosage, as well as capsicum at the recommended dosage were supplemented to lactating dairy cattle to examine their effects on rumen fermentation, milk production, and feeding behavior. The recommended dosage of cinnamaldehyde and eugenol had no effect on rumen fermentation, milk production, or feeding behavior. Capsicum shortened length of the first meal without changing rumen fermentation or production. The high dosage of cinnamaldehyde and eugenol negatively affected rumen fermentation and shortened the length of the first meal. At these dosages, these oils may not be an appropriate additive for lactating dairy cattle.

ESSENTIAL OIL EFFECTS ON LACTATING DAIRY CATTLE

Effect of commercial essential oil products at recommended and high dosages on rumen fermentation, milk production, and feeding behavior in lactating dairy cows

\section{R. Tager*, and K. M. Krause*1}

*Department of Animal and Nutritional Science, West Virginia University, Morgantown 26506

${ }^{1}$ Corresponding Author: K. Marie Krause, Email: Marie.Krause@mail.wvu.edu

This work is published with the approval of the Director of West Virginia Agriculture and Forestry Experiment Station as scientific paper xxxx. This project was supported by Hatch project 474. 


\section{ABSTRACT}

Seven ruminally cannulated lactating Holstein dairy cows were used in an incomplete Latin rectangle design to assess the effects of 2 commercial essential oil (EO) products on rumen fermentation, milk production, and feeding behavior. Cows were fed a TMR with a 42:58 forage:concentrate ratio (DM basis). Treatments included addition of: $0.5 \mathrm{~g} / \mathrm{d}$ XT 6965 (CE Lo; $85 \mathrm{mg}$ cinnamaldehyde and $140 \mathrm{mg}$ eugenol), $10 \mathrm{~g} / \mathrm{d}$ XT 6965 (CE Hi; $1700 \mathrm{mg}$ cinnamaldehyde and $2800 \mathrm{mg}$ eugenol), $0.25 \mathrm{~g} / \mathrm{d}$ XT 6933 (CAP; $50 \mathrm{mg}$ capsicum), or no oil (CON). Cows were fed ad-libitum twice daily for $21 \mathrm{~d}$ per period. Dry matter intake, number of meals/d, h eating/d, mean meal length, rumination events/d, h ruminating/d and mean rumination length were not affected by EO. However, length of the first meal after feeding decreased with addition of CE Hi (47.2 min) and CAP (49.4 min) compared to CON (65.4 min). Milk yield and composition did not change with EO. Total VFA, individual VFA, acetate:propionate ratio, and ammonia concentration were not affected by EO. Mean rumen $\mathrm{pH}$ as well as bouts, total $\mathrm{h}$, mean bout length, total area, and mean bout area under pH 5.6 did not differ among treatments. Total tract digestibility of OM, DM, NDF, ADF, crude protein, and starch were not affected by EO. In situ DM disappearance of ground soybean hulls was not affected by EO. However, OM disappearance tended to decrease compared to CON with CE Hi. Compared to CON, NDF disappearance (41.5\% vs. $37.6 \%)$ and ADF disappearance (44.5\% vs. $38.8 \%)$ decreased with addition of CE Hi. The low dose of CE had no effect on rumen fermentation, milk production, or feeding behavior. Capsicum shortened length of the first meal without changing rumen fermentation or production, making it a possible additive for altering feeding behavior. The high dose of CE negatively affected rumen fermentation and shortened the length of the first meal, suggesting that a dose of $10 \mathrm{~g} / \mathrm{d}$ is not beneficial to lactating dairy cows.

Keywords: essential oil, dairy cow, rumen fermentation, feeding behavior 


\section{INTRODUCTION}

Many essential oils (EO) have been shown to affect rumen fermentation (Wallace, 2004) and they are currently being studied as an alternative to feeding sub-therapeutic levels of antibiotics in ruminants. Several of the studies on EO have been done using in vitro methods such as batch culture and continuous culture (McIntosh et al., 2003; Cardozo et al., 2004; Busquet et al., 2005a; Castillejos et al., 2005; Fraser et al., 2007; Tager and Krause, 2010). Data from these studies are often inconclusive and lead to conflicting results due to variation of dosages, chemical structure of EO compounds, diets, blends, and EO providers. Often, in vitro studies require a very high dosage (>100 $\mathrm{mg} / \mathrm{L} / \mathrm{d}$ ) to elicit an observable response, which would be equivalent to feeding $>10 \mathrm{~g} / \mathrm{cow} / \mathrm{d} \mathrm{EO}$ (assuming a $100 \mathrm{~L}$ rumen volume) in vivo. For most EO, this is $>5$ times the recommended feeding dosage. However, there has been no research using such high dosages in vivo, making it difficult to extrapolate in vitro research to real-life applications.

Cinnamaldehyde (CIN), eugenol (EUG), and capsicum (CAP) are known to have antimicrobial properties, and have been suggested to act as rumen modifiers. However, in vitro, CIN (Busquet et al., 2004; Busquet et al., 2005a; Busquet et al., 2005b; Busquet et al., 2006; Fraser et al., 2007), EUG (Busquet et al., 2005b; Busquet et al., 2006), and CAP (Busquet et al., 2006) often have little effect on microbial fermentation except at very high dosages (> $300 \mathrm{mg} / \mathrm{L}$ rumen fluid). In contrast, a high concentrate diet fed to beef cattle (10:90 forage:concentrate ratio), supplemented with CIN (Cardozo et al., 2006), EUG (Cardozo et al., 2006), or CAP (Cardozo et al., 2006; Fandiño et al., 2008) provided some positive effects on rumen fermentation at lower EO dosages ( $\leq 1.0 \mathrm{~g} / \mathrm{cow} / \mathrm{d})$, leading to increased feed digestibility. Supplementing CAP to beef cattle has been shown to stimulate DMI without decreasing rumen 
pH (Fandiño et al., 2007; Rodriguez-Prado et al., 2008), however no such work has been done in lactating dairy cattle.

While CIN, EUG, and CAP have been studied extensively in vitro, much less is known about their effects in vivo or how they affect feeding behavior, particularly in lactating dairy cattle. Further, EO at recommended dosages in vitro, as well as the few studies using lactating dairy cattle in vivo (Benchaar et al., 2006; Benchaar et al., 2007), are reported to have little or no effect on rumen fermentation. Consequently, the objective of this study was to assess the effects of CAP at a commercial manufacturer's recommended dosage, and a blend of CIN and EUG at the commercial manufacturer's recommended dosage, as well as a high dosage closer to levels used in vitro, on rumen fermentation, milk production, and feeding behavior.

\section{MATERIALS AND METHODS}

\section{Experimental Design, Animals and Diet}

Eight ruminally cannulated Holstein cows (4 primiparous and 4 multiparous) were randomly assigned to four treatments within a Latin rectangle design. Average BW was $566 \pm$ $55 \mathrm{~kg}$ at the beginning of the experiment and $634 \pm 61 \mathrm{~kg}$ at the end of the experiment. Cows averaged $43 \pm 29$ DIM at the beginning of the study. The experiment consisted of 4, 21-day periods with 14 days of adaptation and 7 days of sampling. The experiment was approved by the West Virginia University Animal Care and Use Committee and was conducted at the West Virginia University Research Farm.

Diets were fed as TMR with forage to concentrate ratio of 42:58 (DM basis) formulated to support $45 \mathrm{~kg} / \mathrm{d}$ of milk production in a $623 \mathrm{~kg}$ cow with a predicted DMI of $24.9 \mathrm{~kg} / \mathrm{d}$ (NRC, 2001). Dietary ingredients and nutrient composition are shown in Table 1. Cows were fed ad libitum twice daily at 0800 and $1900 \mathrm{~h}$ in equal portions using the Calan gate feeding system 
(American Calan Inc., Northwood, NH). Water was available ad libitum. The cows were milked twice daily at 0830 and $1930 \mathrm{~h}$.

\section{Experimental Treatments}

One major objective of this study was to examine the effects of feeding EO at a level closer to high in vitro dosages (i.e. $500 \mathrm{mg} / \mathrm{L} / \mathrm{d} \sim 50 \mathrm{~g} / \mathrm{cow} / \mathrm{d}$ ). However, feeding EO at such high levels may affect intake due to palatability problems. Therefore, to determine the highest dosage of XT 6965 (Pancosma S.A., Bellegarde-sur-Valserine, France) that could be fed to cows before affecting intake, a preliminary study was conducted using the Growsafe System (Growsafe Systems Ltd., Airdrie, AB, Canada). Fourteen cows were assigned to a bay with 5 Growsafe bins. Cows were fed ad libitum a TMR (68.2\% DM with 96.1\% OM, 14.8\% CP, $34.2 \% \mathrm{NDF}, 28.6 \% \mathrm{ADF}$, and $16.3 \%$ starch on a DM basis), with increasing dosages of XT 6965 (85 mg CIN and 140 mg EUG; Pancosma S.A., Bellegarde-sur-Valserine, France) randomly assigned to each bin ( 2 bins with $0.5 \mathrm{~g} / \mathrm{cow} / \mathrm{d}, 2$ bins with $1.0 \mathrm{~g} / \mathrm{cow} / \mathrm{d}$, and 1 bin with $2.0 \mathrm{~g} / \mathrm{cow} / \mathrm{d}$ ). Dosages were randomly assigned to a new bin each day so cows would not learn where a specific dosage was fed. Eating behavior was observed for $5 \mathrm{~d}$, and when the highest dosage did not cause decreased intake, the study was continued again for $5 \mathrm{~d}$ with increased dosages ( 2 bins $2.0 \mathrm{~g} / \mathrm{cow} / \mathrm{d}, 2 \mathrm{bins} 4.0 \mathrm{~g} / \mathrm{cow} / \mathrm{d}, 1 \mathrm{bin} 6.0 \mathrm{~g} / \mathrm{cow} / \mathrm{d})$. This procedure continued (5 $\mathrm{d}$ with $4.0,6.0$, and $8.0 \mathrm{~g} / \mathrm{cow} / \mathrm{d}$ and $5 \mathrm{~d}$ with $8.0,10.0$, and $12.0 \mathrm{~g} / \mathrm{cow} / \mathrm{d}$ ) until feed intake was decreased at $12.0 \mathrm{~g} / \mathrm{cow} / \mathrm{d}$. Therefore, the level of $10.0 \mathrm{~g} / \mathrm{cow} / \mathrm{d}$ was chosen as the high dosage for the current study, as this was the greatest level at which feed intake was unaffected.

Based on recommended dosages and the preliminary study, experimental treatments included the addition of: 0.5 g/cow/d XT 6965 (CE Lo), 10 g/cow/d XT 6965 (CE Hi; 1700 mg CIN and 2800 mg EUG), 0.25 g/cow/d XT 6933 (CAP), and no oil (CON). 


\section{Sample Collection}

Forage, concentrate, and TMR samples were collected twice per period. Intake and orts were recorded and a sub-sample of orts were collected at each feeding during each sampling period. Samples for particle size separation were separated using the 3-screen Penn State Particle Separator (Kononoff et al., 2003). Milk samples were collected and milk yields were recorded at each milking for the last 4 days of each experimental period.

To determine total tract digestibility of feed nutrients, lanthanum (La) in solution was used as a marker to estimate fecal output (Hartnell and Satter, 1979) and was ruminally dosed after each milking throughout the entire study to provide $0.8 \mathrm{~g} \mathrm{La} /$ cow/day. Ten fecal samples/cow/period were collected at differing times throughout the $7 \mathrm{~d}$ of sampling to represent a $24 \mathrm{~h}$ period and account for diurnal variation. Fecal samples were immediately frozen, then later dried at $60^{\circ} \mathrm{C}$, pooled by period for each cow and ground through a 1-mm screen using a Wiley Mill (Arthur H. Thomas, Philadelphia, PA).

Twenty-four h ruminal degradation of ground soybean hulls (4-mm screen) was measured using in situ bags made of Dacron polyester cloth with a pore size of $52 \pm 5 \mu \mathrm{m}$ and 5 $\mathrm{x} 10 \mathrm{~cm}$ in size. Bags contained $5 \mathrm{~g}$ of soybean hulls and were weighed in quadruplet, placed in larger mesh bags, soaked in warm water for $10 \mathrm{~min}$ and ruminally incubated for 0 and $24 \mathrm{~h}$ during $\mathrm{d} 6$ of each sampling period. After removal from the rumen, bags were washed under cold, running tap water and then frozen for later analysis. Upon thawing, Dacron bags were rinsed in cold water. Time $0 \mathrm{~h}$ bags were not placed in the rumen, but were subject to the same washing, freezing and rinsing procedure. Bags were then dried at $60^{\circ} \mathrm{C}$ for $48 \mathrm{~h}$.

Rumen fluid was sampled (in relation to morning feeding) at times $0,1,2,4,6$, and $8 \mathrm{~h}$ during the first day of sampling for determination of VFA and ammonia concentrations. Rumen 
fluid was obtained by grab samples of the digesta from the anterior, medial and posterior ventral locations of the rumen and then strained through 4 layers of cheesecloth. Three, $10 \mathrm{ml}$ samples were taken and acidified with $0.5 \mathrm{ml}$ of $\mathrm{H}_{2} \mathrm{SO}_{4}$ and frozen for later VFA analysis. Two, $10 \mathrm{ml}$

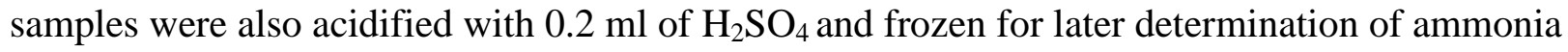
concentrations.

Continuous $\mathrm{pH}$ data were collected using a submersible Lethbridge Research Centre $\mathrm{pH}$ measuring system (LRCpH, Dascor, Escondido, CA). The LRCpH was inserted, with 2, 1-kg weights attached, into the ventral sac of the rumen for $96 \mathrm{~h}$. Before insertion into the rumen, $\mathrm{pH}$ readings were recorded in standard buffers of $\mathrm{pH} 4$ and $\mathrm{pH} 7$, and units were set to record $\mathrm{pH}$ every $30 \mathrm{~s}$. Data transfer from the logger to a computer were conducted every $24 \mathrm{~h}$ and occurred after the morning milking. During this time the logger was removed, logging was disabled, the data were downloaded and then the logger was returned to the respective cow. Standardizations of the $\mathrm{pH}$ electrodes were conducted after 48 and $96 \mathrm{~h}$; readings in standard buffer solutions of $\mathrm{pH} 4$ and 7 were recorded and the data were downloaded. The shift in millivolt readings from the electrodes between the start and end standardizations were assumed to be linear and were used to convert millivolt readings to $\mathrm{pH}$ units (Penner et al., 2006).

Eating and ruminating behaviors were monitored visually for a 24-h period on the fourth day of each sampling period. Eating and ruminating activities were noted every 5 min, and each activity was assumed to persist for the entire 5-min interval. A meal was defined as at least one observation of eating activity occurring after at least 20 min without eating activity. This is based on the definition of eating used by Wangsness et al. (1976) who defined a meal as at least 1 min of eating activity after at least 20 min without eating activity. A period of rumination was defined as at least 5 min of rumination occurring after at least 5 min without ruminating activity. 


\section{Laboratory Analyses}

Analytical DM of feed and fecal samples was determined by oven drying at $100^{\circ} \mathrm{C}$ for 24 h (AOAC, 1995; 967.03). Ether extraction of the feed was performed according to AOAC (1995; 920.39). Ash content of feed and fecal samples was determined by combustion at $550^{\circ} \mathrm{C}$ overnight, and OM was calculated as 100 minus the percentage ash (AOAC, 1995; 942.05). Determination of the NDF and ADF content in feed and fecal samples was done using the Ankom 200 Fiber Analyzer (Ankom Technology Corp, Macedon, NY). Total nitrogen in feed and ammonia concentration of rumen samples were analyzed according to AOAC (1995; 976.05) using an automated Tecator digestion system (Tecator, Inc., Herndon, VA). Analysis of VFA concentrations from rumen samples were performed using a gas chromatograph. The gas chromatograph was a Varian model 3300 with an FID detector (Varian, Inc., Palo Alto, CA). The column was a 2-m $\times 2$-mm glass column packed with $10 \% \mathrm{SP}-1200 / 1 \% \mathrm{H}_{3} \mathrm{HPO}_{4}$ on $80 / 100$ chromosorb WAW (Supelco,. Inc. Bellefonte, PA). Sugars in feed and fecal samples were determined by the extraction procedure adapted from Derias (1961). Reducing sugars were determined with a spectrophotometer and potassium ferricyanide. Starch content of feed and fecal samples was determined by the procedure of Smith (1969). Lanthanum concentrations were determined by dry ashing ground fecal samples at $500^{\circ} \mathrm{C}$ for $16 \mathrm{~h}$. The ashed samples were then dissolved in $70 \%$ nitric acid, diluted to $1: 50$ in $\mathrm{dH}_{2} \mathrm{O}$ and filtered twice through $42 \mu \mathrm{m}$ filter paper. Lanthanum concentrations were then determined by inductively coupled plasma spectroscopy (ICP). Fecal output was calculated based on Lanthanum concentration in feces. Milk samples were sent to Dairy One (Ithaca, New York) for determination of lactose, protein, $\%$ milk fat and SNF.

\section{Statistical Analyses}


Data was analyzed using the mixed model procedure of SAS 9.1 (2001). The data from 1 primiparous cow was discarded due to health issues unrelated to dietary treatments for the entirety of the study. Therefore, results are analyzed as an incomplete Latin rectangle. Data that were not collected as repeated measures were analyzed using a model including treatment as a fixed effect and period and cow as random effects. Ruminal variables collected as repeated measures ( $\mathrm{pH}$, ammonia, VFA concentrations and percentages, and acetate: propionate ratio) were analyzed using a model that included treatment and hours post feeding as fixed effects along with their two-way interaction. Period, cow and cow by period were included as random effects in the model. Based on model fitting statistics a Compound Symmetry covariance structure was used for these analyses. Statistical analysis was conducted using a Kenward-Roger adjustment and reported as least squared means. Separation of means was performed on data with significant treatment differences and tendency for treatment differences, and a Tukey's adjustment was used to make treatment comparisons. Differences were considered significant at $P \leq 0.05$ and considered a trend at $0.05<P \leq 0.10$.

\section{RESULTS AND DISCUSSION}

\section{Feeding and Rumination Behavior}

Dry matter intake was not affected by EO (Table 2), which agrees with other research in dairy cattle (Benchaar et al., 2006, 2007, 2008). Conversely, in beef heifers fed a 10:90 forage:concentrate ratio diet, CAP (0.5 g/cow/d) increased DMI by $12.6 \%$ (6.57 to $7.42 \mathrm{~kg} / \mathrm{d}$; Fandiño et al., 2007). This difference in DMI may be due to the higher concentration of CAP consumed by beef cattle compared to the current study. Dairy cattle have markedly higher DMI (> $20.0 \mathrm{~kg} / \mathrm{d} \mathrm{DMI})$ compared to beef cattle $(<10.0 \mathrm{~kg} / \mathrm{d} \mathrm{DMI})$. Consequently, the concentration of EO consumed in the study by Fandiño et al. (2007) was 71.8 mg CAP/kg DM consumed, 
where as the current study only provided a concentration of $\sim 11.0 \mathrm{mg}$ CAP $/ \mathrm{kg}$ DM consumed, due to both a lower dosage and higher DMI of the animals. Therefore, a higher dosage may be necessary in dairy cattle to stimulate changes in DMI.

Essential oils had no effect on meal events/d, h eating/d, mean meal length, rumination events/d, $\mathrm{h}$ rumination/d, or mean rumination length (Table 2). Using the GrowSafe monitoring system (GrowSafe Systems Ltd., Airdrie, Alberta, Canada), Rodriguez-Prado et al. (2008) observed an increase in total $\mathrm{h}$ eating/d (2.64 vs. $1.92 \mathrm{~h}$ ) as well as a more stable eating pattern (shorter, more frequent meals) in beef heifers fed a 10:90 forage to concentrate ratio diet supplemented with $0.5 \mathrm{~g} \mathrm{CAP} / \mathrm{d}$. Although overall intake was unaffected, the length of the first meal after feeding was shortened by CE Hi and CAP (47.2 min and 49.4 min vs. $65.4 \mathrm{~min}$ for CON; Table 2), suggesting that CE Hi and CAP may cause a change in the palatability of feed and alter feeding behavior. Shortening the length of first meal, which is often the largest meal, may be beneficial in preventing acidosis as it may help control the sharp drop in rumen $\mathrm{pH}$ after feeding (French and Kennelly, 1990). Indeed, Rodriquez-Prado et al. (2008) observed a similar stabilization of feeding behavior in beef heifers fed a 10:90 forage to concentration ratio diet supplemented with $0.5 \mathrm{~g} \mathrm{CAP/d}$. Therefore, while CE Hi may not be economically nor biologically appropriate as a feed additive, further behavioral research with CAP may help to better understand how it affects feeding behavior in lactating dairy cattle.

Although DMI, time spent eating/d, and time spent ruminating/d were comparable to other eating behavior studies, cows on all treatments ate fewer meals/d ( 7.0 to 7.7 meals/d vs. 8.2 to 11.6 meals/d) than usually observed in mid-lactation dairy cattle (Krause and Combs, 2003; Yang and Beauchemin, 2007). Consequently, average meal length was longer in the current study (33.9 $\mathrm{min} / \mathrm{meal})$ than normally observed in dairy cattle $(\sim 26.5 \mathrm{~min} / \mathrm{meal}$; Krause and 
Combs, 2003; Yang and Beauchemin, 2007). This may have been caused by the increased amount of time spent sorting, as was evidenced by a higher NDF content in the orts (36.3 \%NDF) than the TMR (28.6\%NDF). Typically, dairy rations contain 40 to $60 \% \mathrm{DM}$ (Eastridge, 2006), whereas the ration used in the current study contained 64.0\%DM. Rations with a high DM content and containing dry forages, such as the one in this study, often lead to increased sorting behavior (DeVries et al., 2007). Further, the small particle size of the TMR $\left(X_{\mathrm{gm}}=4.8\right.$ vs. recommended $\mathrm{X}_{\mathrm{gm}}>5.0$; Kononoff, 2003) along with larger, less frequent meals may be associated with the low rumen $\mathrm{pH}$ observed in cows for all treatments, as will be discussed in more detail later.

\section{Milk Yield and Composition}

Milk yield and composition were not affected by the addition of EO (Table 3), not surprisingly as there was no change in DMI, VFA's, or total tract nutrient digestibility. This finding is in agreement with other studies in dairy cattle (Benchaar et al., 2006, 2007, 2008), where milk yield and composition were unchanged by EO. There has been little published evidence showing increased production or change in milk composition with EO supplementation. Benchaar et al. (2009) hypothesized that $1.0 \mathrm{~g} / \mathrm{d}$ CIN may affect biohydrogentation in the rumen of lactating dairy cows, thus affecting milk fatty acid profiles. However, no effect on fatty acid composition was reported by Benchaar et al. (2009), suggesting low ability of CIN to alter rumen biohydrogenation. Interesting to note, the TMR in the current study had a small particle size and all cows experienced low rumen $\mathrm{pH}(<5.8)$, which typically leads to milk fat depression (Grant et al., 1990), but milk fat depression was not observed here.

\section{Nutrient Digestibilities and In Situ Disappearance}

Total tract digestibility of DM, OM, NDF, ADF, CP, and starch did not differ among treatments (Table 4), demonstrating that these EO, even at high dosages, do not affect overall 
digestibility of feed. There is very little literature discussing the effects of EO on total tract digestibility in dairy cattle. Benchaar et al. reported no effects of a mixture of EO containing thymol, EUG, vanillin, and limonene fed at $2.0 \mathrm{~g} / \mathrm{d}$ (2006) or a mixture of EO containing thymol, EUG, vanillin, guaicacol, and limonene fed at $0.75 \mathrm{~g} / \mathrm{d}$ (2007) on DM, NDF, CP, or starch digestibility. Unlike the current study, Benchaar et al. (2006) observed an increase in total tract ADF digestibility when feeding $2.0 \mathrm{~g} / \mathrm{d}$ of a mixture of EO. Although EUG was present in both blends, the discrepancy in ADF digestibility between studies may be due to the difference in blend of oils or dosages used. In addition, Benchaar et al. (2006) fed a diet with 24.4\% ADF, which was $28.0 \%$ higher than the ADF content in the current study. A higher percentage of dietary ADF may have increased the availability of fiber for digestion, thus increasing overall total tract digestibility of ADF in comparison to the current study.

Although total tract digestibility of nutrients was unaffected by EO, it is to be noted that digestibility of all nutrients in this study were low compared to similar studies. Several studies by Benchaar et al. (2006, 2007, 2008) reported total tract DM, OM, and CP digestibilities of > $60.0 \%$ and NDF and ADF digestibilities $>45.0 \%$ whereas the current study observed DM and OM digestibilities of $<56.0 \%$, digestibility of $\mathrm{CP}<53.0 \%$, and digestibility of NDF and ADF $<$ 35.0\%. The overall depressed total tract digestibility observed in the current study may be linked, again, to the smaller than recommended particle size of the TMR. Small particle size can cause decreased rumen $\mathrm{pH}$, and consequently, decreased total tract digestibility of nutrients. Indeed, low mean rumen $\mathrm{pH}$ (5.64 to 5.80) was observed for all treatments in this study.

Twenty-four h in situ DM disappearance of soybean hulls was not affected by EO. However, compared to CON, CE Hi depressed NDF (41.5\% vs. 37.6\%) and ADF (44.5\% vs. $38.8 \%)$ disappearance as well as causing a trend towards decreased OM disappearance $(60.3 \%$ 
vs. 57.6\%; Table 5), suggesting that rumen fermentation was altered by such a high dosage of EO. Benchaar et al. (2008) supplemented CIN at a recommended dosage of $1 \mathrm{~g} / \mathrm{cow} / \mathrm{d}$ and reported no effect on in situ digestibility of soybean meal in lactating dairy cattle. However, in sheep fed a blend of EO (0.11 g/d; thymol, guaicacol, and limonene), Newbold et al. (2004) observed depressed in situ DM disappearance of soybean meal. Like beef cattle, sheep have a smaller DMI/kg BW compared to dairy cattle, and consequently, the concentration of EO in the study by Newbold et al. (2004) was very high (110 mg/kg DM consumed) compared to beef studies where diets contained $<75 \mathrm{mg} / \mathrm{kg}$ DM consumed EO. Similar results were found for CE $\mathrm{Hi}$ in the current study where the concentration of EO was exceptionally high $(\sim 425.0 \mathrm{mg} / \mathrm{kg}$ DM consumed), thus causing altered nutrient disappearance.

This is the first study to feed such a high dosage of EO to lactating dairy cattle. The negative effects on in situ digestibility observed in the current study with CE Hi are in concordance with a previous in vitro study by Tager and Krause (2010). In this continuous culture study, CIN tended to decrease OM digestibility and both CIN and EUG strongly numerically decreased NDF and ADF digestibility in continuous culture at a dosage of 500 $\mathrm{mg} / \mathrm{L}$, which the authors attributed to the toxicity of such a high dosage to microbial populations. Therefore, the results observed for $\mathrm{CE} \mathrm{Hi}$, which would be equal to $\sim 100 \mathrm{mg} / \mathrm{L}$ in continuous culture, only validated the results observed for CIN and EUG previously in vitro. While microbial populations were not assessed in the current study, the depressed OM, NDF, and ADF disappearance may be due to the toxic effect of CIN and EUG to the rumen microbes at such a high dosage. Again, it is also important to note that the TMR had smaller particle size than would be considered optimal for lactating dairy cattle, thus leading to decreased rumen digestibility of nutrients. However, since there was no change in total tract digestibility of OM 
or fiber with CE Hi, it seems that the in situ depression of these nutrients may have been compensated for post-ruminally. Moreover, the fiber content of soybean hulls $(67.0 \% \mathrm{NDF})$ is much higher than that of the TMR $(28.6 \%$ NDF), which may also account for the difference in in situ and total tract digestibilities.

\section{Ammonia and Volatile Fatty Acid Concentration}

There was no effect of diet or interaction between diet and h-post-feeding on ammonia concentration (Table 6). Ammonia concentrations increased immediately after feeding, and then began to decline around h 4 or 6 in most cows, as was evidenced by the effect of h-post-feeding $(P<0.01$; data not shown $)$. Essential oils are not often reported to affect ammonia concentration in vivo (Newbold et al., 2004; Benchaar et al., 2006, 2007, 2008; Fandiño et al., 2007). One study by Cardozo et al. (2006), however, observed no change in ammonia with CAP (1 g/d) but did find a decrease with two combinations of CIN and EUG $(0.18 \mathrm{~g} / \mathrm{d}$ CIN $+0.09 \mathrm{~g} / \mathrm{d}$ EUG or $0.6 \mathrm{~g} / \mathrm{d} \mathrm{CIN}+0.3 \mathrm{~g} / \mathrm{d}$ EUG) in beef heifers fed a 10:90 forage:concentrate ratio diet. Authors attributed this to a decrease in deamination of proteins. There was no effect of EO on ammonia concentration in the current study therefore suggesting deamination was not inhibited by any of the oils. However, the diets between these studies were very different, and comparison between them should be made cautiously.

Essential oils did not affect total or individual concentrations of VFA, nor was there an interaction between diet and h-post-feeding (Table 6). Similar to ammonia, concentrations of total VFA, acetate, propionate, butyrate, and valerate increased immediately after feeding and did not decline until h 4 and 6 post feeding ( $P<0.01$; data not shown). Oh et al. (1968) were the first to observe a decrease in VFA concentration in sheep and deer consuming EO from unpalatable species of plants. Since that time, most EO have been reported to have no effect on in vivo total or individual VFA in sheep (Newbold et al., 2004), beef cattle (Cardozo et al., 
2006), or dairy cattle (Benchaar et al., 2006, 2007, 2008). Research in beef cattle fed a 10:90 forage:concentrate ratio diet (Fandiño et al., 2007) reported that CAP (0.5 g/d) decreased acetate concentration, decreased acetate to propionate ratio, and increased butyrate concentration. Still, the diet was very different from that used in the current study, and again, the dietary concentration of EO to DM in the current study was much lower due to the higher DMI dairy cows compared to beef heifers. Nonetheless, the results observed in the current study suggest that, even at a very high dosage (CE Hi), EO did not affect rumen fermentation to any great extent in lactating dairy cattle.

\section{Rumen pH}

To our knowledge, this is the first study to observe continuous rumen $\mathrm{pH}$ with EO supplementation. Mean rumen $\mathrm{pH}$ as well as number of bouts, total time, mean bout length, total area, and mean bout area < pH 5.8 and 5.6 did not differ among treatments (Table 7), which was expected as there was no change in VFA concentration. In other research, rumen $\mathrm{pH}$ was not affected by the addition of CAP up to $2.5 \mathrm{~g}$ /d, even though VFA's were increased (Fandiño et al., 2007; Rodriquez-Prado et al, 2008). However, even with CE Hi, VFA and pH were unaffected in the current study, again implying little effect of these EO on fermentation. Again, this is most likely due to the major difference in diets between beef cattle studies, and the current dairy cattle study.

It is important to note, that although rumen $\mathrm{pH}$ characteristics were unaffected by EO, the mean rumen $\mathrm{pH}$ of the cows in this study was low (5.6 to 5.8) compared to other EO studies in dairy cattle (6.3 to 6.7; Benchaar et al., 2006, 2007, 2008). This may be attributable to the smaller than recommended mean particle size of the TMR and possibly extensive sorting. As discussed earlier, cows on all treatments consumed fewer meals/d usually observed in lactating dairy cattle. Due to decreased frequency of meals, cows may have consumed more DM within 
each meal, which can cause sharp decreases in rumen $\mathrm{pH}$ that do not recover quickly. Ideally, cows should consume smaller, shorter meals to control sharp drops in rumen $\mathrm{pH}$ (Owens et al., 1998). In addition, there was evidence of sorting by all animals (36.3\%NDF in orts compared to 28.6 \% NDF in TMR), possibly causing a deficiency in effective fiber consumption, although particle size of the orts was not measured. Rations that lack the proper amount of effective fiber cause decreased chewing, salivation, and consequently, decreased rumen $\mathrm{pH}$ (Yang and Beauchemin, 2007). Decreased rumen $\mathrm{pH}$ is linked to decreased nutrient digestibility (Kolver and de Veth, 2000). Indeed, the current study reported decreased OM and fiber in situ digestibility of soybean hulls and low total tract digestibilities. Moreover, while cows spent a similar amount of total time ruminating during the day (336 to $402 \mathrm{~min} / \mathrm{d}$ ) as observed in other behavior studies (346 to $522 \mathrm{~min} / \mathrm{d}$; Krause and Combs, 2003; Yang and Beauchemin, 2007), they had fewer rumination events (10 to 10.5 events/d) that lasted longer (35.7 to $39.3 \mathrm{~min}$ ) compared to other studies (13 to 17 events/d; 22.7 to 27.9 min; Krause and Combs, 2003) suggesting that rumination activities may not have been spread out evenly, possibly causing lower mean $\mathrm{pH}$ over the course of the day due to uneven salivation and rumen buffering.

\section{CONCLUSIONS}

At the recommended dosage, CE Lo had no effect on rumen fermentation, milk production, or feeding behavior, suggesting that the recommended dosage of this blend for lactating dairy cattle may not be beneficial. The results observed here with CE Hi were consistent with those observed with high in vitro dosages previously. At such a high dosage, CE Hi negatively affected in situ nutrient fermentation and altered eating behavior, indicating that a dosage of $10 \mathrm{~g} / \mathrm{d}$ is not beneficial to lactating dairy cows. CAP shortened the length of the first meal without changing rumen fermentation or production, making it a possible feed additive for altering feeding behavior; however, more extensive feeding behavior research is required to 
validate this. At these dosages, the oils tested in the current study may not be an appropriate alternative to feeding sub-therapeutic levels of antibiotics in dairy cattle.

\section{ACKNOWLEDGMENTS}

The authors would like to thank the Will McClung and the staff of the West Virginia University Research Farm (Morgantown, West Virginia, USA) for their support in planning and executing this study. Provision of capsicum from Pancosma, S.A. (Bellegarde-sur-Valserine, France) is much appreciated.

\section{REFERENCES}

Association of Official Analytical Chemists. 1995. Official Methods of Analysis. Vol I. $16^{\text {th }}$ ed. AOAC, Arlington, VA.

Benchaar, C., H. V. Petit, R. Berthiaume, T. D. Whyte, P. Y. Chouinard. 2006. Effects of addition of essential oils and monensin premix on digestion, ruminal fermentation, milk production, and milk composition in dairy cows. J. Dairy Sci. 89:4352-4364.

Benchaar, C., H. V. Petit, R. Berthiaume, D. R. Ouellet, J. Chiquette, P. Y. Choinard. 2007b. Effects of essential oils on digestion, ruminal fermentation, rumen microbial populations, milk production, and milk composition in dairy cows fed alfalfa silage or corn silage. J. Dairy Sci. 90:886-897.

Benchaar, C., P. Y. Chouinard. 2009. Short communication: Assessment of the potential of cinnamaldehyde condensed tannins, and saponins to modify milk fatty acid composition of dairy cows. J. Dairy Sci. 92:3392-3396.

Benchaar, C., T. A. McAllister, P. Y. Chouinard. 2008. Digestion, ruminal fermentation, ciliate protozoal populations, and milk production from dairy cows fed CIN, quebracho condensed tannin, or Yucca schidigera saponin extracts. J. Dairy Sci. 24:1033-1038. 
Busquet, M., S. Calsamiglia, A. Ferret, C. Kamel. 2004. Effects of different doses of plant extracts on rumen microbial fermentation. J. Dairy Sci. 87(Suppl. 1):213. (Abstr.).

Busquet, M., S. Calsamiglia, A. Ferret, C. Kamel. 2005a. Screening for the effects of natural plant extracts and secondary plant metabolites on rumen microbial fermentation in continuous culture. Anim. Feed Sci. Technol. 123:597-613.

Busquet, M., S. Calsamiglia, A. Ferret, P. W. Cardozo, C. Kamel. 2005b. Effects of cinnamaldehyde and garlic oil on rumen microbial fermentation in a dual flow continuous culture. J. Dairy Sci. 88:2508-2516.

Busquet, M., S. Calsamiglia, A. Ferret, C. Kamel. 2006. Plant extracts affect in vitro rumen microbial fermentation. J. Dairy Sci. 89:761-771.

Cardozo, P. W., S. Calsamiglia, A. Ferret, C. Kamel. 2004. Effects of natural plant extracts on ruminal protein degradation and fermentation profiles in continuous culture. J. Anim. Sci. 82:3230-3236.

Cardozo, P. W., S. Calsamiglia, A. Ferret, C. Kamel. 2006. Effects of alfalfa extract, anise, capsicum and a mixture of cinnamaldehyde and eugenol on ruminal fermentation and protein degradation in beef heifers fed a high-concentrate diet. J. Anim. Sci84:28012808.

Castillejos, L., S. Calsamiglia, A. Ferret, R. Losa. 2005. Effects of a specific blend of essential oil compounds and the type of diet on rumen microbial fermentation and nutrient flow from a continuous culture system. Anim. Feed Sci. Technol. 119:29-41.

Deriaz, R. E. 1961. Routine analysis of carbohydrates and lignin in herbage. J. Sci. Food Agric. 12:152-160.

DeVries, T. J., K. A. Beauchemin, M. A. G. von Keyserlingk. 2007. Dietary forage 
concentration affects the feed sorting behavior of lactating dairy cows. J. Dairy Sci. 90:5572-5579.

Eastridge, M. L. 2006. Major advances in applied dairy cattle nutrition. J. Dairy Sci. 89:13111323.

Fandiño, G. R., A. V. Chaves, Y. Wang, T. A. McAllister, K.A. Beauchemin, C. Benchaar. 2008. Assessment of the effects of cinnamon leaf oil on rumen microbial fermentation using two continuous culture systems. J. Dairy Sci. 90:2315-2328.

Fraser, G. R., A. V. Chaves, Y. Wang, T.A. McAllister, K. A. Beauchemin, C. Benchaar. 2007. Assessment of the effects of cinnamon leaf oil on rumen microbial fermentation using two continuous culture systems. J. Dairy Sci. 90:2315-2328.

French, N., J. J. Kennelly. 1990. Effects of feeding frequency on ruminal parameters, plasma insulin, milk yield, and milk composition in Holstein cows. J. Dairy Sci. 73:1857-1863.

Grant, R. J., V. F. Colenbrander, D. R. Mertens. 1990. Milk fat depression in dairy cows: role of silage and particle size. J. Dairy Sci. 73:1834-1842.

Hartnell, G.F. L.D. Satter. 1979. Determination of rumen fill, retention time and ruminal turnover rates of ingesta at different stages of lactation in dairy cows. J. Anim. Sci. 48:381-392.

Kolver, E.S., M.J. de Veth. 2002. P rediction of ruminal pH from pasture-based diets. J. Dairy Sci. 85:1255-1266.

Kononoff, P. J, A. J. Heinrichs, D. R. Buckmaster. 2003. Modification of the Penn State Forage and Total Mixed Ration Particle Separator and effects of moisture content on its measurements. J. Dairy Sci. 86:1858-1863.

Krause, K. M., D. K. Combs. 2003. Effects of forage particle size, forage source, and grain 
fermentability on performance and ruminal $\mathrm{pH}$ in midlactation cows. J. Dairy. Sci. $86: 1382-1397$.

McIntosh, F. M., P. Williams, R. Losa, R. J. Wallace, D. A. Beever, C. J. Newbold. 2003. Effects of essential oils on ruminal microorganisms and their protein metabolism. Appl. Environ. Microbiol. 69:5011-5014.

NRC. 2001. Nutrient Requirements of Dairy Cattle. $7^{\text {th }}$ rev. ed. Natl. Acad. Sci., Washington, DC.

Newbold, C. J., F. M. McIntosh, P. Williams, R. Losa, R. J. Wallace. 2004. Effects of a specific blend of essential oil compounds on rumen fermentation. Anim. Feed Sci. and Technol. 114:105-112.

Odongo, N. E., M. M. Or-Rashid, R. Bagg, G. Vessi, P. Dick, E. Kebreab, J. France. 2007. Long-term effects of feeding monensin on milk fatty acid composition in lactating dairy cows. J. Dairy Sci. 90:5126-5133.

Oh, H. K., M. B. Jones, W. M. Longhurst. 1968. Comparison of rumen microbial fermentation inhibition resulting from various essential oils isolated from relatively unpalatable plant species. Appl. Microbiol. 16:39-44.

Owens, F. N., D. S. Secrist, W. J. Hill, D. R. Gill. 1998. Acidosis in cattle: a review. J. Anim. Sci. 76:275-286.

Penner, G.B., K.A. Beauchemin, T. Mutsvangwa. 2006. An evaluation of the accuracy and precision of a stand-alone submersible continuous ruminal $\mathrm{pH}$ measurement system. J. Dairy Sci. 89:2132-2140.

Rodriguez-Prado, M. S. Calsamiglia, A. Ferret, J. Zieten, L. Gonzalez, D. Bravo. 2008. Effects of cinnamaldehyde-eugenol and capsicum on rumen fermentation and feeding behavior in 
beef heifers fed a high-concentrate diet. J. Anim. Sci. 86(Suppl. 2):588. (Abstr.)

Smith, D. 1969. Removing and analyzing non-structural carbohydrates from plant tissue. Page 1 in Wisconsin Agric. Exp. Sta. res. Rep. 41. Wisconsin Agric. Exp. Sta., Madison, WI.

Tager, L. R., K. M. Krause. 2010. Effects of cinnamaldehyde, eugenol, and capsicum on fermentation of a corn-based dairy ration in continuous culture. Can. J. Anim. Sci. In Press.

Wallace, R. J. 2005. Symposium on 'Plants as animal foods: a case of catch 22?': Antimicrobial properties of plant secondary metabolites. Proc. of Nut. Soc. 63:621-629.

Wangsness, P. J., L. E. Chase, A. D. Peterson, T. G. Hartsock, D. J. Kellmel, B. R. Baumgardt. 1976. System for monitoring feeding behavior of sheep. J. Anim. Sci. 42:1544-1549.

Yang, W. Z., K. A. Beauchemin. 2007. Altering physically effective fiber intake through forage proportion and particle length: chewing and ruminal pH. J. Dairy Sci. 90:2826-2838. 
Table 1. Diet ingredient, chemical composition, and particle size distribution of the TMR

\begin{tabular}{|c|c|}
\hline Ingredient & $\%$ of Total DM \\
\hline Corn silage & 34.4 \\
\hline Ground corn grain & 32.0 \\
\hline Soybean hulls & 11.0 \\
\hline Chopped alfalfa hay ${ }^{2}$ & 7.3 \\
\hline Hydrolyzed feather meal & 2.9 \\
\hline Calcium diphosphate & 0.5 \\
\hline Salt & 0.5 \\
\hline Limestone & 0.3 \\
\hline Urea & 0.3 \\
\hline Vitamin premix ${ }^{4}$ & 0.3 \\
\hline Magnesium oxide & 0.1 \\
\hline \multicolumn{2}{|l|}{ Nutrients, DM basis } \\
\hline DM, as fed basis & 64.0 \\
\hline $\mathrm{OM}$ & 94.8 \\
\hline $\mathrm{CP}$ & 16.3 \\
\hline NDF & 28.6 \\
\hline $\mathrm{ADF}$ & 19.1 \\
\hline Starch & 29.6 \\
\hline NSC & 32.2 \\
\hline Ether extract & 2.3 \\
\hline \multicolumn{2}{|c|}{ Particle size distribution, as fed basis $^{3}$} \\
\hline$>19.0 \mathrm{~mm}$ & 5.9 \\
\hline $19.0-8.0 \mathrm{~mm}$ & 29.1 \\
\hline $8.0-1.18 \mathrm{~mm}$ & 49.8 \\
\hline$<1.18 \mathrm{~mm}$ & 15.2 \\
\hline$X_{\mathrm{gm}}^{5}$ & 4.8 \\
\hline
\end{tabular}

${ }^{1}$ Nutrient analysis (DM basis): 39.7\% DM (as fed); 42.9\% NDF; 22.4\% ADF; 46.1\% Starch;

2.8\% Ash; 2.6\% Ether Extract; 5.0\% >18 mm particle size; 64.8\% 9-18 mm particle size; $28.4 \%$

$1.18-9 \mathrm{~mm}$ particle size; $1.8 \%<1.18 \mathrm{~mm}$ particle size

${ }^{2}$ Nutrient analysis (DM basis): $84.8 \%$ DM (as fed); $42.5 \%$ NDF; $31.7 \%$ ADF; $3.1 \%$ Starch;

9.7\% Ash; 1.3\% Ether Extract; $4.1 \%>18 \mathrm{~mm}$ particle size; $28.1 \%$ 9-18 mm particle size; $44.3 \%$

1.18-9 mm particle size; $23.5 \%<1.18 \mathrm{~mm}$ particle size

${ }^{3}$ As determined by the Penn State Particle Separator

${ }^{4}$ Vitamin ADE premix (North American Nutrition Companies Inc., Brookville, OH); 9,920.9

$\mathrm{IU} / \mathrm{g}$ vitamin $\mathrm{A} ; 2,204.6 \mathrm{IU} / \mathrm{g}$ vitamin $\mathrm{D} ; 4.4 \mathrm{IU} / \mathrm{g}$ vitamin $\mathrm{E}$

${ }^{5} \mathrm{X}_{\mathrm{gm}}=$ calculated geometric mean length (ASAE, 2001) 
Table 2. Feeding and rumination behavior of lactating Holstein dairy cows fed a 42:58 forage to concentrate ratio diet supplemented with essential oils

\begin{tabular}{lrrrrrc}
\hline & \multicolumn{7}{c}{ Treatment $^{1}$} \\
\cline { 2 - 7 } Item & CON & CE Lo & CE Hi & CAP & SEM & $P$ \\
\hline DMI, kg/d & 23.9 & 23.3 & 23.2 & 22.9 & 0.9 & 0.56 \\
meal events/d & 7.3 & 7.0 & 7.6 & 7.7 & 0.6 & 0.65 \\
h eating/d & 4.2 & 3.5 & 4.1 & 4.0 & 0.4 & 0.53 \\
mean meal length, min & 35.3 & 35.6 & 34.0 & 30.7 & 2.8 & 0.20 \\
length 1 $^{\text {st }}$ meal, min & $65.4^{\mathrm{a}}$ & $58.7^{\mathrm{ab}}$ & $47.2^{\mathrm{b}}$ & $49.4^{\mathrm{b}}$ & 7.6 & 0.01 \\
rumination events/d $_{\text {h rumination/d }}$ & 10.2 & 10.3 & 10.0 & 10.5 & 0.6 & 0.57 \\
mean rumination length, min & 6.7 & 5.6 & 5.9 & 6.5 & 0.6 & 0.46 \\
\hline
\end{tabular}

${ }^{\mathrm{a}, \mathrm{b}}$ Means within a row with different superscripts differ $(P<0.05)$

${ }^{1} \mathrm{CON}=$ control (no oil); CE Lo = $0.5 \mathrm{~g} / \mathrm{d}$ XT 6965 (85 mg cinnamaldehyde and $140 \mathrm{mg}$

eugenol); CE Hi = 10 g/d XT 6965 (1700 mg cinnamaldehyde and $2800 \mathrm{mg}$ eugenol); CAP = $0.25 \mathrm{~g} / \mathrm{d}$ XT 6933 (capsicum)

${ }^{2} \mathrm{DMI}=$ dry matter intake 
Table 3. Milk yield and composition of lactating Holstein dairy cows fed a 42:58 forage to concentrate ratio diet supplemented with essential oils

\begin{tabular}{lcccccc}
\hline & \multicolumn{7}{c}{ Treatment $^{1}$} \\
\cline { 2 - 7 } Item & CON & CE Lo & CE Hi & CAP & SEM & $P$ \\
\hline Milk Yield, kg/d & 33.0 & 32.8 & 31.6 & 31.1 & 1.2 & 0.35 \\
Milk Composition & & & & & & \\
$\quad$ \% fat & 3.5 & 3.5 & 3.4 & 3.6 & 0.2 & 0.63 \\
kg/d fat & 1.2 & 1.2 & 1.1 & 1.1 & 0.1 & 0.61 \\
\% lactose & 4.8 & 4.8 & 4.8 & 4.8 & 0.1 & 0.86 \\
kg/d lactose & 1.6 & 1.6 & 1.5 & 1.5 & 0.1 & 0.28 \\
\% protein & 2.8 & 2.8 & 3.5 & 2.7 & 0.4 & 0.41 \\
$\mathrm{~kg} / \mathrm{d}$ protein & 0.9 & 0.9 & 1.0 & 0.9 & 0.1 & 0.61 \\
\hline
\end{tabular}

${ }^{\mathrm{T}} \mathrm{CON}=$ control (no oil); CE Lo = 0.5 g/d XT 6965 (85 mg cinnamaldehyde and $140 \mathrm{mg}$ eugenol); CE Hi = 10 g/d XT 6965 (1700 mg cinnamaldehyde and $2800 \mathrm{mg}$ eugenol); CAP = $0.25 \mathrm{~g} / \mathrm{d}$ XT 6933 (capsicum) 
Table 4. Total tract digestibility of lactating Holstein dairy cows fed a $42: 58$ forage to concentrate ratio diet supplemented with essential oils

\begin{tabular}{lcccccc}
\hline \multirow{2}{*}{ Total tract digestibility, \% } & \multicolumn{7}{c}{ Treatment $^{1}$} \\
\cline { 2 - 7 } & CON & CE Lo & CE Hi & CAP & SEM & $P$ \\
\hline DM & 51.4 & 51.9 & 53.8 & 53.0 & 3.4 & 0.75 \\
NDF & 52.6 & 53.7 & 55.5 & 55.3 & 3.4 & 0.68 \\
ADF & 29.6 & 27.4 & 35.4 & 30.3 & 6.0 & 0.73 \\
CP & 30.4 & 28.2 & 32.5 & 31.6 & 4.5 & 0.77 \\
Starch & 51.3 & 46.4 & 52.3 & 50.9 & 5.1 & 0.54 \\
\hline
\end{tabular}

${ }^{\top} \mathrm{CON}=$ control (no oil); CE Lo $=0.5 \mathrm{~g} / \mathrm{d}$ XT 6965 (85 mg cinnamaldehyde and $140 \mathrm{mg}$

eugenol); CE Hi = 10 g/d XT 6965 (1700 mg cinnamaldehyde and 2800 mg eugenol); CAP = $0.25 \mathrm{~g} / \mathrm{d}$ XT 6933 (capsicum) 
Table 5. 24-h in situ nutrient disappearance of soybean hulls in lactating Holstein dairy cows fed a 42:58 forage to concentrate ratio diet supplemented with essential oils

\begin{tabular}{lcccccc}
\hline & \multicolumn{7}{c}{ Treatment $^{1}$} \\
\cline { 2 - 7 } 24 h in situ nutrient disappearance, $\%$ & CON & CE Lo & CE Hi & CAP & SEM & $P$ \\
\hline DM & 59.7 & 60.8 & 60.3 & 57.9 & 2.4 & 0.56 \\
OM & $60.3^{\mathrm{a}}$ & $58.6^{\mathrm{ab}}$ & $57.6^{\mathrm{b}}$ & $59.1^{\mathrm{ab}}$ & 2.3 & 0.08 \\
NDF & $41.5^{\mathrm{a}}$ & $38.2^{\mathrm{ab}}$ & $37.6^{\mathrm{b}}$ & $38.0^{\mathrm{ab}}$ & 3.0 & 0.05 \\
ADF & $44.5^{\mathrm{a}}$ & $41.6^{\mathrm{ab}}$ & $38.8^{\mathrm{b}}$ & $40.0^{\mathrm{ab}}$ & 2.8 & 0.04 \\
\hline
\end{tabular}

${ }^{\mathrm{a}, \mathrm{b}}$ Means within a row with different superscripts differ $(P<0.05)$

${ }^{1} \mathrm{CON}=$ control (no oil); CE Lo = $0.5 \mathrm{~g} / \mathrm{d}$ XT 6965 (85 mg cinnamaldehyde and $140 \mathrm{mg}$ eugenol); CE Hi = 10 g/d XT 6965 (1700 mg cinnamaldehyde and 2800 mg eugenol); CAP = $0.25 \mathrm{~g} / \mathrm{d}$ XT 6933 (capsicum) 
Table 6. Ammonia and VFA (volatile fatty acid) concentration in lactating Holstein dairy cows fed a 42:58 forage to concentrate ratio diet supplemented with essential oils

\begin{tabular}{|c|c|c|c|c|c|c|c|c|}
\hline \multirow[b]{2}{*}{ Item } & \multicolumn{4}{|c|}{ Treatment $^{1}$} & \multirow[b]{2}{*}{ SEM } & \multicolumn{3}{|c|}{ Effects $^{2}$} \\
\hline & $\mathrm{CON}$ & CE Lo & CE Hi & CAP & & $\mathrm{D}$ & HPF & D x HPF \\
\hline Ammonia, mg/dL & 11.9 & 13.0 & 13.1 & 13.8 & 1.0 & 0.41 & $<0.01$ & 0.16 \\
\hline \multicolumn{9}{|l|}{ VFA, $\mathrm{mmol} / \mathrm{L}$} \\
\hline Total & 129.1 & 127.9 & 129.1 & 130.4 & 5.5 & 0.98 & $<0.01$ & 0.19 \\
\hline Acetate & 79.6 & 77.7 & 78.8 & 80.1 & 3.1 & 0.86 & $<0.01$ & 0.23 \\
\hline Propionate & 29.7 & 30.5 & 30.2 & 29.3 & 2.4 & 0.92 & $<0.01$ & 0.27 \\
\hline Butyrate & 15.3 & 15.5 & 15.6 & 16.3 & 0.8 & 0.82 & $<0.01$ & 0.17 \\
\hline Isobutyrate & 1.2 & 1.1 & 1.2 & 1.2 & 0.1 & 0.59 & 0.28 & 0.26 \\
\hline Isovalerate & 0.9 & 0.8 & 1.0 & 0.9 & 0.1 & 0.69 & 0.61 & 0.68 \\
\hline Valerate & 2.3 & 2.2 & 2.3 & 2.3 & 0.2 & 0.96 & $<0.01$ & 0.63 \\
\hline $\mathrm{A}: \mathrm{P}^{3}$ & 2.8 & 2.6 & 2.7 & 2.8 & 0.2 & 0.37 & 0.11 & 0.45 \\
\hline \multicolumn{9}{|l|}{ VFA, molar $\%$} \\
\hline Acetate & 61.7 & 60.8 & 61.2 & 61.6 & 1.1 & 0.67 & 0.39 & 0.66 \\
\hline Propionate & 22.8 & 23.8 & 23.2 & 22.2 & 1.1 & 0.33 & 0.08 & 0.38 \\
\hline Butyrate & 12.0 & 12.1 & 12.1 & 12.6 & 0.5 & 0.64 & 0.45 & 0.14 \\
\hline Isobutyrate & 0.9 & 0.9 & 1.0 & 0.9 & 0.1 & 0.51 & 0.11 & 0.32 \\
\hline Isovalerate & 0.8 & 0.6 & 0.8 & 0.7 & 0.1 & 0.70 & 0.33 & 0.63 \\
\hline Valerate & 1.8 & 1.8 & 1.8 & 1.7 & 0.1 & 0.99 & 0.08 & 0.84 \\
\hline
\end{tabular}

${ }^{1} \mathrm{CON}=$ control (no oil); CE Lo = $0.5 \mathrm{~g} / \mathrm{d}$ XT 6965 (85 mg cinnamaldehyde and $140 \mathrm{mg}$ eugenol); CE Hi = 10 g/d XT 6965 (1700 mg cinnamaldehyde and 2800 mg eugenol); CAP = $0.25 \mathrm{~g} / \mathrm{d}$ XT 6933 (capsicum)

${ }^{2} \mathrm{D}=$ diet; HPF = hours post feeding; $\mathrm{D} x \mathrm{HPF}=$ diet by hours post feeding interaction

${ }^{3}$ Acetate to propionate ratio 
Table 7. Rumen $\mathrm{pH}$ of lactating Holstein dairy cows fed a $42: 58$ forage to concentrate ratio diet supplemented with essential oils

\begin{tabular}{lrrrrrc}
\hline \multirow{2}{*}{ Item } & \multicolumn{7}{c}{ Treatment $^{1}$} \\
\cline { 2 - 7 } Mean $\mathrm{pH}$ & CON & CE Lo & CE Hi & CAP & SEM & $P$ \\
pH < 5.8 & 5.64 & 5.71 & 5.80 & 5.73 & 0.12 & 0.46 \\
$\quad$ \# bouts & & & & & & \\
$\quad$ total time, $\mathrm{h}$ & 17.6 & 19.7 & 19.1 & 15.9 & 3.3 & 0.66 \\
mean bout length, min & 14.6 & 15.3 & 12.0 & 16.0 & 2.3 & 0.40 \\
total area, $\mathrm{pH}^{*} \mathrm{~h} / \mathrm{d}$ & 69.8 & 55.2 & 46.6 & 53.7 & 17.7 & 0.51 \\
mean bout area, $\mathrm{pH}^{*} \min / \mathrm{d}$ & 5.7 & 5.4 & 4.9 & 5.3 & 1.6 & 0.95 \\
pH < 5.6 & 26.6 & 23.2 & 23.2 & 20.2 & 10.8 & 0.85 \\
\# bouts & & & & & & \\
total time, $\mathrm{h}$ & 20.8 & 22.1 & 18.5 & 19.1 & 2.8 & 0.72 \\
mean bout length, min & 12.0 & 9.0 & 5.8 & 10.2 & 2.0 & 0.34 \\
total area, $\mathrm{pH} \mathrm{H}^{*} \mathrm{~h} / \mathrm{d}$ & 31.4 & 19.7 & 24.7 & 31.9 & 7.6 & 0.31 \\
$\quad$ mean bout area, $\mathrm{pH}^{*} \mathrm{~min} / \mathrm{d}$ & 2.8 & 2.9 & 1.9 & 2.9 & 1.0 & 0.79 \\
\hline
\end{tabular}

${ }^{\mathrm{T}} \mathrm{CON}=$ control (no oil); CE Lo = 0.5 g/d XT 6965 (85 mg cinnamaldehyde and $140 \mathrm{mg}$

eugenol); CE Hi = 10 g/d XT 6965 (1700 mg cinnamaldehyde and 2800 mg eugenol); CAP = $0.25 \mathrm{~g} / \mathrm{d}$ XT 6933 (capsicum) 


\section{CHAPTER 4}

\section{Effect of capsicum oil on feeding behavior and milk production in lactating dairy cattle ${ }^{1}$}

\footnotetext{
${ }^{1}$ Formatted for submission to the Journal of Dairy Science
} 
Effect of capsicum oil on feeding behavior and milk production in lactating dairy cattle. Tager. Capsicum was supplemented to lactating dairy cows to assess its effects on eating behavior and milk production. Capsicum did not affect eating behavior or milk production. Capsicum may not be a beneficial feed additive for altering feeding behavior or milk production in lactating dairy cattle.

SHORT COMMUNICATION: CAPSICUM EFFECT ON LACTATING DAIRY COWS

Short Communication: Effect of capsicum oil on feeding behavior and milk production in lactating dairy cattle.

L. R. Tager*, C. Leonardi ${ }^{\dagger}$, and K. M. Krause ${ }^{* 1}$

*Department of Animal and Nutritional Science, West Virginia University, Morgantown 26506

$\dagger$ Department of Experimental Statistics, Louisiana State University, Baton Rouge 70803

${ }^{1}$ Corresponding Author: K. Marie Krause, Email: Marie.Krause@ mail.wvu.edu

This work is published with the approval of the Director of West Virginia Agriculture and Forestry Experiment Station as scientific paper xxxx. This project was supported by Hatch project 474. 


\section{ABSTRACT}

Forty Holstein $(\mathrm{n}=32)$ and Ayrshire $(\mathrm{n}=8)$ dairy cows were used in a replicated crossover design to study the effect of capsicum oil on feeding behavior and milk production in lactating dairy cows. Feeding behavior was monitored using the GrowSafe system (GrowSafe Systems Ltd., Airdrie, AB, Canada). After balancing for milk yield and DIM, 10 cows were randomly assigned to each of 2 pens ( 5 GrowSafe bins/pen) during each replicate. Cows were fed a TMR with a 54:46 forage:concentrate ratio (DM basis) ad-libitum twice daily. Experimental treatments included: 1 g/cow/d Xtract 6933 (CAP; 200 mg capsicum oil) or no oil $(\mathrm{CON})$. Cows were allowed $10 \mathrm{~d}$ adaptation to experimental treatments. Data were then collected until $15 \mathrm{~d}$ of sound data were accumulated for each experimental period. There was no difference in DMI (23.4 kg/d vs. $23.1 \mathrm{~kg} / \mathrm{d})$, number of meals/d (12.5 vs. 12.2), total h spent eating/d (3.1 h vs. $3.1 \mathrm{~h})$, mean meal length (16.3 min vs. 16.4), length of first meal after feeding (44.6 min vs. $45.7 \mathrm{~min})$, or eating rate $(7.8 \mathrm{~kg} / \mathrm{h}$ vs. $8.0 \mathrm{~kg} / \mathrm{h})$ between CAP and CON. Milk yield did not differ between CAP and CON $(31.8 \mathrm{~kg} / \mathrm{d}$ vs. $32.3 \mathrm{~kg} / \mathrm{d})$. Feeding CAP at $1 \mathrm{~g} / \mathrm{cow} / \mathrm{d}$ did not significantly change eating behavior or milk production in lactating dairy cattle.

\section{Keywords: capsicum oil, eating behavior, dairy cow}

With the recent emergence of plant derived secondary metabolites as animal feed additives, capsicum oil has become a popular subject for study in ruminant systems (Cardozo et al., 2004; Cardozo et al., 2006; Fandiño et al., 2007; Tager and Krause, 2010). Capsicum oil is extracted from the hot pepper plant (Capsicum annum ssp.). The main component of capsicum oil is the terpenoid capsaicin (10 to $15 \%$; Calsamiglia et al., 2007). In vitro observation of capsicum has shown that with typical dairy diets (60:40 forage to concentrate ratio), capsicum has little effect on rumen fermentation (Cardozo et al., 2004; Busquet et al., 2005; Tager and 
Krause, 2010). On the other hand, when added in vitro with rumen fluid from cattle receiving higher concentrate beef diets (10:90 forage to concentrate ratio), capsicum has the ability to positively alter rumen fermentation (decreased ammonia, increased total VFA, and reduced acetate:propionate), particularly at low pH (5.5; Cardozo et al., 2005).

More recently, it has been suggested that capsicum may affect feeding behavior in ruminant animals. Increased DMI and water consumption have been reported in beef cattle receiving capsicum as a supplement (Cardozo et al., 2006; Fandiño et al., 2007), possibly increasing production. It has further been suggested that capsicum may modify eating patterns beneficially by stabilizing intake patterns and controlling drastic drops in rumen $\mathrm{pH}$ caused by high concentrate beef diets (Rodriquez-Prado et al., 2008). Steadier DMI over the course of the day is thought to stabilize rumen $\mathrm{pH}$, which can reduce the risk for ruminal acidosis and other metabolic disorders (French and Kennelly, 1990). However, there is no available data to support this observation in lactating dairy cattle. A prior, smaller scale study by our lab indicated that capsicum $(0.25 \mathrm{~g} / \mathrm{cow} / \mathrm{d})$ may alter feed intake pattern in lactating dairy cattle by shortening the length of the first meal after each feeding, however more validation was necessary to confirm this observation (Tager and Krause; Chapter 3). Therefore, the objective of this study was to evaluate the effects of capsicum oil on eating behavior and milk production in lactating dairy cattle.

A total of 40 lactating Holstein $(n=32)$ and Ayrshire $(n=8)$ cows were used in a replicated crossover design (27 primiparous and 13 multiparous). The 2 replicates were conducted one after the other because of barn limitations. During each of 2 replicates, 20 cows were randomly assigned to the 2 free stall pens (10 cows/pen) such that pens had similar DIM and milk yield. Each pen contained 5 GrowSafe feed nodes (GrowSafe Systems Ltd., Airdrie, 
Alberta, Canada), and all animals were tagged with an Allflex ${ }^{\circledR}$ electrical identification transponder for wireless transmission of eating behavior to a computer containing GrowSafe software for behavioral analysis.

Cows were fed a TMR (Table 1) ad libitum twice daily at $0800 \mathrm{~h}$ and $1700 \mathrm{~h}$ containing one of 2 treatments: control (CON; no supplement) or $1 \mathrm{~g}$ Xtract 6933/cow/d (CAP; $200 \mathrm{mg}$ capsicum; Pancosma S.A., Bellegarde-sur-Valserine, France). Capsicum was added to the ration during mixing of the TMR. Water was provided ad libitum, however consumption was not monitored. During each replicate, pens were randomly assigned 1 of each treatment in the first study period. Treatments were administered to each pen for $10 \mathrm{~d}$ without data collection at the beginning of each study period to allow the animals adaptation time to treatments. Then, data were collected until $15 \mathrm{~d}$ of valid observations were compiled (data discarded when electrical or maintenance errors occurred). Treatments were then crossed over and the same procedure was repeated (10 d adaptation; $15 \mathrm{~d}$ valid data collection).

Variables collected and calculated daily using the GrowSafe system included DMI, number of meals/d, h eating/d, mean meal length, eating rate, and length of first meal after feeding. The GrowSafe system defines a meal as a period of eating without absence of more than $300 \mathrm{~s}$ (5 min). Meals comprised of several feedings at different bunks were combined by the GrowSafe software as one continuous meal. Dry matter intake, number of meals/d, h eating/d, and length of first meal after feeding were recorded directly from the GrowSafe data files. Mean meal length was calculated by averaging the length of all meals for each cow on each day. Eating rate was calculated as DMI divided by total h eating/d. Milk yields were recorded for all animals during the entire study. Animals in this study were cared for under the guidelines of the West Virginia University Animal Care and Use Committee. 
Data were analyzed using the mixed model procedure of SAS 9.1 (2001). Milk yield (31.6 vs. $32.2 \mathrm{~kg} / \mathrm{d}$ ), DIM (128 vs. $123 \mathrm{~d}$ ), feeding time, animal handling, sampling procedures, and diet fed were similar between replicates; therefore the analysis was conducted as if the 2 replicates were conducted concurrently. Data were analyzed using a model with treatment, sequence, and period as a fixed effect. Pen within sequence was included into the model as a random effect. The Kenward-Roger denominator degrees of freedom adjustment was used. The LSMEANS statement was used to estimate treatment means and standard error of the mean. Differences were declared significant at $P \leq 0.05$ and considered a trend at $0.05<P \leq 0.10$. Supplementation of CAP at $1 \mathrm{~g} / \mathrm{cow} / \mathrm{d}$ to lactating dairy cattle had no effect on eating behavior or milk production (Table 2). While supplementation with CAP in beef cattle at a variety of dosages (0.5, 1.0 and $2.5 \mathrm{~g} / \mathrm{d})$ has been reported to increase DMI (Cardozo et al., 2006; Fandiño et al., 2007; Rodriquez-Prado et al., 2008), the current study indicates this may not be the case in lactating dairy cattle. This discrepancy between beef and dairy cattle may be due to the difference in the concentration of CAP in the diet being consumed. Beef cattle in previous research studying CAP typically consumed an average of $7.8 \mathrm{~kg} / \mathrm{d}$ DM (Cardozo et al., 2006; Fandiño et al., 2007; Rodriquez-Prado et al., 2008). Accordingly, the concentration of CAP in these beef cattle diets was $\sim 64.0$ to $321.0 \mathrm{mg} / \mathrm{kg}$ DM consumed. In dairy cattle, however, DMI is significantly higher. Indeed, the current study observed DMI of $\sim 23.0 \mathrm{~kg} / \mathrm{d}$, thus making the concentration of CAP in the diet only $43.5 \mathrm{mg} / \mathrm{kg}$ DM consumed. This lower concentration may not be high enough to affect eating behavior and, consequently, milk production in lactating dairy cattle. It is important to note that a higher dosage may be more effective; however, it may not be economical. 
A previous study by Tager and Krause (2010; Chapter 3) indicated that CAP fed at a dosage of $0.25 \mathrm{~g} / \mathrm{cow} / \mathrm{d}$ may alter eating behavior as evidenced by the shorter length of first meal after feeding compared to a control diet (49.4 min vs. $65.4 \mathrm{~min})$. However, the effect of CAP on length of first meal after feeding was not evident in the current study (45.7 vs. 44.6 min; CON vs. CAP). This result was surprising as the concentration of CAP in the current study was much higher $(43.5 \mathrm{mg} / \mathrm{kg}$ DM consumed) compared to the prior study $(10.6 \mathrm{mg} / \mathrm{kg} \mathrm{DM}$ consumed). Theoretically, an even higher concentration of CAP should have elicited an effect on feeding behavior, although this was not the case.

The similarity in length of first meal between treatments is most likely attributable to competition at the bunks after feeding. The prior study by Tager and Krause (Chapter 3) was conducted using the Calan gate system (American Calan Inc., Northwood, NH), which eliminates competition during eating by allowing a personal bunk for each animal. However, the current study had 10 animals assigned to 5 GrowSafe bunks in each pen, with each bunk only able to accommodate one animal at a time. This created competition for feeding space at the bunks similar what might be seen in a free stall operation with limited bunk space. The effect of competition on eating behavior with the current experimental design is further substantiated by the shorter mean meal length (16.4 vs. $33.0 \mathrm{~min}$.) and the greater number of meals/d (12.4 vs. 7.5) compared to the prior study by Tager and Krause (Chapter 3). Shorter, yet more frequent, meals allow each animal to consume the necessary amount of feed, much like a free stall operation where competition occurs for space at the bunk. Further, more dominant animals may have consumed a greater concentration of CAP due to their higher DMI, meaning CAP concentration was most likely inconsistent among animals. Therefore, in dairy operations with high competition for bunk space, CAP may not have any beneficial effects. However, a study 
with less competition, similar to the prior Calan gate study or a tie-stall study, may show effects of CAP on eating behavior of lactating dairy cattle.

At a dosage of $1 \mathrm{~g} / \mathrm{cow} / \mathrm{d}, \mathrm{CAP}$ had no effect on eating behavior or milk production. Due to high DMI, dairy cattle may require a higher dosage of CAP to elicit an effect on eating behavior and milk production. However, a higher dosage may not be economical or biologically appropriate. While prior research indicated that CAP may be beneficial in beef cattle consuming high concentrate diets, the current study indicates that it does not provide any benefits to lactating dairy cattle in a situation where bunk space is limited.

\section{ACKNOWLEDGMENTS}

The authors would like to thank the Will McClung and the staff of the West Virginia University Research Farm (Morgantown, West Virginia, USA) for their support in planning and executing this study. Provision of capsicum from Pancosma, S.A. (Bellegarde-sur-Valserine, France) is much appreciated.

\section{REFERENCES}

Busquet, M., S. Calsamiglia, A. Ferret, P. W. Cardozo, C. Kamel. 2005b. Effects of cinnamaldehyde and garlic oil on rumen microbial fermentation in a dual flow continuous culture. J. Dairy Sci. 88:2508-2516.

Calsamiglia, S., M. Busquet, P. W. Cardozo, L. Castillejos, A. Ferret. 2007. Invited Review: Essential oils as modifiers of rumen microbial fermentation. J. Dairy Sci. 90:2580-2595.

Cardozo, P. W., S. Calsamiglia, A. Ferret, C. Kamel. 2004. Effects of natural plant extracts on ruminal protein degradation and fermentation profiles in continuous culture. J. Anim. Sci. 82:3230-3236.

Cardozo, P. W., S. Calsamiglia, A. Ferret, C. Kamel. 2005. Screening for the effects of natural 
plant extracts at different $\mathrm{pH}$ on in vitro rumen microbial fermentation of highconcentrate diet for beef cattle. J. Anim. Sci. 83:2572-2579.

Cardozo, P. W., S. Calsamiglia, A. Ferret, C. Kamel. 2006. Effects of alfalfa extract, anise, capsicum and a mixture of cinnamaldehyde and eugenol on ruminal fermentation and protein degradation in beef heifers fed a high-concentrate diet. J. Anim. Sci 84:28012808.

Fandiño, G. R., A. V. Chaves, Y. Wang, T. A. McAllister, K.A. Beauchemin, C. Benchaar. 2008. Assessment of the effects of cinnamon leaf oil on rumen microbial fermentation using two continuous culture systems. J. Dairy Sci. 90:2315-2328.

French, N., J. J. Kennelly. 1990. Effects of feeding frequency on ruminal parameters, plasma insulin, milk yield, and milk composition in Holstein cows. J. Dairy Sci. 73:1857-1863.

Tager, L. R., K. M. Krause. 2010. Effects of cinnamaldehyde, eugenol, and capsicum on fermentation of a corn-based dairy ration in continuous culture. Can. J. Anim. Sci. In Press.

Rodriguez-Prado, M. S. Calsamiglia, A. Ferret, J. Zieten, L. Gonzalez, D. Bravo. 2008. Effects of cinnamaldehyde-eugenol and capsicum on rumen fermentation and feeding behavior in beef heifers fed a high-concentrate diet. J. Anim. Sci. 86(Suppl. 2):588. (Abstr.) 
Table 1. Diet ingredients and chemical composition of TMR

\begin{tabular}{lr}
\hline Ingredient & \% of Total DM \\
\hline Corn silage $^{1}$ & 23.5 \\
Alfalfa hay $^{2}$ & 30.5 \\
Dairy pellets $^{3}$ & 34.4 \\
Concentrate and vitamin premix $^{4}$ & 11.1 \\
Zar-Min $^{2}$ & 0.6 \\
Nutrients (DM basis) & \\
DM (as fed basis) & 65.1 \\
OM & 92.1 \\
CP & 17.4 \\
NDF & 36.3 \\
ADF & 25.2 \\
Starch & 18.6 \\
NSC & 23.7 \\
Ether Extract & 2.9 \\
\hline
\end{tabular}

${ }^{1}$ Nutrient analysis (DM basis): 38.6\% DM (as fed); 41.2\% NDF; 23.1\% ADF; 45.7\% Starch;

8.1\% CP; $3.1 \%$ Ash; $2.8 \%$ Ether Extract

${ }^{2}$ Nutrient analysis (DM basis): $86.2 \%$ DM (as fed); $41.8 \%$ NDF; 32.3\% ADF; $32.1 \%$ Starch;

17.8\% CP; 9.5\% Ash; 1.4\% Ether Extract

${ }^{3}$ Consisted of soy bean hulls (33.6\%), ground corn (37.5\%), 48\% soybean meal (25.3\%), urea $(1.2 \%)$, ground limestone $(1.0 \%)$, dicalcium phosphate $(0.4 \%)$, magnesium oxide $(0.2 \%)$, salt and SaltTMineral Mix (0.5\%), and vitamin ADE premix (0.4\%; 9,920.9 IU/g vitamin A; 2,204.6 $\mathrm{IU} / \mathrm{g}$ vitamin $\mathrm{D} ; 4.4 \mathrm{IU} / \mathrm{g}$ vitamin $\mathrm{E})$, on a DM basis

${ }^{4}$ Consisted of dry beet pulp pellets (7.9\%), 60\% CP corn gluten meal (10.3\%), cracked corn grain $(39.7 \%), 48 \%$ soybean meal $(19.9 \%)$, dicalcium phosphate $(1.6 \%)$, Megalac $(5.9 \%)$, soybean oil (1.5\%), E-soy (12.7\%), and mineral mix (0.5\%), on a DM basis 
Table 2. Eating behavior and milk production of lactating dairy cattle supplemented with capsicum oil

\begin{tabular}{lcccc}
\hline & Treatment $^{1}$ & & \\
\cline { 2 - 4 } Item & CON & CAP & SEM & $P$ \\
\hline DMI, kg/d & 23.1 & 23.4 & 0.3 & 0.57 \\
h eating/d & 3.1 & 3.1 & 0.1 & 0.73 \\
meal events/d & 12.2 & 12.5 & 0.7 & 0.76 \\
mean meal length, min & 16.4 & 16.3 & 0.6 & 0.89 \\
eating rate, kg/h & 8.0 & 7.8 & 0.2 & 0.54 \\
length 1 ${ }^{\text {st }}$ meal, min & 45.7 & 44.6 & 0.7 & 0.31 \\
Milk yield, kg/d & 32.3 & 31.8 & 1.5 & 0.81 \\
${ }^{1}$ CON = control (no oil); CAP $=1.0 \mathrm{~g} / \mathrm{d}$ Xtract $6933(200 \mathrm{mg}$ capsicum) & \\
${ }^{2}$ DMI = dry matter intake & & &
\end{tabular}




\section{GENERAL SUMMARY}

Recent decreased social acceptance of antibiotics in animal feeding, along with their ban for animal feeding in Europe, has led researchers to investigate natural products made by plants as an alternative. While much research has been done in vitro with plant extracts and EO, results have varied greatly due to oil type, dosage, and diet, among other factors. In the current in vitro study, the addition of EO to continuous culture using a dairy ration with steam-flaked corn did not positively modify fermentation. Although the CIN and EUG treatments raised $\mathrm{pH}$, the digestibilities of $\mathrm{OM}$, fiber, and $\mathrm{CP}$ as well as bacterial nitrogen production, were negatively impacted, most likely due to the high, and possibly toxic (to microbes), dosage of oil used. Further, CIN increased ammonia production and decreased EMPS. Although total VFA production was not changed by EO, EUG increased the acetate to propionate ratio, as well as increasing the total production of butyrate and BCVFA. While the CAP treatment did not increase $\mathrm{pH}$, it also had no negative effects on ammonia production, EMPS, bacterial nitrogen production, or VFA production, even at this high dosage. The EO used in this study had little effect on rumen fermentation compared to CON. Moreover, a dosage of $500 \mathrm{mg} \mathrm{L}^{-1}$ is equivalent to feeding $\sim 50 \mathrm{~g}$ of EO in vivo, which may be biologically toxic (although microbial populations were not measured) and economically infeasible.

In the first in vivo study, the recommended dosage of CE Lo had no effect on rumen fermentation, milk production, or feeding behavior, suggesting that the recommended dosage of this blend for lactating dairy cattle may not provide a high enough concentration in the diet to elicit any effects. However, at a higher concentration, CE Hi negatively affected in situ nutrient fermentation and altered eating behavior, indicating that a dosage of $10 \mathrm{~g} / \mathrm{d}$ is not beneficial to lactating dairy cows. Moreover, the negative effects observed with CE Hi were consistent with 
those observed with high in vitro dosages of CIN and EUG in our first study. CAP shortened the length of the first meal without changing rumen fermentation, total DMI, or production, making it a possible feed additive for altering feeding behavior and creating a steadier intake of DM over the course of the day. The results for CAP in this experiment suggested that it may create a steadier pattern of DMI, possibly reducing the risk for ruminal acidosis and other metabolic disorders.

Although there has been evidence that CAP can alter eating behavior in beef cattle, our first in vivo study is the only research, to the best of our knowledge, that reports CAP may alter feeding behavior in dairy cattle. However our second in vivo study did not validate these findings. At a dosage of $1 \mathrm{~g} / \mathrm{cow} / \mathrm{d}$ (4 times the amount fed in the first study), CAP had no effect on eating behavior or milk production. Due to high DMI, dairy cattle may require an even higher dosage of CAP to elicit an effect on eating behavior and milk production. However, a higher dosage may not be economical or biologically appropriate. Further, it is possible that competition at the GrowSafe bunks may have negated the effects of CAP on eating behavior. While prior research indicated that CAP may be beneficial in beef cattle consuming high concentrate diets, the current study indicates that it does not provide any benefits to lactating dairy cattle in a situation where bunk space is limited. 